NUREG/CR-2336

PNL-4008

$1-$

\title{
Steam Generator Tube Integrity Program
}

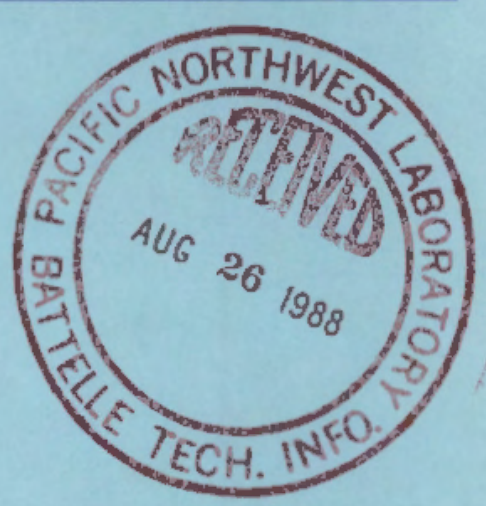

Phase II Final Report

Prepared by R.J. Kurtz, R.L. Bickford, R.A. Clark, C.J. Morris, F.A. Simonen, K.R. Wheeler

Pacific Northwest Laboratory Operated by

Battelle Memorial Institute

Prepared for U.S. Nuclear Regulatory Commission 


\section{NOTICE}

This report was prepared as an account of work sponsored by an agency of the United States Government. Neither the United States Government nor any agency thereof, or any of their employees, makes any warranty, expressed or implied, or assumes any legal liability of responsibility for any third party's use, or the results of such use, of any information, apparatus, product or process disclosed in this report, or represents that its use by such third party would not infringe privately owned rights.

\section{NOTICE}

\section{Availability of Reference Materials Cited in NRC Publications}

Most documents cited in NRC publications will be available from one of the following sources:

1. The NRC Public Document Room, 1717 H Street, N.W. Washington, DC 20555

2. The Superintendent of Documents, U.S. Government Printing Office, Post Office Box 37082 , Washington, DC 20013-7082

3. The National Technical Information Service, Springfield, VA 22161

Although the listing that follows represents the majority of documents cited in NRC publications. it is not intended to be exhaustive.

Referenced documents available for inspection and copying for a fee from the NRC Public Docu. ment $F$, $n$ include NRC correspondence and internat NRC memoranda; NRC Office of Inspecti in and Enforcement bulletins, circulars, information notices, inspection and investigation notices Licensee Event Peports; vendor reports and correspondence; Commission papers; and applicant ano licensee documents and correspondence.

The following documents in the NUREG series are availabie for purchase from the GPO Sales Program: formal NRC staff and contractor reports, NRC-sponsored conference proceedings, and NRC booklets and brochures. Also available are Regulatory Guides, NRC regulations in the Code of Federal Regulations, and Nuclear Regulatory Commission /ssuances.

Documents available from the National Technical Information Service include NUREG series reports and technical reports prepared by other federal agencies and reports prepared by the Atomic Energy Commission, forerunner agency to the Nuclear Regulatory Commission.

Documents available from public and special technical libraries include all open literature iterns, such as books, journal and periodical articles, and transactions. Federal Register notices, federal and state legislation, and congressional reports can usually be obtained from these libraries.

Documents such as theses, dissertations, foreign reports and translations, and non-NRC conference proceedings are available for purchase from the organization sponsoring the publication cited.

Single copies of NRC draft reports are available free, to the extent of supply, upon written request to the Division of Information Support Services, Distribution Section, U.S. Nuclear Regulatory Commission, Washington, DC 20555.

Copies of industry codes and standards used in a substantive manner in the NRC regulatory process are maintained at the NRC Library, 7920 Norfolk Avenue, Bethesda, Maryland, and are available there for reference use by the public. Codes and standards are usually copyrighted and may be purchased from the originating organization or, if they are American National Standards, from the American National Standards Institute, 1430 Broadway, New York, NY 10018. 
NUREG/CR-2336

PNL-4008

R5

\section{Steam Generator Tube Integrity Program}

Phase II Final Report

Manuscript Completed: November 1987

Date Published: August 1988

Prepared by

R.J. Kurtz, R.L. Bickford, R.A. Clark

C.J. Morris, F.A. Simonen, K.R. Wheeler

Pacific Northwest Laboratory

Richland, WA 99352

\section{Prepared for}

Division of Engineering

Office of Nuclear Regulatory Research

U.S. Nuclear Regulatory Commission

Washington, DC 20555

NRC FIN B2097 



\section{ABSTRACT}

The Steam Generator Tube Integrity Program (SGIIP) was a three phase progran conducted for the U, $\$$. Nuclear Regulatory Comission (NRC) by Pacific Horthwest Laboratory (PHL). (a) The first phase involved burst and collapse testing of typical steam generator tubing with machined defects. The second phase of the SGTIP continued the integrity testing work of Phase 1 , but tube specimens were degraded by chenical means rather than machining methods. The third phase of the program used a removed-from-service stean generator as a test bed for investigating the reliability and effectiveness of in-service nondestructive eddy-current inspection methods and as a source of service degraded tubes for validating the Phase I and Phase II data on tube integrity. This report describes the results of phase 11 of the SGTIP. The object of this effort included burst and collapse testing of chemically defected pressurized water reactor (PWR) stean generator tubing to validate empirical equations of remaining tube integrity developed during Phase I. Three types of defect geometries were investigated; stress corrosion cracking (SCC), uniform thinning and elliptical wastage. In addition, a review of the pubiicly avallable leak rate data for stean generator tubes with axill and circumferential SCC and a comparison with an analytical leak rate nodel is presented, Lastly, nondestructive eddy-current (EC) measurements of defect severity are reported. Laboratory EC measurements to determine accuracy of defect depth sizing using conventional and alternate standards is described. To supplement the laboratory EC data and obtain an estinate of EC capability to detect and size $S C C$, a nini-round robin test utilizing several firms that routinely perform inmservice inspections was conducted.

(a) Pacific Northwest Laboratory is operated for the U.S. Department of Energy by Battelle Menorial Institute under Contract DE-ACO6-76RLO 1830. 



\section{SUMAARY}

This report presents the results of Phase II of the SGTIP. This program was sponsored by the U.S. MRC at Battelle-PNL. Results of pressure tests and nondestructive characterization of stean generator tube segments with chemically induced defects are described. These tests were performed to establish the margin-to-failure of degraded PWR steam generator tubes under normal operating and accident loading conditions. The principal goal of Phase II was to validate and extend empirical correlations of remaining tube integrity developed during Phase 1. An additional objective was to evaluate EC nondestructive inspection methods for determining the extent of defects in stean generator tubing.

During Phase 1 , pressure tests and nondestructive measurements were abtained from tube segments defected by mechanical means. Uniform thinning and elliptical wastage type defects were produced by machining techniques and crack type defects were simulated by electromischarge machined (EDM) notches. Defect geometries produced by chemical means more closely approximate service-induced defects with respect to variable shape, size, depth and orientation. For Phase 11, the sane three types of defect geometries were investigated but were produced by chemical reactions rather than machining techniques.

Hormal operating conditions in a stean generator vary with facility, but typically the temperature ranges between $550^{\circ} \mathrm{F}$ and $620^{\circ} \mathrm{F}$ with a primary loop pressure of about 2200 psig. The secondary loop pressure is typically about 1000 psig. During a main-steam-line-break accident, the secondary pressure could drop to almost zero, resulting in an internal tube pressure differential approxinately equal to the primary loop operating pressure. This is the worst credible burst mode accident for steam generator tubing. Thus, burst testing was done to allow nargin-to-failure predictions for defected tubing under operating and burst mode accident conditions.

During a loss-of-coolant accident, the primary pressure could drop to almost zero resulting in a tube external pressure differential approximately equal to the secondary pressure. This is the worst credible collapse node accident for stean generator tubing. Thus, collapse testing was perforned to permit margin-to-faflure predictions for defected tubing under a collapse mode accident condition.

Burst and collape tests were perfomed in a simulated PWR steam generator environment. Phase II failure pressures showed the sane general trends as the Phase I results. Data scatter was sinilar to Phase I.

Burst pressures of $5 C \mathrm{C}$ defected tubes were about $10 \mathrm{z}$ higher, on the average, than those neasured from the EDM notch defect simulations. On the other hand, burst pressures of unifom thinning and elliptical wastage defects were less than 10\% lower, on the average, than those predicted from 
the Phase 1 empirical relationships. Thus, additional conservatisn for evaluation of uniform thinning and elliptical wastage type defects from the Phase I relationships may be justified.

A review of the avallable leak rate data for $\$ C C$ defected stean generator tubes subjected to nomal operating and accident pressure differentials indicated that the neasured leak rates were highly variable when compared to analytical predictions. Predicted leak rates were, in some cases, ten times greater than measured. Nevertheless, most (but not all) of the tubes leaked at detectable rates for nomal operating conditions and none of the tubes burst at main-steam-line-break accident loadings. The tata suggest that a substantial level of conservatisn should be applied to predictions of leakage that are used for leak-before-break evaluations and that such conservatisn would also appear appropriate for establishing leak detection limits for detection systems.

Laboratory EC neasurements of SCC depths indicated that these types of defects were, on the average, undersized, with the data displaying a great deal of scatter. Elliptical wastage and uniform thinning defects were nore accurately sized than SCC, with much less scatter observed. Sizing accuracy increased as the volune of material removed by the defecting process increased. Thus, unifomly thinned specimens were the most accurately sized. A plot of burst pressure versus laboratory EC estimated depth from all defect types indicated that the $40 \%$ plugging linit presently used is conservative. Results from a mini-round robin perfomed with $\$ C C$ defected tubes showed that depth and length sizing were highly variable and assessments of remaining tube integrity based on EC estimated flaw dinensions were conservative, except for a few cases in which the level of conservatism was less than the margin currently allowed. Further, the best average probability of detecting SCC for all inspection techniques was 0.63 , indicating that detection of cracking was a signiflcant problem.

Alternate standards designed to simulate elliptical wastage, uniform thinning and EOM slot type defects were fabricated to detemine if these standards offered improved depth sizing over the conventional flat-bottom hole standard. The test data indicated that more accurate depth measurements were obtained from EC inspection for elliptical wastage and uniform thinning type flaws but were not as effective for EOM slots. Substantial scatter in the EON slot test results was noted. 


\section{CONTENTS}

SUMMARY ............................ v

1.0 TEST SPECIMEN DESCRIPTION . . . . . . . . . . . . . . . . 1

1.1 STRESS CORROSION CRACKING SPECIMENS . . . . . . . . . . 1

1.2 UNIFORM THINNING SPECIMENS ................ 3

1.3 ELLIPTICAL WASTAGE SPECIMENS . . . . . . . . . . . . 3

2.0 PRESSURE TESTS . . . . . . . . . . . . . . . . . . . . . . 5

2.1 BURST AND COLLAPSE TEST PROCEDURES . . . . . . . . . . . . 5

2.2 BURST TEST RESULTS . . . . . . . . . . . . . . . . . 5

2.2.1 Undefected Specimen Data ............... 5

2.2.2 Stress Corrosion Cracking Burst Tests . . . . . . . . 6

2.2.3 Uniform Thinning Tests ............... 9

2.2.4 Elliptical Wastage Burst Tests ............. . 10

2.3 COLLAPSE TEST RESULTS . . . . . . . . . . . . . . 11

2.3.1 Undefected Specimen Data . . . . . . . . . . . 11

2.3.2 Uniform Thinning and Elliptical Wastage Test Results . . . 12

2.4 PHASE I AND II EMPIRICAL RELATIONSHIPS . . . . . . . . . . 14

3.0 REVIEW AND EVAluation OF LEAK RATE DATA . . . . . . . . . . . . . 19

3.1 LEAK TEST DATA . . . . . . . . . . . . . . . . 19

3.2 LEAK RATE MODEL ......................... 21

3.2.1 Crack Opening Area . . . . . . . . . . . . . 21

3.2.2 Fluid Mechanics ................. . . 22

3.3 COMPARISON OF TESTS WITH PREDICTIONS . . . . . . . . . . 22

3.3.1 Combustion Engineering Tests . . . . . . . . . . 23

3.3.2 French Tests ................... 28 
3.3.3 Battelle Columbus Data .............. 30

3.3.4 Sources of variability ............... 31

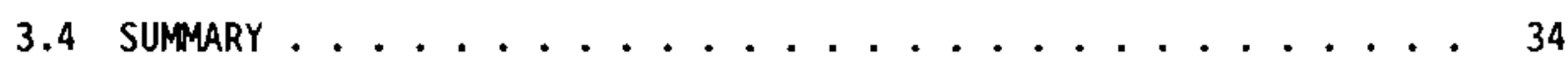

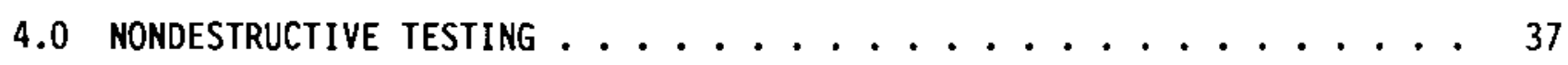

4.1 EDDY-CURRENT RESULTS FOR SCC AND WASTAGE DEGRADED TUBES . . . . 37

4.1.1 Stress Corrosion Crack Specimen Results ........ 37

4.1.2 Wastage Specimen Results ............... 39

4.2 SCC MINI-ROUNO ROBIN ...................... 44

4.3 EVAlUation OF NDE RELIABILITY FOR SCC . . . . . . . . 45

4.3.1 Probability of Detection ............. 45

4.3.2 Crack Depth Sizing Analysis ............ 46

4.3.3 Crack Length Sizing Analysis ............ . 49

4.3 .4 Summary .................... 53

4.4 ALTERNATE STANDARDS FOR INTERPRETATION OF EC DATA FROM

STEAM GENERATOR TUBING ................ 58

4.4.1 Results .................. 58

4.4 .2 Sumary ........................ 63

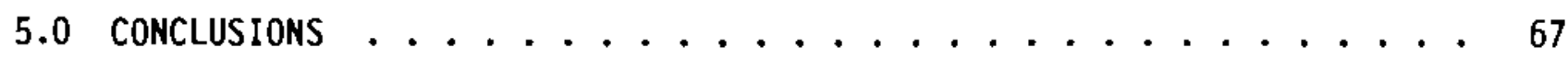

6.0 REFERENCES ................................. 69 APPENDIX A Eddy-Current Flaw Depth Measurements 


\section{FIGURES}

1. Chemically Degraded Tube Specimens ............. 2

2. Intergranular Attack of Inconel 600 Tubing Exposed to 25* Solution of Boiling Nitric Acid . . . . . . . 4

3. Calculated Normalized Burst Pressure from the EDM Slot Empirical Equation vs. Measured Normalized Burst Pressure for Tubes with Laboratory Produced SCC ......... 8

4. Ratio of Defected Tube Burst Strength (AP) to Undefected Tube Burst Strength $\left(\Delta P_{0}\right)$ Versus Defect Length for Average EDM Slot Defects Compared with ASME, IWB-3640 Calculation .........99

5. Calculated Nomalized Burst Pressure from the Uniform Thinning Empirical Equation vs. Measured Hormalized Burst Pressure for Tubes with Chemically Produced Uniform Thinning ......... 12

6. Calculated Normalized Burst Pressure from the Elliptical Wastage Empirical Equation ys. Measured Normalized Burst Pressure for tubes with Chemically Produced Elliptical Wastage . . 13

7. Calculated Mormalized Collapse Pressure from the Uniform Thinning Empirical Equation vs. Measured Normalized Collapse Pressure for Tubes with Chemically Produced Uniform Thinning ... 15

8. Calculated Normalized Collapse Pressure from the Eiliptical Wastage Empirical Equation ys. Measured Hormalized Collapse Pressure for Tubes with Chemically Produced Elliptical yastage . . 15

9. Comparison of Calculated and Measured Normalized Burst Pressure for Uniform Thinning Specimens - Adjusted Phase I Equation ..................... 17

10. Comparison of Calculated and Measured Normalized Collapse Pressure for Uniform Thinning Specimens - Adjusted Phase I Equation .......................

11. Comparison of Calculated and Measured Normalized Burst Pressure for Elliptical Wastage Specinens - Adjusted Phase I Equation ...................... 18

12. Comparison of PNL and EPR1 Leak Rate Models .......... 23

13. Comparison of Combustion Engineering Leak Test Data with Model Predictions, Normal operating Condition ......... 24 
14. Comparison of Combustion Engineering Leak Test Data with Model Predictions, Nomal Operating Condition .......... 25

15. Comparison of Combustion Engineering Leak Test Data with Model Predictions, Steamline Break Condition ......... 26

16. Comparison of Combustion Engineering Leak Test Data with Model Predictions, Steamline Break Condition ........ 27

17. Comparison of French Leak Test Data with Model Predictions, Komal operating Condition .............. 29

18. Comparison of Battelle Columbus Leak Test Data with Model Predictions, Test 10 , Axial Crack .............. 31

19. Comparison of Battelle Columbus Leak Test Data with Model Predictions, Test 120 , Circumferential Crack ........ 31

20. Comparison of Battelle Colunbus Leak Test Data with Model Predictions Test 129 , Circumferential crack .......... 32

21. Single-Frequency Eddy-Current Signal Indications from stress Corrosion Crack Tube No. B-1. ............... 38

22. Eddy-Current Indicated Flaw Depth Versus Actual Depth for SCC Flaws .....................440

23. Eddy-Current Indicated Flaw Depth Versus the Actual Depth for Elliptical Wastage Flaws (electroetch) ........440

24. Eddy-Current Indicated Flaw Depth Versus the Actual Depth for Elliptical Wastage Flaws (intergranular attack) . . . . 41

25. Eddy-Current Indicated Flaw Depth Versus the Actual Depth for Uniform Thinning Wastage (electroetch) $\ldots \ldots \ldots$

26. Eddy-Current Indicated Flaw Depth Versus the Actual Depth for Uniform Thinning Wastage (intergranular attack) . . . . 42

27. Measured Normalized Burst Pressure vs. Eddy-Current Depth for Phase I and Phase II Specimens ............443

28. Calculated Normalized Burst Pressure from EC Data Assuming One Inch Defect Length vs. Measured Normalized Burst for Phase I and Phase II Specimens. . . . . . . . . . . . . 43

29. Eddy-Current Estimated vs. Actual SCC Depth for Team MC . . . . 48

30. Eddy-Current Estimated vs. Actual scC Depth for Team MF ..... 50 
31. Eddy-Current Estimated vs. Actual SCC Depth for Team MA . . ... 50

32. Eddy-Current Estimated vs. Actual SCC Depth for Team MH ..... 51

33. Eddy-Current Estimated vs. Actual SCC Depth for Team MI . . . 51

34. Eddy-Current Estimated v5. Actual SCC Depth for Tean Mo . . . . 52

35. Eddy-Current Estimated vs. Actual SCC Depth for Team MG . . . . . 52

36. Eddy-Current Estimated vs. Actual SCC Length for Team MD .... 54

37. Eddy-Current Estimated vs. Actual SCC Length for Team MF . . . . 54

38. Eddy-Current Estimated vs. Actual $\$ C C$ Length for Tean MH . . . . 55

39. Eddy-Current Estimated v5. Actual SCC Length for Team MP . . . . 55

40. Calculated (EC Data) versus Measured Nornalized Burst

Pressure for Bobbin-Coil inspection Teams MD and MF ....... 56

41. Calculated (EC Data) versus Measured Normalized Burst Pressure for Alternate Inspection Teams MO and MH . . . . . . 57

42. EDM Slots, Elliptical Wastage, and Uniform Thinning

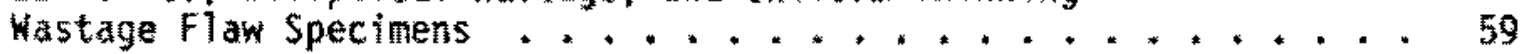

43. Single-Frequency Eddy-Current Interpretation Curves Generated from ASME-FBH, EOM Slot, Elliptical Wastage, and Uniform Thinning Wastage Standards ...........661

44. EDM Slot Specimen Eddy-Current Depth Sizing Results Achieved using ASME Flat-Botton Hole and EOM \$lot Standards ........ 62

45. Elliptical Wastage Specimen Eddy-Current Depth Sizing Resuits Achieved using ASME Flat-Bottom Hole and Elliptical Wastage standards ............... 62

46. Uniform Thinning Wastage Specimen Eddy-Current Depth Sizing Results Achieved using ASME Flat-Bottom Hole and Uniform Thinning wastage Standards ........... 


\section{TABLES}

1. Undefected Tube Burst Pressures ............... 5

2. Phase II Burst Test Results for SCC Defected Tubes . . . . . . 7

3. Phase 11 Burst Test Results for Uniform Thinning Defected Tubes .................. 10

4. Phase II Burst Test Results for Elliptical Wastage defected rubes .................. 11

5. Undefected Tube Collapse Pressures .............. 12

6. Phase II Collapse Test Results for Uniform

Thinning Defected Tubes................. 13

7. Phase II Collapse Test Results for Elliptical Wastage Defected Tubes ................. 14

8. Predictive Failure Equations ............... 16

9. Single-Frequency EC Flaw Depth Measurement Error ....... 39

10. SCC Mini-Round Robin Defect Conditions ........... 45

11. SCC Mini-Round Robin Bobbin-Coil Results ......... 46

12. SCC Mini-Round Robin Alternate Results .......... 47

13. Probability of Detection, Depth Sizing and Length Sizing Analyses for \$CC Mini-Round Robin Teams ......... 49

14. Statistical Data for EOM Slot, Elliptical Wastage, Uniform Thinning Wastage and Flat-Bottom Hole Standards ..... 65

A.1 Phase I - SGTI Program Eddy-Current Data EDM Slot $($ Heats $B, E$, and $F) \ldots \ldots . \ldots$ A.1

A.2 Phase I - SGII Program Eddy-Current Data

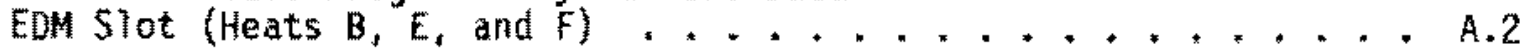

A.3 Phase I - SGTI Program Eddy-Current Data EDM Slot (Heats $E$ and $F) \ldots \ldots \ldots$

A.4 Phase I - SGTI Program Eddy-Current Data Elliptical Wastage (Heat B) ................ A 
A.5 Phase I - SGTI Program Eddy-Current Data Elliptical Wastage (Heats $B, E$, and $F) \ldots \ldots . . \ldots$

A.6 Phase I - SGTI Program Eddy-Current Data Uniform Thinning (Heats $B, E$, and F) ..............

\section{A.7 Phase I - SGTI Eddy-Current Oata} Uniform Thinning (heat 8$) \ldots \ldots \ldots \ldots$ A.7 


\subsection{IEST SPECIMEN DESCRIPTION}

Chemically produced defects more closely simulate actual defects found in PWR steam generators than machined defects. Emphasis was placed on SCC and uniform thinning type defects. These defect types were of greatest interest from a structural integrity and eddy-current testing viewpoint. This section describes the techniques employed for creating the defects tested during Phase II.

The test matrix consisted of 86 chemically degraded Inconel $600^{\circledR}$ (a) tubes from material heats B, E and F. A description of the material properties of these three heats was given in the Phase I report (Alzheimer et al. 1979). The tubing had a nominal outer diameter (OD) of 0.875 inches and a nominal wall thickness of 0.050 inches. Specimens were approximately 12 inches in length with the degraded regions located at the midpoint of the tube. The three types of flaws included in the test matrix were; 1) stress corrosion cracking, 2) uniform thinning, and 3) elliptical wastage. The various flaw geometries are shown schematically in Figure 1.

\subsection{STRESS CORROSION CRACKING SPECIMENS}

Several heats of Inconel 600 tubing were chemically defected by stress corrosion cracking. The method employed has been described by Clark and Burr (1980) but is summarized here for completeness. The precracking method consisted of exposing internally pressurized segments of tubing to a solution of $5 \mathrm{lb} / \mathrm{gal} \mathrm{NaOH}$ and $0.001 \mathrm{lb} / \mathrm{gal} \mathrm{Cu}$ (electrolytic dust) at $600^{\circ} \mathrm{F}$. Tube segments had Inconel 600 caps welded on each end. One end cap contained a $0.25 \mathrm{in}$. diameter Inconel 600 tube through which pressure was introduced.

The location and orientation of stress corrosion cracking was determined by masking. Teflon (b) tape was wrapped around the entire tube with Teflon caps fitted over the specimen ends. The entire length of tube was then covered with shrink fit Teflon tubing. The masking was removed from the region to be exposed to attack. Copper wire was wound around the edge of the exposed area to strengthen the cut edge and minimize leakage under the mask.

Precracking was performed by placing up to seven identically masked specimens (each prefilled with deionized water) into an autoclave with the 0.25 in. pressurizing tubes protruding through the autoclave head fitting. The autoclave was precharged half full of the solution described above, then sealed. All pressurizing lines were connected to a common manifold and pressurized to $1000 \mathrm{psi}$. The autoclave was then heated to $600^{\circ} \mathrm{F}$ after which the specimens were pressurized to about $60 \%$ of yield strength by use of a high pressure pump. An accumulator was used to provide pressure stability.

(a) Inconel is a registered trademark of INCO Alloys International (Huntington Alloys), Huntington, West Virginia.

(b) Teflon is a registered trademark of E.I. duPont De Nemours and Co., Inc., Wilmington, Delaware. 


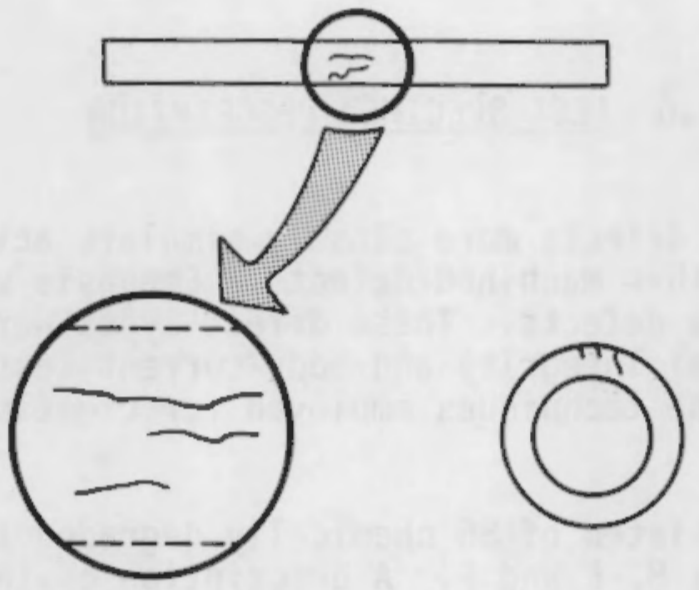

(a) STRESS CORROSION CRACKING

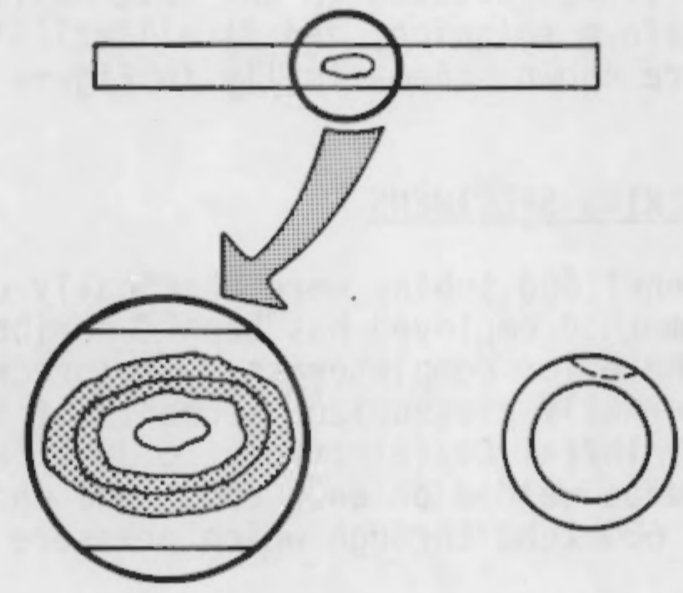

(b) ELLIPTICAL WASTAGE

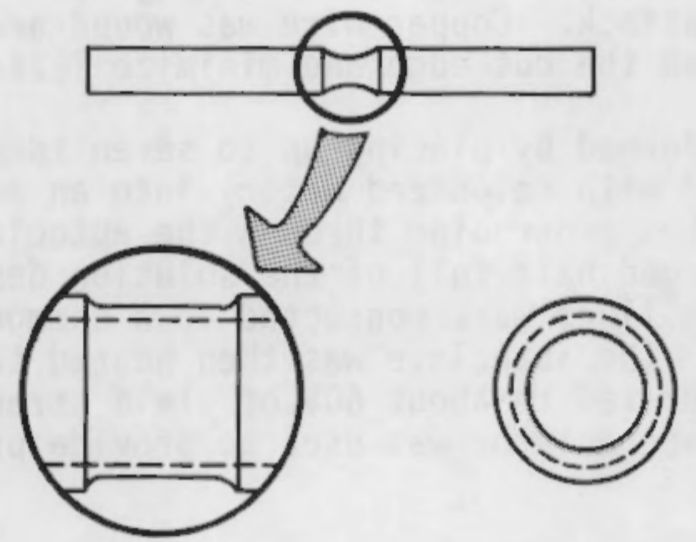

(c) UNIFORM THINNING WASTAGE

FIGURE 1. Chemically Degraded Tube Specimens 
Through-wall penetration of one of the tubes usually occurred in about 18 to 20 hours. The failure of a tube relieved pressure on all remaining specimens through the common manifold. After loss of specimen pressure, a switch on the specimen pressure line turned off the autoclave heaters. After autoclave cooldown, the specimens were removed and the masking stripped off. Typically for a given batch of specimens, a distribution of crack sizes was observed that ranged from no apparent stress corrosion up to the throughwall failure.

\subsection{UNIFORM THINNING SPECIMENS}

Two methods were used to generate thinning (wastage). Some tubes were thinned by electroetching in a solution of $80 \%$ phosphoric acid and $20 \%$ sulfuric acid with an applied current density of $1 \mathrm{amp} / \mathrm{cm}^{2}$ or less. Other sections of Inconel 600 tubing were exposed to a $25 \%$ solution of boiling nitric acid to cause thinning by an intergranular attack (IGA) mechanism. An electric potential of $290 \mathrm{mV}$ was applied to initiate the attack by promoting penetration of the naturally protective oxide film on the specimen surface. The potential was gradually reduced during the first half-hour to about $24 \mathrm{mV}$ and then held constant for the remainder of the exposure. Areas of the tube not intended for exposure were masked by wrapping Teflon tape tightly around the tube. Following thinning by the IGA mechanism, some tubes were electroetched to smooth the transition region between the unthinned and thinned portions of the tube.

Typically, the penetration rates of the IGA defecting mechanism were quite high due to the rapid destruction of the metal structure. Whole grains were literally separated from the corroding surface. The attack penetrated inward and followed the grain boundary network. Because of the preferential grain boundary attack, a possibility existed that the tube wall may have been microscopically weakened by separation of grains below the level of the macroscopic surface thinning. A metallurgical cross-section was prepared through a tube exposed to the IGA defecting process. The micrograph shown in Figure 2 indicates that the IGA defecting process typically removed entire grains but did not result in appreciable subsurface grain boundary penetration. Thus the IGA mode of surface attack would not be expected to significantly alter the mechanical properties of the remaining tube wall. The principal difference between chemical and mechanical defecting methods would be the relative non-uniformity of the former. For this reason, a greater variation in Phase II data compared to Phase I was expected.

\subsection{ELLIPTICAL WASTAGE SPECIMENS}

Elliptical wastage was produced in a manner similar to uniform thinning except that additional masking was used to restrict the attacked segment of tubing and thereby produce the elliptical wastage defect geometry. 


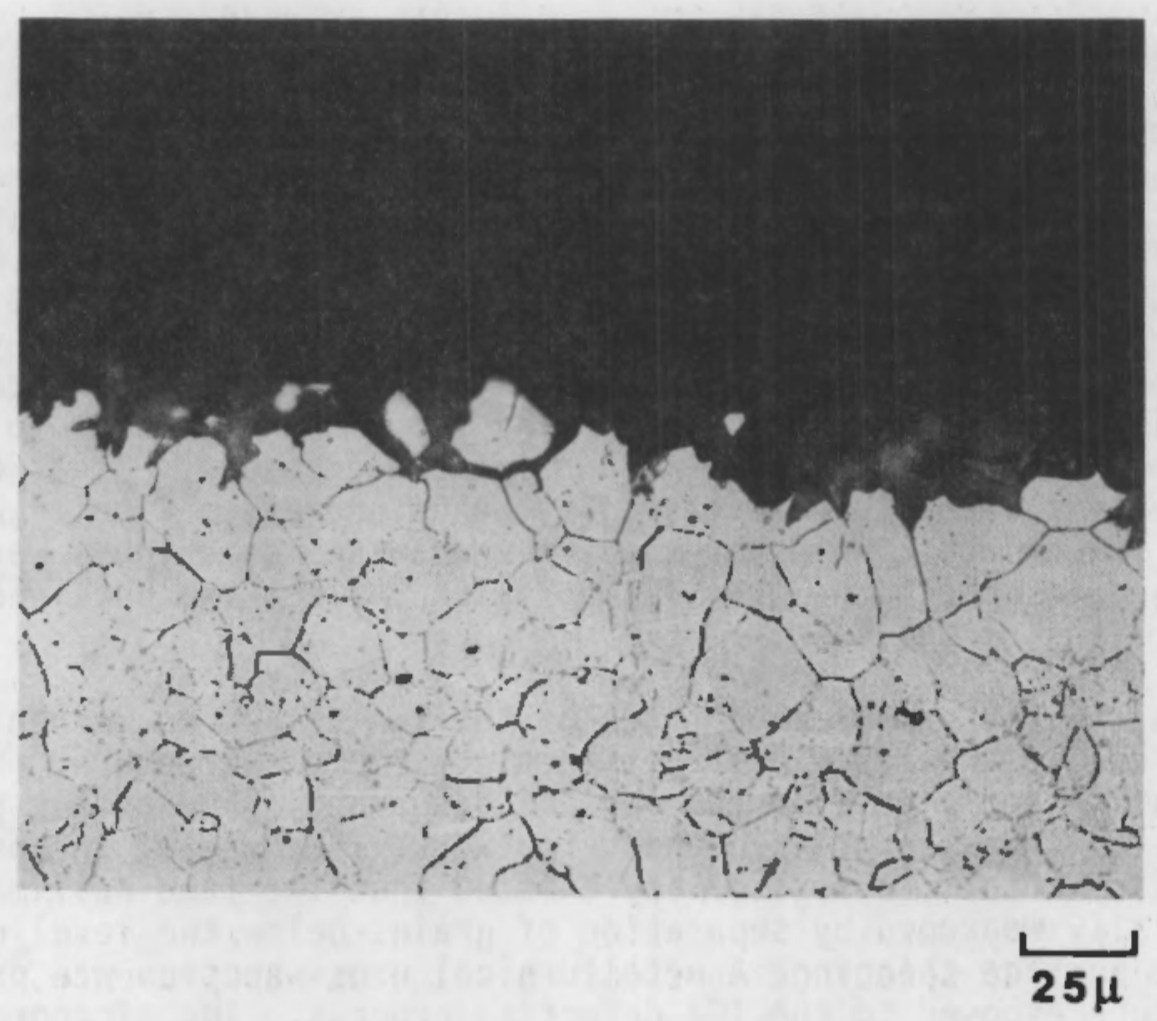

FIGURE 2. Intergranular Attack of Inconel 600 Tubing Exposed to $25 \%$ Solution of Boiling Nitric Acid 


\subsection{PRESSURE TESTS}

\subsection{BURST AND COLLAPSE TEST PROCEDURES}

The burst and collapse test procedures for Phase II were unchanged from those used in Phase 1 except for a modification in the collapse test procedure for specimens with defects greater than $75 \%$ of wall. For these tubes, the collapse test procedure was modified to preclude undetected collapse during blowdown of the specimen pressure to atmosphere. For these special cases, both the bomb and specimen were vented to atmosphere during autoclave heating. With both the bomb and specimen at one atmosphere pressure and at test temperature the bomb vent was closed and the bomb pressurized to specimen collapse as described elsewhere (Alzheimer, et al. 1979). Collapse was noted from the audible click, as a drop in bomb pressure at specimen collapse was difficult to detect with normal instrumentation.

\subsection{BURST TEST RESULTS}

Burst results are presented as tables and plots and discussed by defect type. Empirical relationships for predicting burst pressure of each type of defect were derived. A least squares approach to the development of empirical equations was used. Undefected tube properties were discussed in the Phase I report (Alzheimer et al. 1979) and are briefly repeated here for comparison to the defected tube data.

\subsubsection{Undefected Specimen Data}

Three undefected tubing specimens from each heat of material were burst to provide baseline data. The results of these tests are given in Table 1. Additional material specifications for this tubing was presented in the Phase I report.

TABLE 1. Undefected Tube Burst Pressures

\begin{tabular}{|c|c|c|}
\hline Heat & $\begin{array}{c}\text { Average Failure } \\
\text { Pressure, psi }\end{array}$ & $\begin{array}{r}\text { Standa } \\
\text { Deviation }\end{array}$ \\
\hline $\begin{array}{l}\mathrm{B} \\
\mathrm{E}\end{array}$ & $\begin{array}{l}9,325 \\
9,542 \\
9,290\end{array}$ & $\begin{array}{l}100 \\
109 \\
142\end{array}$ \\
\hline
\end{tabular}

These data are useful in three ways. First, the variations in burst pressure from samples in each heat indicate the amount of scatter that might be expected in the defected tube burst data. Second, these data establish the margin-to-failure for undefected steam generator tubing. Lastly, the undefected data serves as the baseline for analyzing defected burst data. A discussion of the variations among program tubing heats and a review of the influence of tube wall thickness to diameter ratios on burst strength was given in the Phase I report. From that discussion it was concluded that the 
burst strength of undefected specimens was more sensitive to ultimate strength than to yield strength.

Tube rupture resulted from net section yielding of the undefected ligament, with the failure point occurring at random locations along the specimen axis, although no specimens failed at the end fittings. Significant plastic deformation of the entire tube wall occurred before failure. The diameter of the tube after failure increased between $15 \%$ and $20 \%$ in portions of the tube not near the failure zone. More tube deformation was observed near the point of failure.

\subsubsection{Stress Corrosion Cracking Burst Tests}

Twenty six segments of steam generator tubing with 00 initiated, axially oriented SCC were burst tested. The results of these tests are presented in Table 2. The length and depth of SCC causing tube failure given in Table 2 was determined in several ways. Prior to burst testing, the OD surface of each tube was examined by optical techniques to estimate the maximum length of SCC present. Initially, most tubes were dye penetrant tested (PT) and the maximum indication length measured. Next, a Gaertner traveling stage microscope with $32 x$ magnification and digital readout was utilized to provide an independent measurement of crack length. These examinations revealed that the masking procedure did not completely restrict the SCC to a single axial location. On many tubes cracks were found around the entire circumference, although the predominant cracking was typically restricted to a limited circumferential extent. Often, several parallel axial cracks were observed. In instances where the cracks were closely spaced ( 0.1 in.) and overlapping, an overall crack length was determined to conservatively bound the sum of the shorter cracks. For purposes of comparing the Phase II results with Phase I data the average of the two visual estimates of crack length were used (Table 2).

Flaw depth-of-penetration was determined after burst testing by visual measurement of the fracture surface. The failure location was sectioned and then photographed with a Zeiss metallograph at 50X magnification. The 50X magnification was suitable for viewing the entire tube wall thickness and the SCC portion of the fracture surface was, in most cases, readily distinguishable from the ductile rupture region. The depth of SCC was generally non-uniform and so the maximum depth-of-penetration was estimated and reported in Table 2 .

Eddy-current (EC) testing was also performed prior to burst testing to determine the effectiveness of this nondestructive test method for sizing SCC type defects. Results of these measurements are given in Table 2. In addition, a round robin test program was performed with 15 of the specimens listed in Table 2. A detailed description of the test methods employed and results obtained from these investigations is presented in Section 5.0 below.

The burst test pressures from Table 2 were normalized by dividing by the appropriate undefected burst pressure from Table 1. Note that the specimen numbers shown in Table 2 begin with a letter that designates the heat of 
TABLE 2. Phase II Burst Test Results for SCC Defected Tubes

\begin{tabular}{|c|c|c|c|c|c|c|}
\hline $\begin{array}{l}\text { Specimen } \\
\text { Number }\end{array}$ & $\begin{array}{l}\text { Defect } \\
\text { Depth } \\
\text { (\% Wal1) }\end{array}$ & $\begin{array}{l}\text { ECT Oefect } \\
\text { Depth } \\
\text { (\% Wall) }\end{array}$ & $\begin{array}{l}\text { PT Defect } \\
\text { Length } \\
\text { (in.) }\end{array}$ & $\begin{array}{l}\text { Opt. Defect } \\
\text { Length } \\
\text { (in.) }\end{array}$ & $\begin{array}{l}\text { Ave. Defect } \\
\text { Length } \\
\text { (in.) }\end{array}$ & $\begin{array}{c}\text { Burst } \\
\text { Pressure } \\
\text { (psi) }\end{array}$ \\
\hline 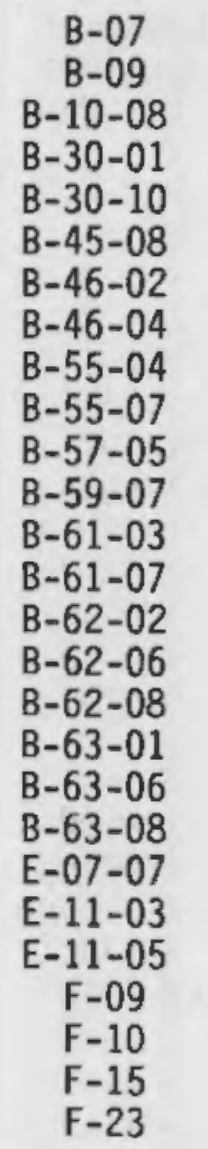 & $\begin{array}{l}43 \\
53 \\
99 \\
51 \\
38 \\
86 \\
31 \\
58 \\
59 \\
37 \\
24 \\
76 \\
47 \\
42 \\
61 \\
42 \\
42 \\
44 \\
59 \\
26 \\
58 \\
86 \\
50 \\
45 \\
37 \\
38 \\
47\end{array}$ & $\begin{array}{l}40 \\
40 \\
100 \\
60 \\
30 \\
60 \\
60 \\
70 \\
80 \\
25 \\
30 \\
100 \\
40 \\
20 \\
50 \\
60 \\
60 \\
40 \\
50 \\
0 \\
\text { NI } \\
\text { NI } \\
\text { NI } \\
20 \\
25 \\
25 \\
70\end{array}$ & $\begin{array}{l}0.60 \\
1.12 \\
1.25 \\
0.73 \\
0.25 \\
1.13 \\
1.10 \\
0.75 \\
0.90 \\
0.10 \\
0.50 \\
0.81 \\
0.75 \\
0.25 \\
0.50 \\
1.25 \\
-1 .-12 \\
1.00 \\
-.-- \\
-. .- \\
-.-- \\
--.- \\
0.05 \\
0.25 \\
0.25 \\
0.43\end{array}$ & $\begin{array}{l}0.71 \\
1.13 \\
0.92 \\
0.47 \\
0.80 \\
1.08 \\
1.02 \\
0.64 \\
0.92 \\
-0.76 \\
0.80 \\
0.62 \\
-.-1 \\
--.- \\
1.21 \\
1.43 \\
1.16 \\
1.21 \\
1.41 \\
0.45 \\
0.44 \\
0.64 \\
0.03 \\
--.- \\
---. \\
0.68\end{array}$ & $\begin{array}{l}0.66 \\
1.13 \\
1.09 \\
0.60 \\
0.53 \\
1.11 \\
1.06 \\
0.70 \\
0.91 \\
0.10 \\
0.63 \\
0.81 \\
0.69 \\
0.25 \\
0.50 \\
1.23 \\
1.43 \\
1.14 \\
1.11 \\
1.41 \\
0.45 \\
0.44 \\
0.64 \\
0.04 \\
0.25 \\
0.25 \\
0.56\end{array}$ & $\begin{array}{l}7730 \\
6316 \\
1855 \\
6155 \\
6900 \\
3510 \\
7355 \\
5495 \\
5630 \\
8425 \\
7195 \\
4255 \\
6250 \\
8750 \\
5883 \\
6517 \\
6260 \\
6725 \\
6102 \\
8085 \\
5630 \\
3595 \\
6575 \\
--. . \\
6070 \\
7450 \\
7013\end{array}$ \\
\hline
\end{tabular}

material from which the specimen was fabricated. The measured normalized burst pressures were then compared to predicted values calculated by inserting the average maximum crack length and maximum crack depth from Table 2 into the Phase I EDM slot empirical equation. A plot of this comparison is shown in Figure 3. Data points falling between the 45-degree lines indicate that the calculated and measured normalized burst pressures agree within $\$ 10 \%$. Points falling in the upper left hand corner of the plot would be nonconservative, since the predicted burst pressure would be greater than the actual burst pressure. Conversely, points falling in the lower right hand portion of the graph indicate conservative results. For nearly all of the specimens the results demonstrate that the Phase I relationship yields a conservative estimate of remaining tube integrity. Some of this conservatism 
was caused by the methods used to characterize crack dimensions, but these procedures intentionally attempted to follow the philosophy used for inservice evaluations of flaws in nuclear piping or pressure vessels. On the other hand, the actual crack lengths may have been slightly underestimated in some cases since it was difficult to visually locate the crack tip of the tight SCC produced by the chemical defecting process. Nevertheless, it is clear from the results given in Figure 3 that the empirical equation developed from EDM notches provides a realistic estimate of remaining margin to failure for tubes with SCC when bounding flaw dimensions are used.

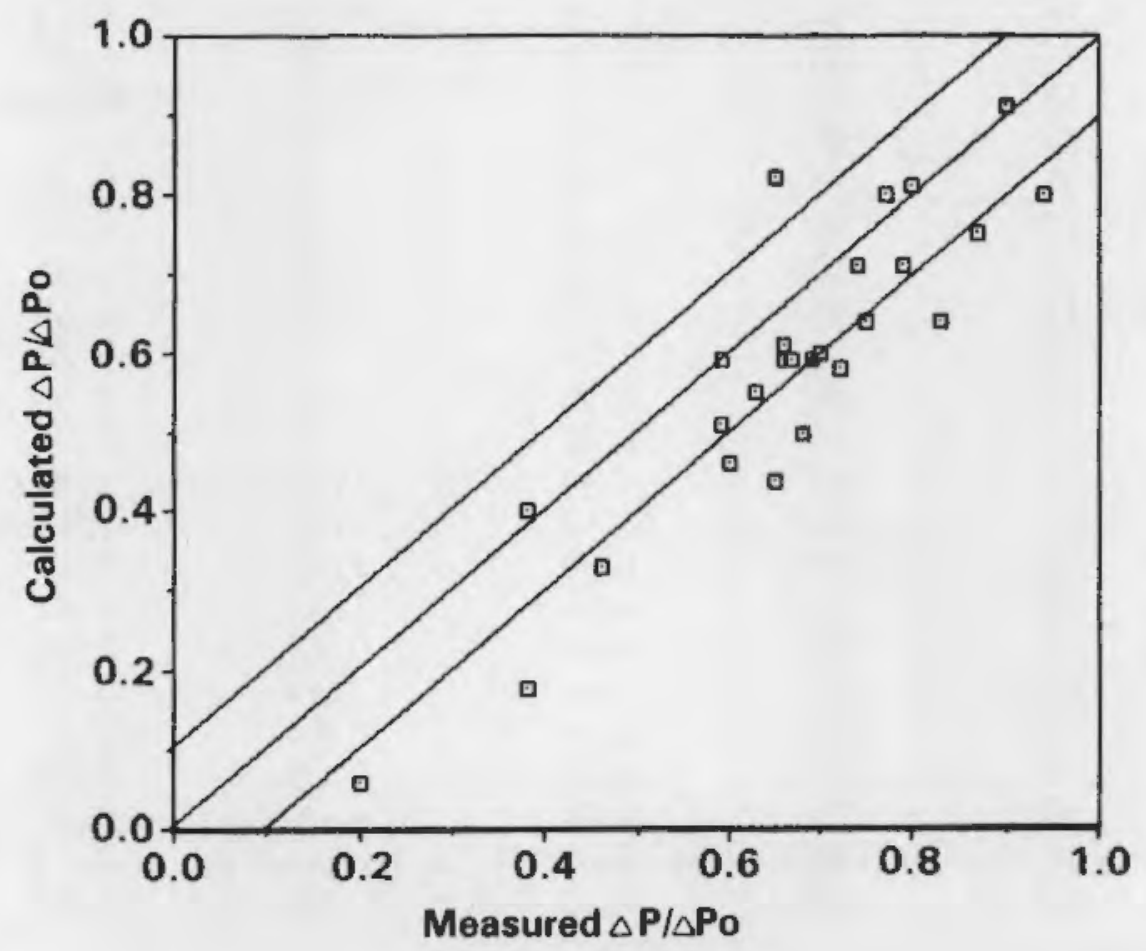

FIGURE 3. Calculated Normalized Burst Pressure from the EDM Slot Empirical Equation vs. Measured Normalized Burst Pressure for Tubes with Laboratory Produced SCC.

A comparison of the EDM notch burst equation with the analytical expression presented in Section XI, Subsection IWB-3640 of the American Society of Mechanical Engineers (ASME) Code (ASME 1986) is shown in Figure 4 . It is evident that the EDM slot empirical equation closely matches the analytical equation developed to describe failure of axially oriented cracks in stainless steel piping. Hydraulic failure of stainless steel piping is governed by net section yielding of the unflawed ligament. Thus, it seems reasonable to postulate that flawed Inconel 600 steam generator tubes fail by the same mechanism. 


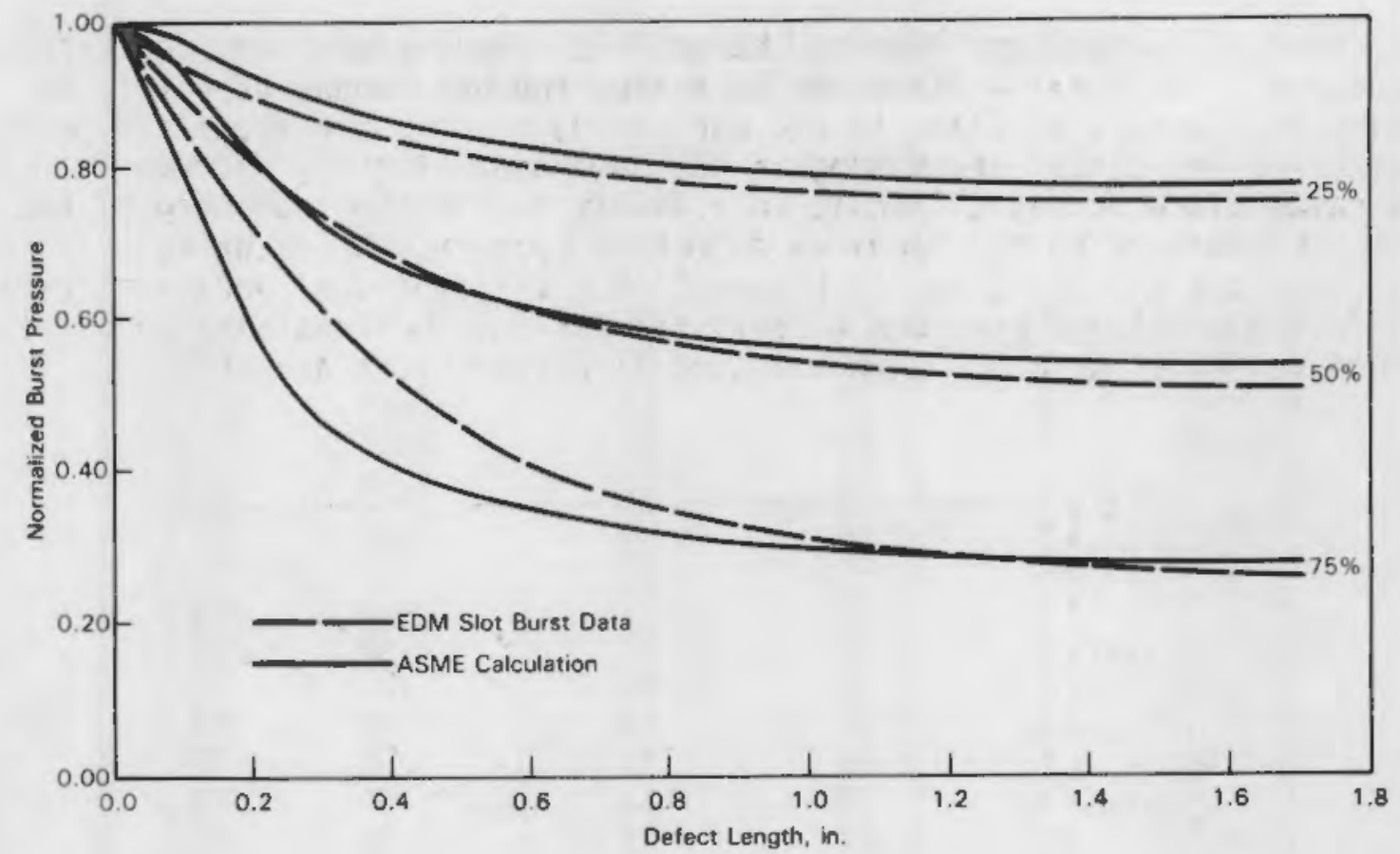

FIGURE 4. Ratio of Defected Tube Burst Strength $(\Delta P)$ to Undefected Tube Burst Strength $\left(\triangle P_{0}\right)$ Versus Defect Length for Average EDM Slot Defects Compared with ASME, IWB-3640 Calculation.

\subsubsection{Uniform Thinning Tests}

The uniform thinning burst test results are listed in Table 3 . The defect lengths and depths were determined by direct measurement before burst testing. The burst behavior of uniform thinning specimens was similar to the equivalent Phase I specimens. The tube and defect shapes of all these specimens were comparable. The only significant difference between the Phase I and II defects was the way the material was removed. Whereas the Phase I uniform thinning defects were precision machined shapes, the uniform thinning defects of Phase II were produced by chemical reactions, processes which resulted in increased variability in the final defect geometry.

Figure 5 displays a plot comparing the calculated and measured normalized burst pressures for the Phase II uniform thinning specimens. The Phase I uniform thinning empirical equation was used to calculate the normalized burst pressure from the defect dimensions given in Table 3 . Specimens defected by the IGA process are compared to those defected by the electroetching technique by use of different plotting symbols. Examination of the data in Figure 5 indicates that the different chemical defecting procedures did not cause significant differences in burst test results. Agreement between predicted and actual normalized burst pressure was (except for three data points) within the $\pm 10 \%$ scatter band. The data suggests that the Phase I uniform thinning equation may underpredict the actual burst pressures of the Phase II specimens slightly. 
TABLE 3. Phase II Burst Test Results for Uniform Thinning Defected Tubes



$\begin{array}{llllll}\text { B-11-10 } & \text { I } & 11 & 26 & 1.60 & 8000 \\ \text { B-04-02 } & \text { I } & 13 & 30 & 1.63 & 8100 \\ \text { B-75-10 } & \text { I } & 13 & 30 & 1.65 & 8036 \\ \text { B-09-02 } & \text { I } & 29 & 33 & 1.52 & 7180 \\ \text { B-27-10 } & \text { I } & 30 & 37 & 1.50 & 6621 \\ 8-60-06 & \text { I } & 35 & 45 & 0.22 & 8885 \\ \text { B-70-02 } & \text { I } & 35 & 46 & 0.24 & 8913 \\ \text { B-41-04 } & \text { I } & 40 & 56 & 1.50 & 6040 \\ \text { B-05-04 } & \text { I } & 49 & 52 & 1.48 & 4826 \\ \text { B-37-06 } & \text { I } & 57 & 69 & 1.50 & 4215 \\ \text { B-41-10 } & \text { I } & 57 & 65 & 1.51 & 4003 \\ \text { B-70-08 } & \text { I } & 60 & 74 & 1.55 & <7250 * \\ \text { B-60-10 } & \text { I } & 63 & 74 & 1.51 & 3545 \\ \text { B-43-10 } & \text { I } & 67 & 77 & 1.52 & 2834 \\ \text { B-32-02 } & \text { I } & 80 & 90 & 1.52 & 2095 \\ \text { B-39-08 } & \text { I } & 85 & 97 & 0.20 & 1275 \\ \text { B-44-08 } & \text { I } & 30 & 38 & 1.51 & ---. \\ \text { B-36-02 } & \text { I } & 95 & 100 & 1.50 & ---. \\ \text { E-06-08 } & \text { E } & 38 & 44 & 1.50 & 8010 \\ \text { F-03-08 } & \text { E } & 39 & 43 & 1.56 & 7350 \\ \text { F-03-10 } & \text { E } & 50 & 60 & 1.47 & 4546 \\ \text { E-06-02 } & \text { E } & 54 & 63 & 0.21 & 7764 \\ \text { B-21-06 } & \text { E } & 56 & 62 & 0.21 & 7677 \\ \text { E-09-08 } & \text { E } & 56 & 63 & 1.53 & 4537 \\ \text { B-33-04 } & \text { E } & 66 & 81 & 1.53 & 2677 \\ \text { B-23-06 } & \text { E } & 70 & 82 & 0.20 & 5730 \\ \text { B-25-02 } & \text { E } & 76 & 86 & 0.22 & 4937 \\ \text { B-28-04 } & \text { E } & 78 & 83 & 1.51 & 1595 \\ \text { B-30-04 } & \text { E } & 60 & 62 & 1.40 & -\cdots-.- \\ \text { B-08-02 } & \text { E } & 30 & 45 & 1.46 & --.-\end{array}$

$I=I G A$

$E=$ Electroetch

* = Anomalous Test

\subsubsection{Elliptical Wastage Burst Tests}

The elliptical wastage burst test results are given in Table 4 . This group of chemically produced defects had different depths, but were all about the same length ( 1.5 in.), with the circumferential extent ranging between $45^{\circ}$ and $119^{\circ}$. Phase I results indicated that circumferential extents between $0^{\circ}$ and $135^{\circ}$ for this type of defect did not appreciably affect the burst pressure. 
TABLE 4. Phase II Burst Test Results for Elliptical Wastage Defected Tubes

\begin{tabular}{|c|c|c|c|c|c|c|}
\hline $\begin{array}{l}\text { Specimen } \\
\text { Number }\end{array}$ & Type & $\begin{array}{l}\text { Defect } \\
\text { Depth } \\
(\% \text { Wall) }\end{array}$ & $\begin{array}{l}\text { ECT Defect } \\
\text { Depth } \\
\text { (\% Wa11) }\end{array}$ & $\begin{array}{l}\text { Circum. } \\
\text { Extent } \\
\text { (Deg.) }\end{array}$ & $\begin{array}{l}\text { Defect } \\
\text { Length } \\
\text { (in.) }\end{array}$ & $\begin{array}{l}\text { Burst } \\
\text { Pressure } \\
\text { (psi) }\end{array}$ \\
\hline $\begin{array}{l}\text { B-38-10 } \\
\text { B-08-06 } \\
\text { B-44-02 } \\
\text { B-31-02 } \\
\text { B-75-02 } \\
\text { B-75-08 } \\
\text { B-06-08 } \\
\text { B-22-10 } \\
\text { B-40-04 } \\
\text { B-16-06 } \\
\text { B-37-10 } \\
\text { B-25-1D } \\
\text { B-18-1D }\end{array}$ & $\begin{array}{l}\mathrm{I} \\
\mathrm{I} \\
\mathrm{I} \\
\mathrm{I} \\
\mathrm{E} \\
\mathrm{E} \\
\mathrm{E} \\
\mathrm{E} \\
\mathrm{E} \\
\mathrm{E} \\
\mathrm{E} \\
\mathrm{E} \\
\mathrm{E}\end{array}$ & $\begin{array}{c}62 \\
58-70 \\
70-80 \\
70-80 \\
30 \\
30 \\
32 \\
48 \\
53 \\
56 \\
62 \\
88 \\
98\end{array}$ & $\begin{array}{l}73 \\
76 \\
85 \\
80 \\
25 \\
22 \\
29 \\
44 \\
48 \\
47 \\
58 \\
85 \\
90\end{array}$ & $\begin{array}{l}97 \\
86 \\
97 \\
119 \\
45 \\
45 \\
45 \\
45 \\
45 \\
45 \\
45 \\
45 \\
45\end{array}$ & $\begin{array}{l}1.58 \\
1.45 \\
1.56 \\
1.60 \\
1.48 \\
1.50 \\
1.50 \\
1.48 \\
1.48 \\
1.54 \\
1.54 \\
1.50 \\
1.52\end{array}$ & $\begin{array}{l}3670 \\
2745 \\
1655 \\
---- \\
7688 \\
6991 \\
6615 \\
7050 \\
5390 \\
5290 \\
4175 \\
1973 \\
----\end{array}$ \\
\hline
\end{tabular}

A plot of the data similar to Figures 3 and 5 is shown in Figure 6 . The trends for the chemically defected specimens were similar to those for the mechanically defected specimens. In general, good agreement was obtained when the Phase I elliptical wastage equation was used to estimate normalized burst strength. The IGA defected tubes appear to display somewhat nonconservative behavior, but this is not conclusive due to the limited amount of data for this defect type.

\subsection{COLLAPSE TEST RESULTS}

Collapse results are presented as tables and plots by defect type. Considering that the original matrix of collapse tests was smaller than that for burst tests, and collapse testing, by its nature, produced more no-data runs, there is less test data available on collapse behavior of the chemically defected specimens.

\subsubsection{Undefected Specimen Data}

Three undefected tubing specimens from each heat were collapsed to provide baseline information, Table 5 . The results of these tests were reported in the Phase I report and repeated here for completeness. 


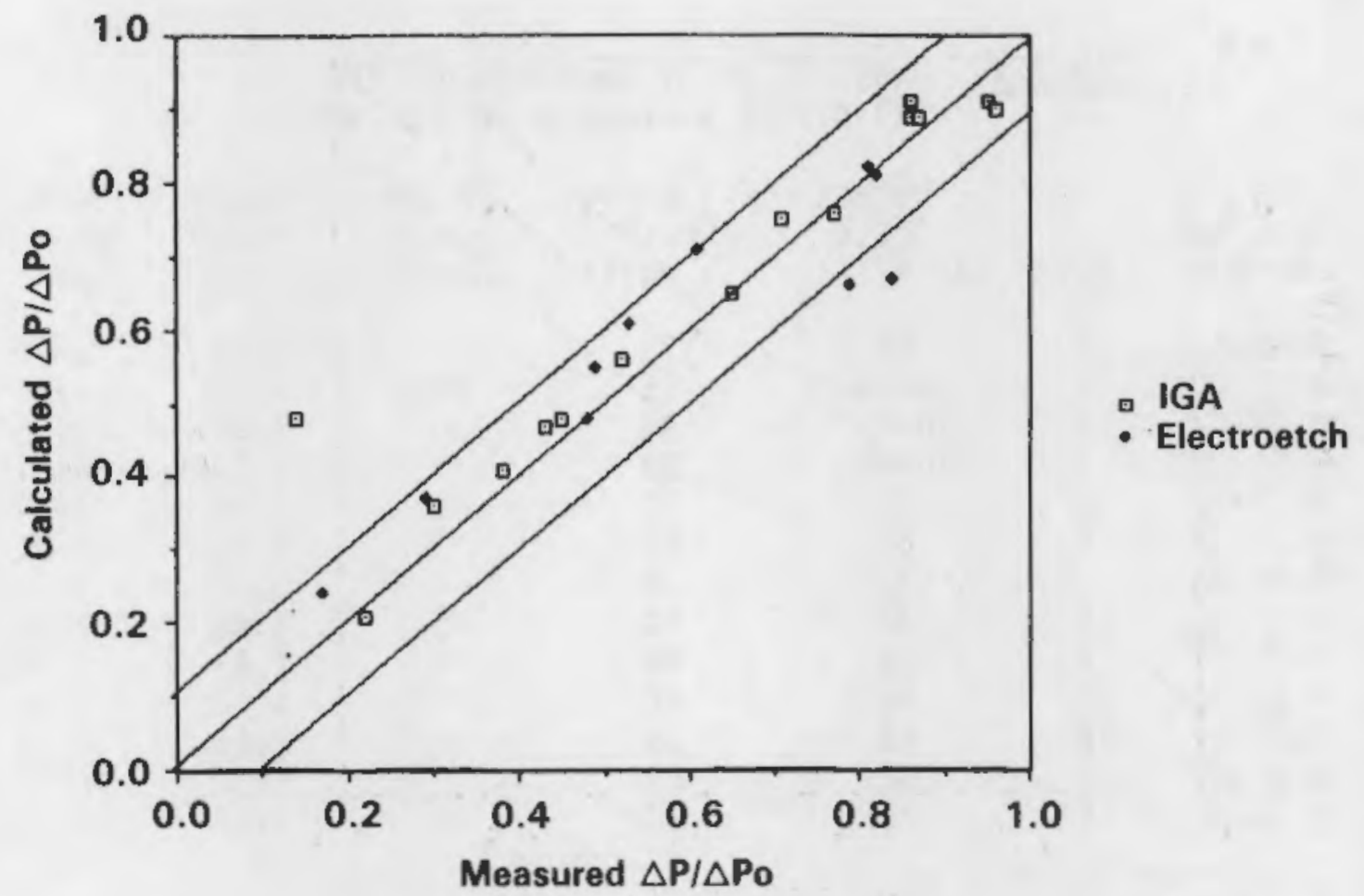

FIGURE 5. Calculated Normalized Burst Pressure from the Uniform Thinning Empirical Equation vs. Measured Normalized Burst Pressure for Tubes with Chemically Produced Uniform Thinning.

TABLE 5. Undefected Tube Collapse Pressures

\begin{tabular}{|c|c|c|}
\hline Heat & $\begin{array}{l}\text { Average Failure } \\
\text { Pressure, psi }\end{array}$ & $\begin{array}{r}\text { Standa } \\
\text { Deviation }\end{array}$ \\
\hline $\begin{array}{l}B \\
E \\
F\end{array}$ & $\begin{array}{l}4,890 \\
4,405 \\
4,030\end{array}$ & $\begin{array}{r}10 \\
92 \\
108\end{array}$ \\
\hline
\end{tabular}

\subsubsection{Uniform Thinning and Elliptical Wastage Test Results}

The collapse pressures for the uniform thinning and elliptical wastage specimens are presented in Tables 6 and 7, respectively. Plots of the calculated and measured normalized collapse pressures are provided in Figures 7 and 8 for uniform thinning and elliptical wastage, respectively. The test data indicate that collapse pressures for both of these defect types were slightly lower than similar mechanically defected specimens. Due to limited data, it is not possible to make firm conclusions, but it appears that the lower collapse pressures resulted from variability in residual wall thickness. 


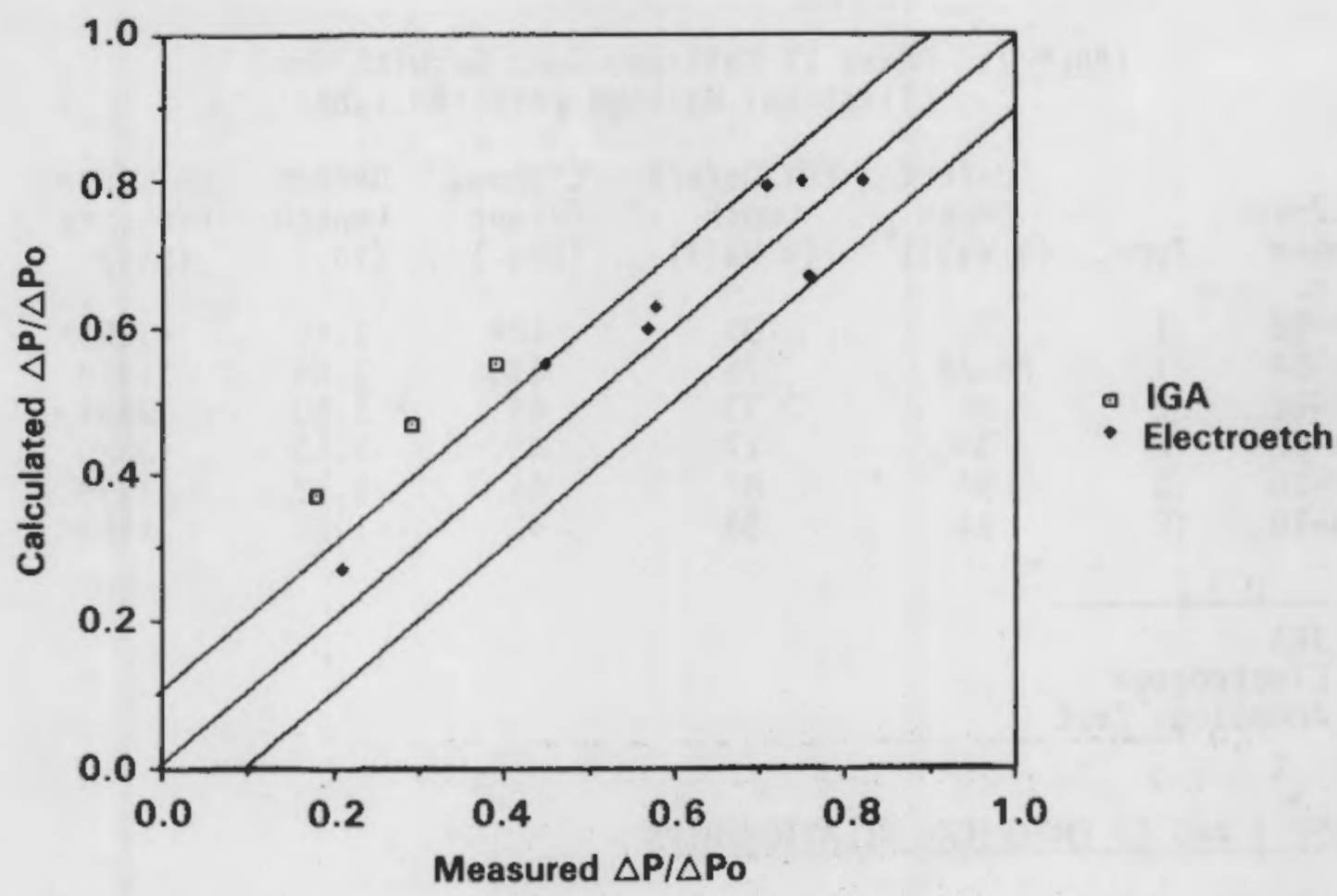

FIGURE 6. Calculated Normalized Burst Pressure from the Elliptical Wastage Empirical Equation vs. Measured Normalized Burst Pressure for tubes with Chemically Produced Elliptical

TABLE 6. Phase II Collapse Test Results for Uniform Thinning Defected Tubes

$\begin{array}{lccccc}\begin{array}{c}\text { Specimen } \\ \text { Number }\end{array} & \text { Type } & \begin{array}{c}\text { Defect } \\ \text { Depth } \\ \text { (\% Wal1) }\end{array} & \begin{array}{c}\text { ECr Defect } \\ \text { Depth } \\ \text { (\% Wal1) }\end{array} & \begin{array}{c}\text { Defect } \\ \text { Length } \\ \text { (in.) }\end{array} & \begin{array}{c}\text { Collapse } \\ \text { Pressure } \\ \text { (psi) }\end{array} \\ \text { B-34-09 } & \text { I } & 30 & 40 & 1.53 & 3680 \\ \text { B-70-06 } & \text { I } & 44-50 & 63 & 1.54 & 2645 \\ \text { B-07-02 } & \text { I } & 65 & 74 & 1.49 & 1840 \\ \text { B-75-06 } & \text { I } & 82 & 92 & 1.51 & 600 \\ \text { B-36-08 } & \text { E } & 18 & 30 & 1.48 & 4420 \\ \text { B-33-06 } & \text { E } & 26 & 30 & 1.47 & 4260 \\ \text { B-39-04 } & \text { E } & 60 & -- & 1.40 & 2360 \\ \text { B-53-02 } & \text { E } & 62 & 63 & 1.51 & 2080 \\ \text { B-39-02 } & \text { E } & 78 & 83 & 1.51 & 1920 \\ \text { B-42-04 } & \text { E } & 78 & 84 & 1.48 & 1240 \\ & & & & & \\ \text { I = IGA } & & & & & \\ \text { E = Electroetch } & & & & & \end{array}$


IABLE 7. Phase II Collapse Test Results for Elliptical Wastage Defected Tubes

$\begin{array}{ccccccc}\begin{array}{c}\text { Specimen } \\ \text { Number }\end{array} & \text { Type } & \begin{array}{c}\text { Defect } \\ \text { Depth } \\ \text { (\% Wal1) }\end{array} & \begin{array}{c}\text { ECT Defect } \\ \text { Depth } \\ \text { (\% Wal1) }\end{array} & \begin{array}{c}\text { Circum. } \\ \text { Extent } \\ \text { (Deg.) }\end{array} & \begin{array}{c}\text { Defect } \\ \text { Length } \\ \text { (in.) }\end{array} & \begin{array}{c}\text { Collapse } \\ \text { Pressure } \\ \text { (psi) }\end{array} \\ \text { B-54-08 } & \text { I } & 72 & 91 & 104 & 1.46 & <1600^{*} \\ \text { B-60-04 } & \text { I } & 66-74 & 76 & 140 & 1.54 & 1310 \\ \text { B-06-02 } & \text { E } & 30 & 33 & 45 & 1.50 & 3354 \\ \text { B-11-02 } & \text { E } & 30 & 17 & 45 & 1.50 & 3620 \\ \text { B-48-10 } & \text { E } & 90 & 87 & 45 & 1.52 & 1350 \\ \text { B-33-10 } & \text { E } & 94 & 88 & 45 & 1.53 & 1450\end{array}$

$$
\begin{aligned}
I & =I G A \\
E & =\text { Electroetch } \\
* & =\text { Anomalous Test }
\end{aligned}
$$

\subsection{PHASE I AND II EMPIRICAL RELATIONSHIPS}

During Phase I of the SGTIP, empirical relationships were derived to predict the failure pressures of mechanically defected specimens. These relationships were based on burst and collapse tests performed on specimens with EDM slots, uniform thinning and elliptical wastage. Least squares regression analysis was used to establish the constants used in the various relationships.

During Phase II, data on the failure pressures of chemically defected specimens were obtained. The data from Phase II were used to update the Phase I empirical equations. Wherever appropriate, the constants in the predictive relationships were recalculated using the Phase II data. The functional form of the equations was not changed. Since the collapse data for the elliptical wastage defect type was very sparse and nonexistent for SCC defected specimens, the Phase I relationships were not updated.

Table 8 lists the functional form of the six empirical relationships that were obtained along with the constants. Where appropriate, the values of the constants are given for the Phase I data by itself, for the Phase II data by itself and for the Phase I and Phase II data taken together. All six equations are listed for completeness, even though only three of the equations were modified by the Phase II data. Figures 9 to 11 provide graphs comparing the calculated versus measured normalized burst and collapse pressures for the three equations that were modified with Phase II data. The modified equations yielded predicted burst and collapse pressures that almost always fell within $\leqslant 10 \%$ of actual values over the range of defect dimensions investigated. 


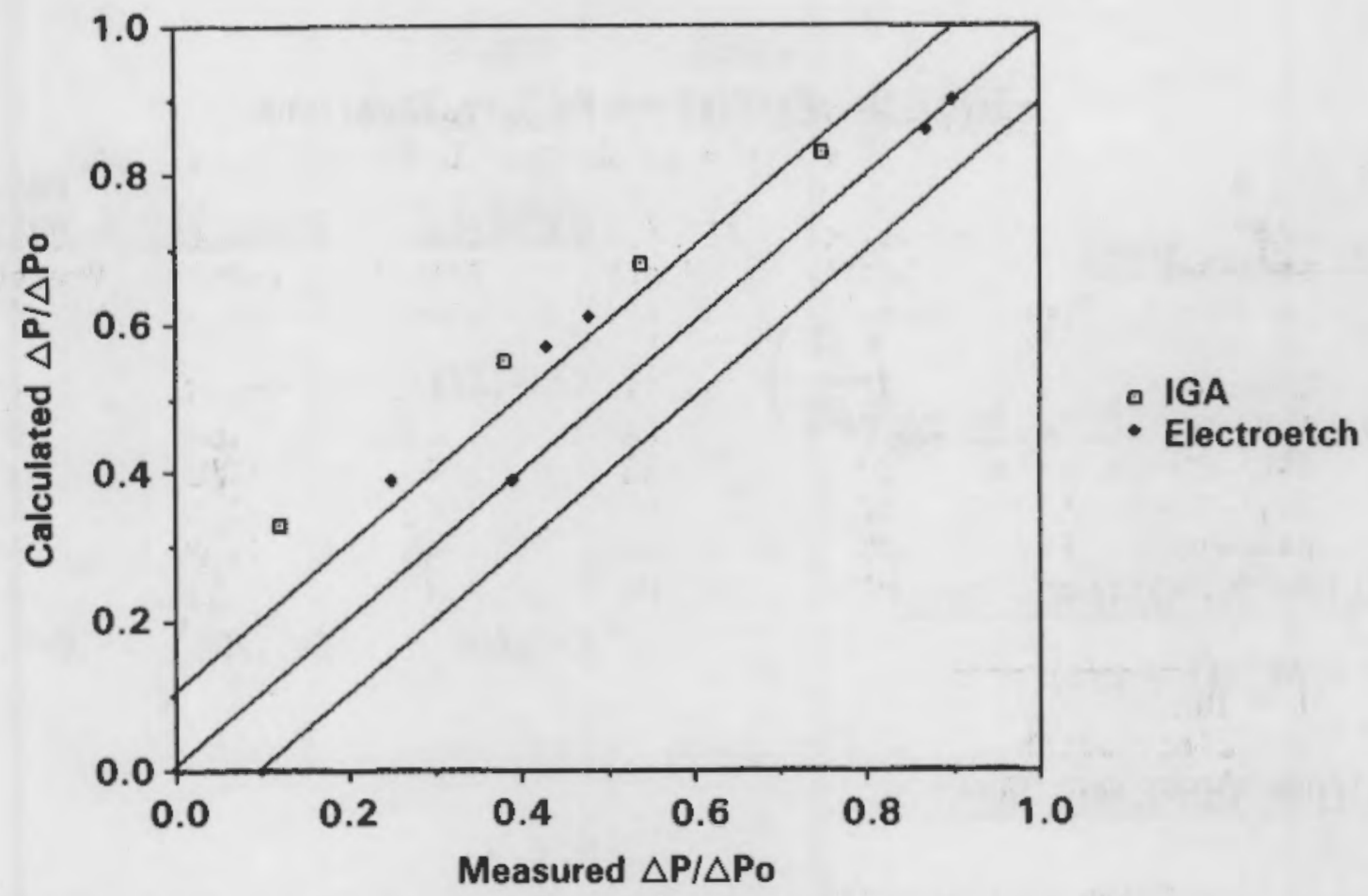

FIGURE 7. Calculated Normalized Collapse Pressure from the Uniform Thinning Empirical Equation vs. Measured Normalized Collapse Pressure for Tubes with Chemically Produced Uniform Thinning.

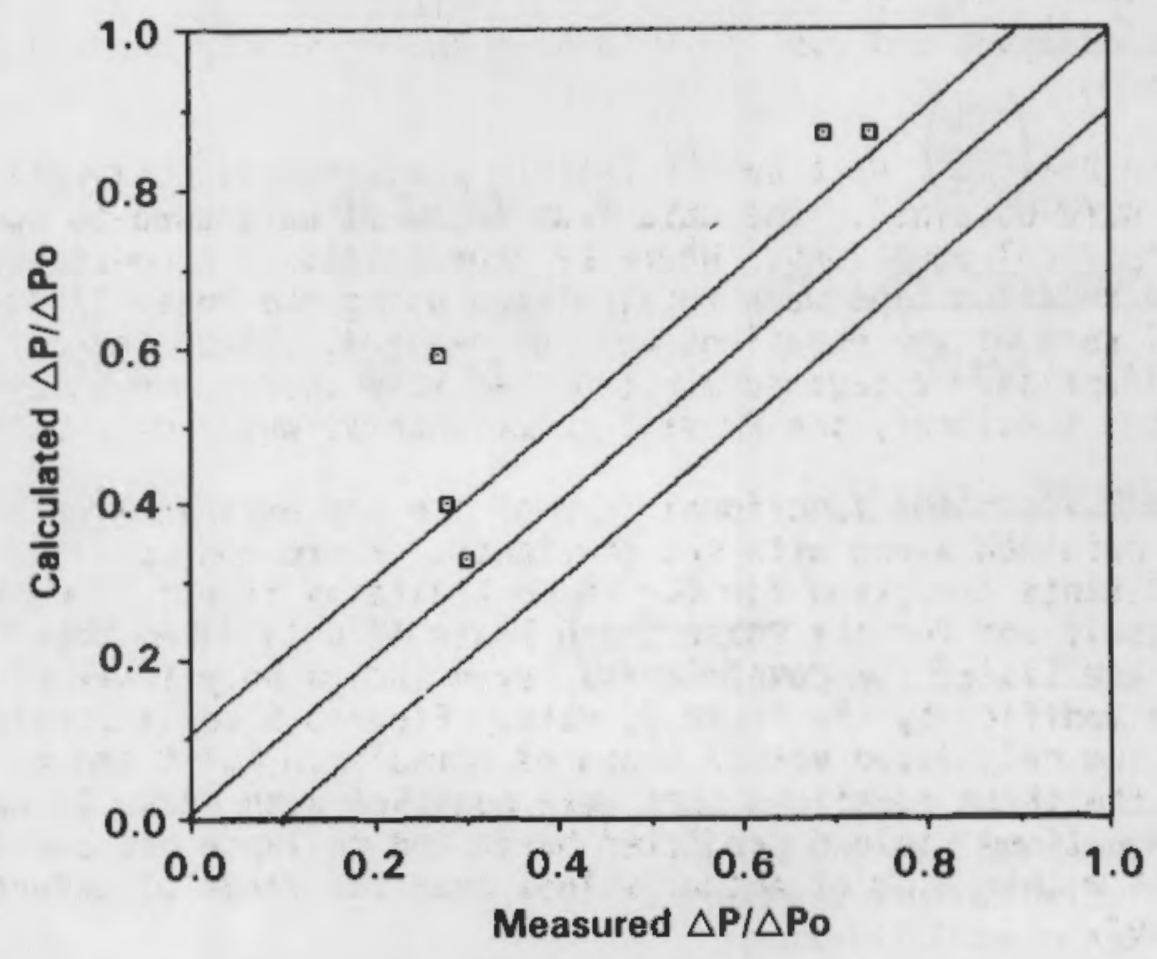

FIGURE 8. Calculated Normalized Collapse Pressure from the Elliptical Wastage Empirical Equation vs. Measured Normalized Collapse Pressure for Tubes with Chemically Produced Elliptical Wastage. 
TABLE 8. Predictive Failure Equations

EDM SLOT - BURST

PHASE I PHASE II PHASE II

$\Delta P / \Delta P_{0}=1-\frac{h}{t}+\frac{h}{t} \exp \left(\frac{C L}{\sqrt{R t}}\right) \quad C=-.373$

ELLIPTICAL WASTAGE - BURST

$\Delta P=\Delta P_{0}(1-h / t)^{C}$

$C=.604 \quad C=.700 \quad C=.626$

UNIFORM THINNING - BURST

$\Delta P / \Delta P_{0}=(1-h / t)^{1-\exp }\left(\frac{C L}{\sqrt{R(t-h)}}\right)$

$C=-.130 \quad C=-.200 \quad C=-.142$

EDM SLOT - COLLAPSE

$\Delta P / \Delta P_{0}=1-\exp \left(\frac{C L}{\sqrt{R t}}\right)$

$C=-2.49$

ELLIPTICAL WASTAGE - COLLAPSE

$\Delta P=\Delta P_{0} \quad(1-h / t)^{C}$

$C=.396$

UNIFORM THINNING - COLLAPSE

$\Delta P / \Delta P_{0}=1-\frac{h}{t}+\frac{h}{t} \exp \left(\frac{C L}{\sqrt{R(t-h)}}\right) \quad C=-.066 \quad C=-.118 \quad C=-.079$

$\Delta P=$ Predicted failure pressure

$\Delta P_{0}=$ Undefected failure pressure

$t^{0}=$ Undefected wall thickness

h = Maximum defect depth

$L \quad=$ Maximum defect length

$\mathrm{R}$ = Inside tube radius

$\mathrm{C}=$ Curve fitting constant 


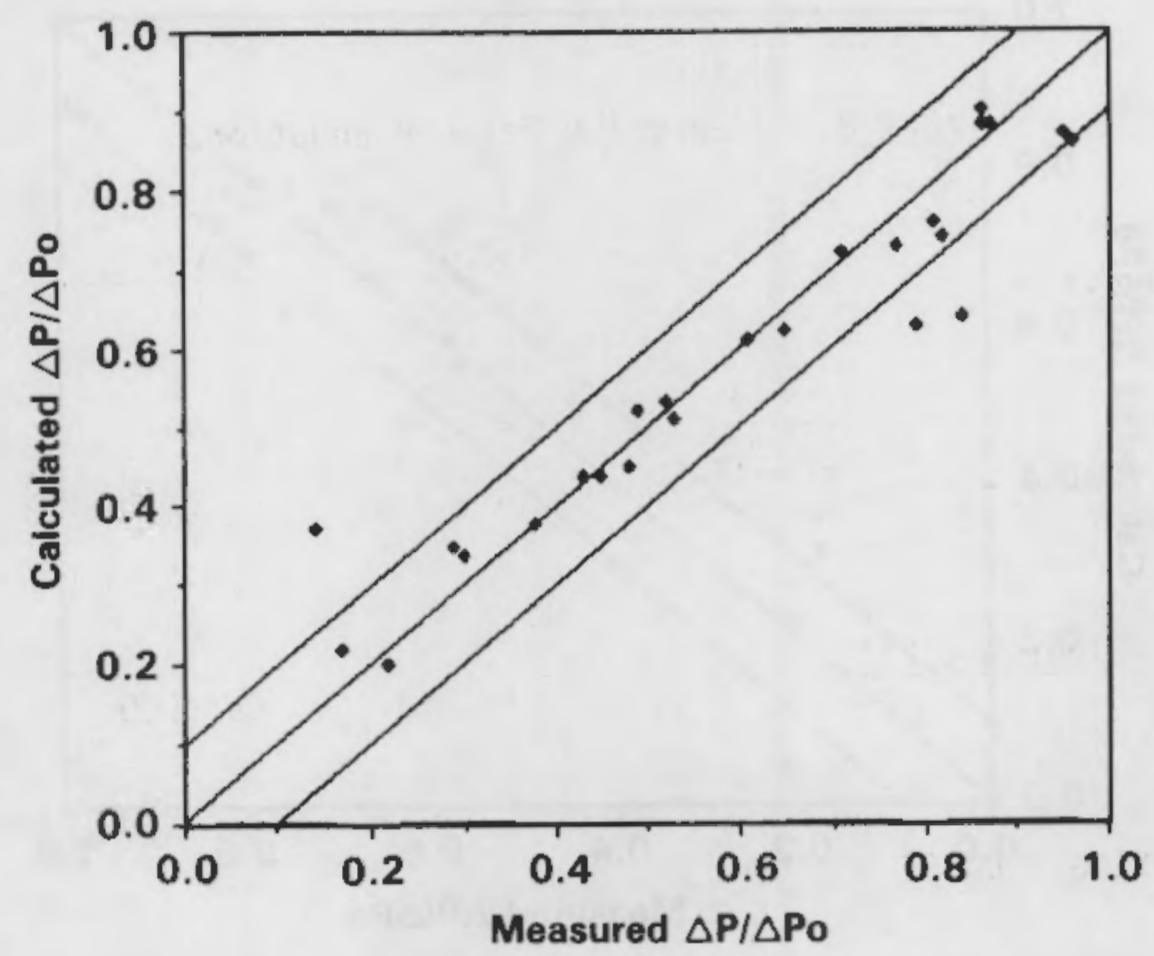

FIGURE 9. Comparison of Calculated and Measured Normalized Burst Pressure for Uniform Thinning Specimens - Adjusted Phase I Equation.

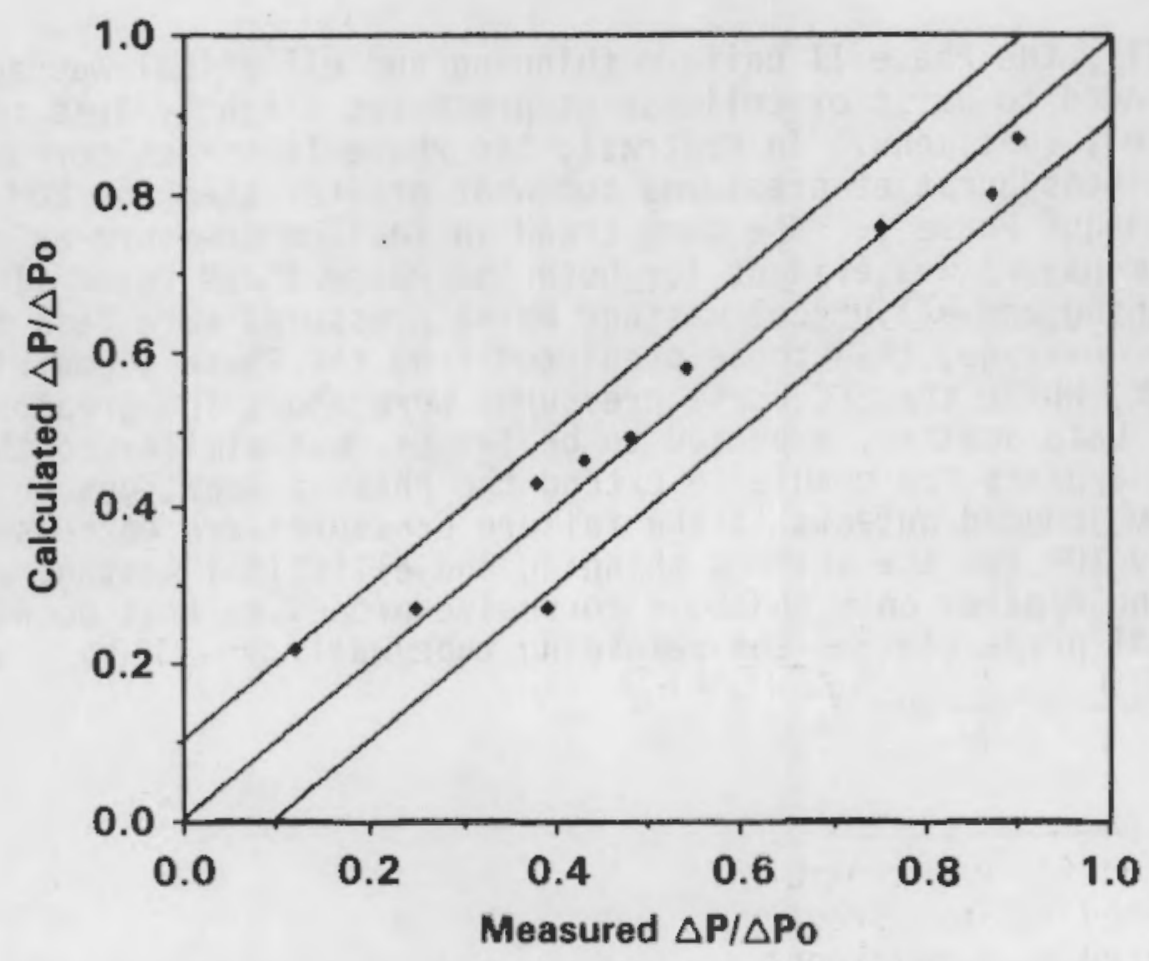

FIGURE 10. Comparison of Calculated and Measured Normalized Collapse Pressure for Uniform Thinning Specimens - Adjusted Phase I Equation. 


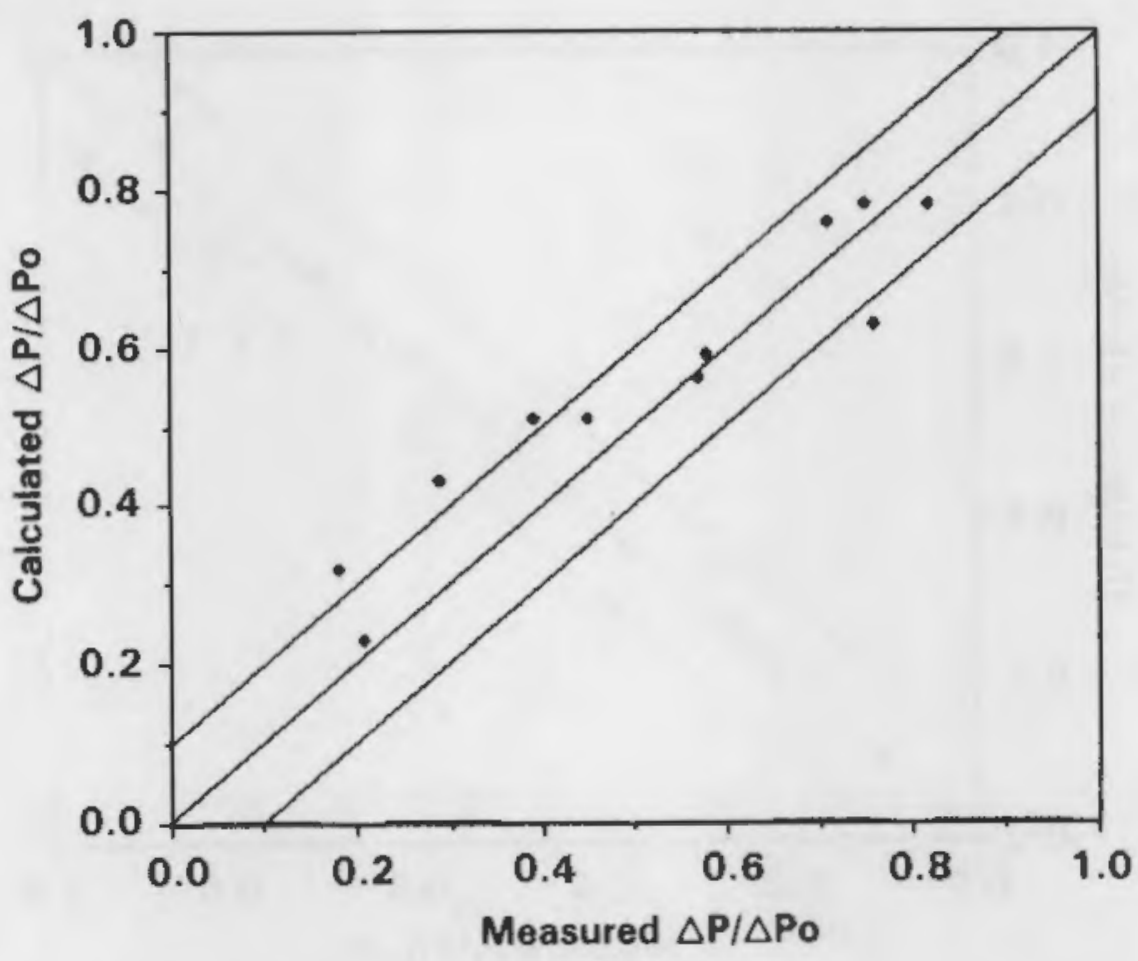

FIGURE 11. Comparison of Calculated and Measured Normalized Burst Pressure for Elliptical Wastage Specimens Adjusted Phase I Equation.

Generally, the Phase II uniform thinning and elliptical wastage specimens tended to burst or collapse at pressures slightly less than for similar Phase I specimens. In contrast, the Phase II stress corrosion cracked specimens burst at pressures somewhat greater than the EDM notch defected tubes of Phase I. The same trend in failure pressure as a function of defect dimensions was evident for both the Phase I and Phase II specimens. Uniform thinning and elliptical wastage burst pressures were less than $10 \%$ lower, on the average, than those predicted from the Phase I empirical relationships, while the SCC burst pressures were about $10 \%$ greater than calculated. Data scatter, expected to be larger, was similar to that of Phase I. It appears reasonable to extend the Phase I equations to the Phase II chemically induced defects if the failure pressures are decreased approximately $10 \%$ for the uniform thinning and elliptical wastage cases. This reasoning applies only to those corrosive processes that do not alter the mechanical properties of the remaining tube wall. 


\section{D REVIEW AND EVALUATION OF LEAK RATE DATA}

This section describes a survey of data from leak rate tests on laboratory defected steam generator tubes with corrosion type cracks which were intended to simulate service induced cracks. The objective was to determine if a given crack will leak at a rate that is consistent with the length of the crack and the fluid pressure differential across the wall of the tube. The accuracy of leak rate predictions is an important consideration in the evaluation of leak-before-break analyses, and in the establishment of leak detection requirements as they relate to allowable leak rates stated in plant technical specifications.

The discussion below begins with a review of the sources of the leak test data used for the present evaluation. This is followed by a description of the leak rate model used here in attempts to correlate the measured leak rates with crack lengths and pressure differentials. A set of plots is then presented to compare measured leak rates with the corresponding predicted rates. Reasons for differences between predictions and tests are proposed. The discussion addresses the concept of leak-before-break as it may apply to steam generator tubes. Finally, the implications of the leak test data are related to the technical bases for leak detection requirements for steam generators in operating reactors.

\subsection{LEAK TEST DATA}

For the present evaluation, suitable leak test data were sought that met the following general requirements:

- The tube specimens had cracks typical of service induced degradation mechanisms such as stress corrosion cracking. In all cases the tubes were cracked by laboratory procedures. Machined defects were excluded.

- The tests were performed for fluid conditions relevant to leakage at the pressure and temperature for normal operating and accident conditions.

- The data were reported in nonproprietary documents that could be referenced.

Three sets of data were used in the present evaluation:

- Combustion Engineering (CE) Data - These tests were performed by Combustion Engineering as part of a research project funded by the Electric Power Research Institute (EPRI). Details of these tests were given by Powell and Hall (1987). The defects were produced in sensitized tubing by exposure to a pressurized corrosive sulfur based solution. Leak tests were performed with $600^{\circ} \mathrm{F}$ water at 2250 psig, both with and without a 900 psig secondary side pressure. The capacity of the test system was sufficient to maintain the 


\subsection{REVIEW AND EVALUATION OF LEAK RATE DATA}

This section describes a survey of data from leak rate tests on laboratory defected steam generator tubes with corrosion type cracks which were intended to simulate service induced cracks. The objective was to determine if a given crack will leak at a rate that is consistent with the length of the crack and the fluid pressure differential across the wall of the tube. The accuracy of leak rate predictions is an important consideration in the evaluation of leak-before-break analyses, and in the establishment of leak detection requirements as they relate to allowable leak rates stated in plant technical specifications.

The discussion below begins with a review of the sources of the leak test data used for the present evaluation. This is followed by a description of the leak rate model used here in attempts to correlate the measured leak rates with crack lengths and pressure differentials. A set of plots is then presented to compare measured leak rates with the corresponding predicted rates. Reasons for differences between predictions and tests are proposed. The discussion addresses the concept of leak-before-break as it may apply to steam generator tubes. Finally, the implications of the leak test data are related to the technical bases for leak detection requirements for steam generators in operating reactors.

\subsection{LEAK TEST DATA}

For the present evaluation, suitable leak test data were sought that met the following general requirements:

- The tube specimens had cracks typical of service induced degradation mechanisms such as stress corrosion cracking. In all cases the tubes were cracked by laboratory procedures. Machined defects were excluded.

- The tests were performed for fluid conditions relevant to leakage at the pressure and temperature for normal operating and accident conditions.

- The data were reported in nonproprietary documents that could be referenced.

Three sets of data were used in the present evaluation:

- Combustion Enqineering (CE) Data - These tests were performed by Combustion Engineering as part of a research project funded by the Electric Power Research Institute (EPRI). Details of these tests were given by Powell and Hall (1987). The defects were produced in sensitized tubing by exposure to a pressurized corrosive sulfur based solution. Leak tests were performed with $600^{\circ} \mathrm{F}$ water at 2250 psig, both with and without a 900 psig secondary side pressure. The capacity of the test system was sufficient to maintain the 
leakage flow rates for indefinite time periods so that steady state leak rates could be established and measured. Other specimens with cracks of comparable length (deep part through cracks) were burst. The measured burst pressures were a factor of two or more greater than the 2250 psi pressure differential of the steam line break accident condition addressed by the leak tests.

- French Tests - An abbreviated description of leak tests performed in France has been given by Berge (1987). Leak rates were measured for a pressure differential of $1450 \mathrm{psi}$ at room temperature, $248^{\circ} \mathrm{F}$ and $550^{\circ} \mathrm{F}$, and thus included simulations of the normal operating condition for steam generators. The cracks were described as OD initiated, and were evidently of axial orientation. Apparently, the cracks were initiated in the laboratory by corrosion induced means, although details of the specimen fabrication were not described in the paper. Results of burst tests of the laboratory stress corrosion cracked tubes were also given in the French paper.

- Battelle Columbus Data - Tests were performed at Battelle Columbus Laboratories (BCL) under subcontract to this program. All specimens had laboratory induced stress corrosion cracks. Both axial and circumferential cracks were included in the specimen set. The complete data set was reviewed in depth by PNL specialists in the field of thermal hydraulics to establish the relevance of each test to the operating conditions of steam generators. Only a small fraction (total of three) of the tests proved to be of interest to predictions of leak rates at operating conditions. In many cases no leakage was obseryed, due evidently to the fact that the cracks in many of the specimens did not extend entirely through the wall of the tube. Another group of tests were disregarded because the control of temperature, pressure, and flow rates was inadequate to prevent boiling of water within the tube. This meant that the presence of steam at the inlet side of the leaking cracks failed the criterion of subcooled water, and thus the measured flow rates were not relevant to steam generator conditions. Pressure differentials for the three valid tests covered the range of interest to steam generator operation, although the fluid temperatures were significantly less than $600^{\circ} \mathrm{F}$. Nevertheless, these tests did provide an independent source of experiment flow rate data for use in benchmarking the leak rate predictions used in leak-before-break evaluations.

All three sources of data suffered from a lack of clarity regarding the lengths of the cracks in the individual test specimens, with a typical factor of two to five being reported between the upper and lower bounds on estimated crack length. The reasons for the uncertainty in the crack lengths were not documented. It is speculated that differences between ID and OD observations of crack length for the stress corrosion cracks may have been a factor. Also, the tightness of the cracks may have inhibited crack length measurements by nondestructive means. 


\subsection{LEAK RATE MODEL}

A set of equations was assembled to predict the leak rates from throughwall (axial and circumferential) cracks in steam generator tubes. This predictive model aided in the interpretation and comparison of measured leak rates from the various tests by different laboratories. This model was adapted from one developed by PNL for leakage from axial cracks in reactor pressure vessels (Simonen et al. 1986). Only the main assumptions and features of the model will be discussed in this report.

\subsubsection{Crack Opening Area}

The model uses fracture mechanics solutions to predict the crack opening area as a function of the crack length and the pressure differential across the tube wall. Given this crack opening area, well known equations from the fluid mechanics literature for the flow through an elongated orifice are then used to predict leak rates.

A basic assumption in the fracture mechanics equations is that of a simple through-wall crack with its length being equal on both the inside and outside surfaces of the tube. Since the work described by Simonen et al. (1986) addresses only axial cracks, it was necessary in this study to identify analogous equations for the opening of through-wall circumferential cracks.

The calculations begin with elastic fracture mechanics solutions, and make an approximate correction for elastic plastic behavior (generally small for the crack lengths and pressures of interest of concern here). This plasticity correction was originally developed by Simonen et al. (1986) using three dimensional finite element calculations for cracked cylinders. The solutions for specific geometries were then normalized for general application by using trends of flat plate solutions from Kumar, German, and Shih (1981) and were plotted in a limit load format with the applied stress term modified in the usual manner by elastic bulging factors for axially cracked cylinders. For the elastic-plastic calculations it was necessary to adopt a stress strain curve to represent a characteristic steam generator tubing material. Such a curve was selected from a tensile test reported by Berge (1987). Strain hardening coefficients were fit from the selected stress strain curve. This particular curve had an ultimate strength of $101 \mathrm{ksi}$ and a yield strength of $55 \mathrm{ksi}$. In applications to other lots of tubes the normalized results could be adjusted for different values of flow stress. For purposes of this report, a common value of flow stress of $67.5 \mathrm{ksi}$ was used, which corresponded to a yield strength of $45 \mathrm{ksi}$ and an ultimate strength of $90 \mathrm{ksi}$.

A number of assumptions are inherent to the present as well as other published equations for predicting crack opening areas. The crack geometry is idealized as a simple through-wall crack either purely axial or circumferential in orientation. The cracked tube is assumed to be stress free when there is no pressure in the tube, and the opening area is exactly zero for this zero pressure condition. In practice, tubes will have some residual stresses from tube fabrication or from prior loading history. Thus, a 
certain minimum level of pressure is needed to overcome the stresses tending to hold the crack closed. Alternatively, residual stresses and prior plastic deformation may give some crack opening for an unpressurized tube.

\subsubsection{Fluid Mechanics}

The essential features of the fluid mechanics model for predicting leak rates through a crack of a given opening area are described by Simonen et al. (1986). This model accounts for a pressure drop along the narrow opening of the flow path corresponding to the extension of the crack from the inside to the outside of the tube. The model relates this pressure drop to the surface roughness of the fracture surfaces of the crack. For short cracks and small pressure differentials (hence small crack opening displacements) this predicted frictional pressure drop can be a substantial fraction of the total pressure differential across the tube wall.

The leakage model due to Simonen et al. (1986) was developed for reactor pressure vessels under conditions of severe subcooling of the water inside the vessel. As such, it was necessary to modify the model both to account for a back pressure at the secondary side of the stean generator tube, and to account for possible two phase flow as the $600^{\circ} \mathrm{F}$ primary system water flashes into steam. A simplified treatment of two phase flow was adopted, in which the saturation pressure for the primary system water was used instead of the actual secondary side back pressure, if this saturation pressure was greater than the actual secondary side pressure.

The prediction of leak rates within the framework of the idealized assumptions was viewed as a relatively straight forward calculation. Accordingly, the predictions of the present model were benchmarked against a somewhat more sophisticated model (more sophisticated in it's treatment of two phase flow in the crack). This model is described by Griesbach, Cipolla, and Lang (1985); and Norris et al. (1984).

Figure 12 shows the relatively good agreement between the numerical predictions of leak rates from the model of this report and the Griesbach et al. (1985) model. These results provide a bench mark validation of the predictions used in this report, and also tends to confirm the viewpoint expressed above regarding the relative straight forward nature of leak rate predictions within the framework of idealized crack opening behavior.

\subsection{COMPARISON OF TESTS WITH PREDICTIONS}

The three sets of measured leak rate data were each compared with the predictions of the leak rate model. The objective was to evaluate the reproduceabilty and predictability of leak rates from steam generator tubes with service type degradation. 


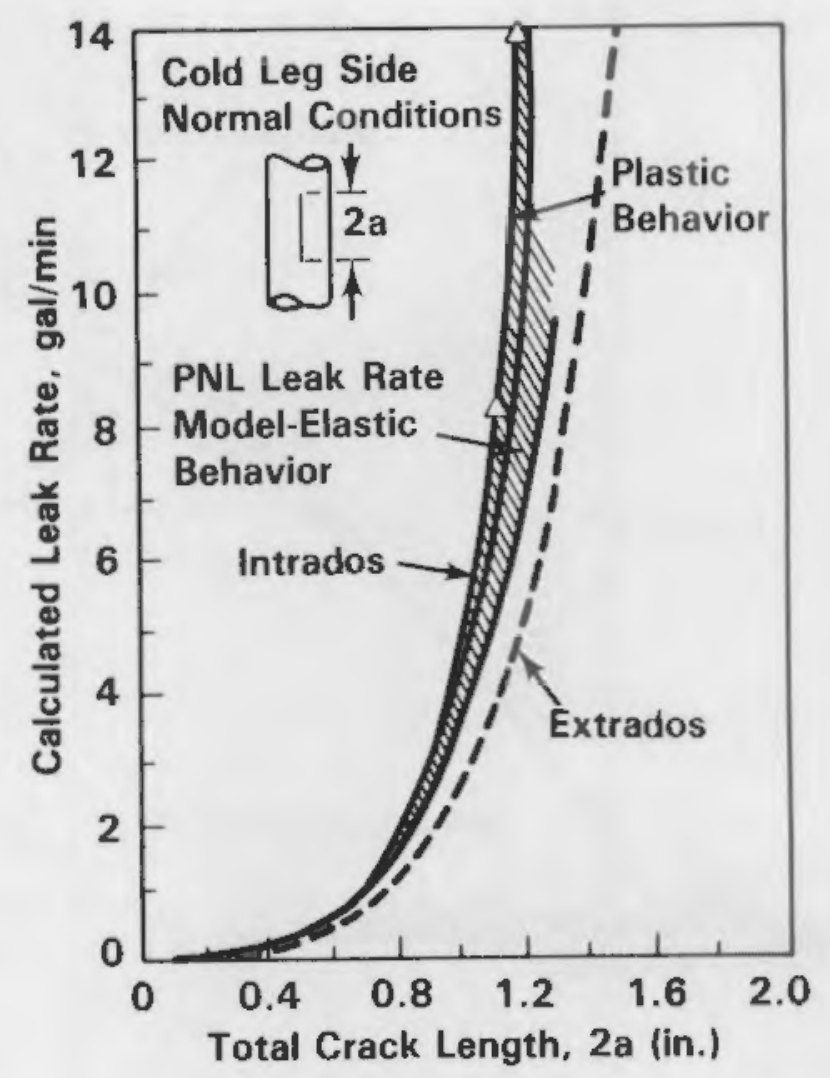

FIGURE 12. Comparison of PNL and EPRI Leak Rate Models

\subsubsection{Combustion Engineering Tests}

Figures $13-16$ are plots of the measured leak rate data as a function of the reported lengths of the axial cracks. Curves giving predicted leak rates are also plotted for comparison with the experimental data points.

The crack lengths for the test specimens were reported by Powell and Hall (1987) as bounding values. In Figures 13 and 15, these bounding values are indicated as a line. However, in Figures 14 and 16 , these bounding values were averaged to allow plotting of a single "best estimate" crack length. The appropriate interpretation of the two reported bounds on crack length was not made clear. It is speculated that irregular crack shapes resulted in different indications of crack length at the ID and OD intersections of the cracking with the tube surfaces. In such a case, the minimum crack length could be viewed as the most appropriate correlation parameter, since the minimum crack length would control the length of the actual flow orifice. On the other hand, the average crack length might be more appropriate since the crack opening displacement may be governed in an approximate manner by the average crack length.

From an examination of the tabulated test data, it was apparent that quite a large number of tests had a reported leak rate of exactly 0.1 $\mathrm{gal} / \mathrm{min}$. This was interpreted as an indication of a limitation on the 


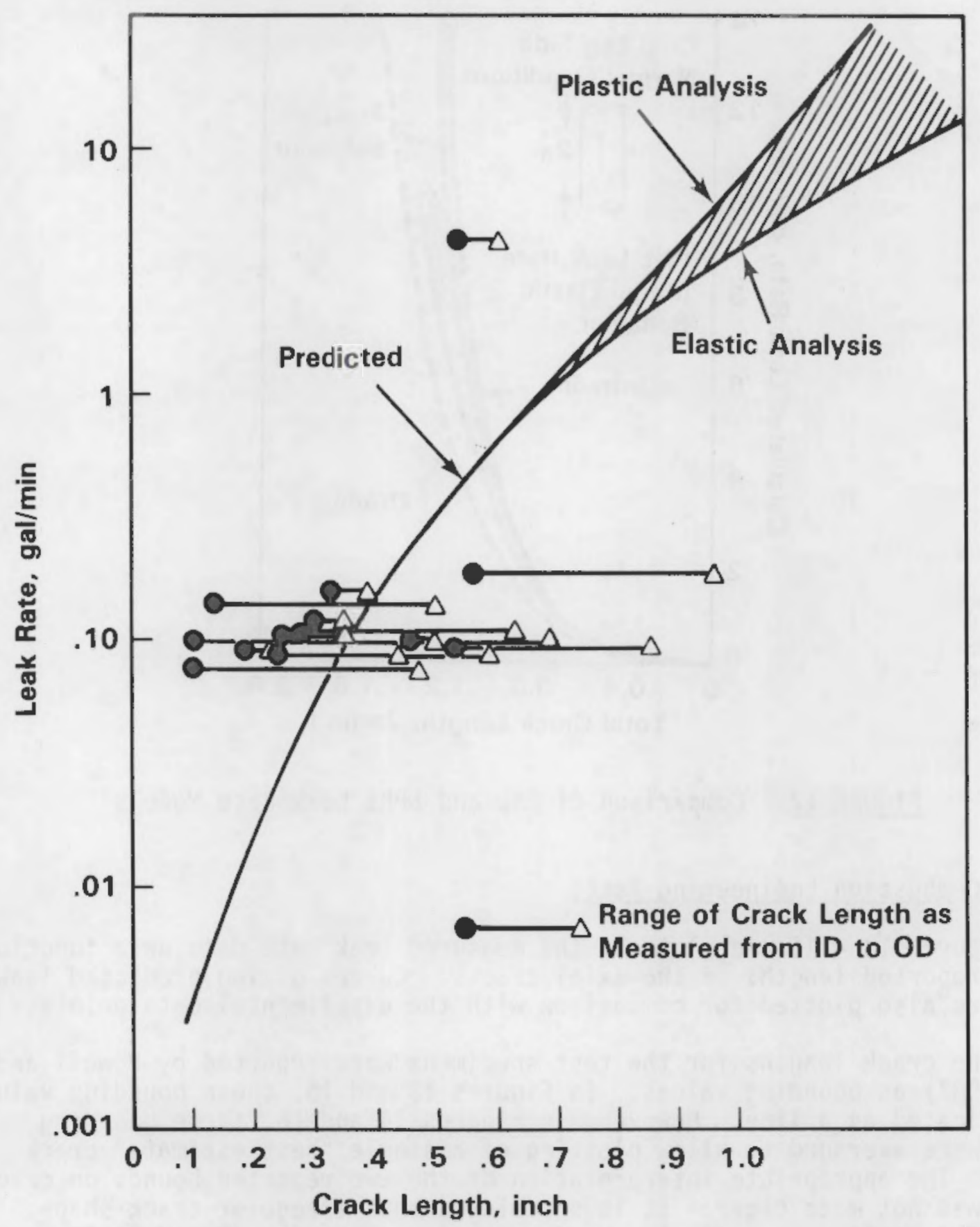

FIGURE 13. Comparison of Combustion Engineering Leak Test Data with Model Predictions, Normal Operating Condition 


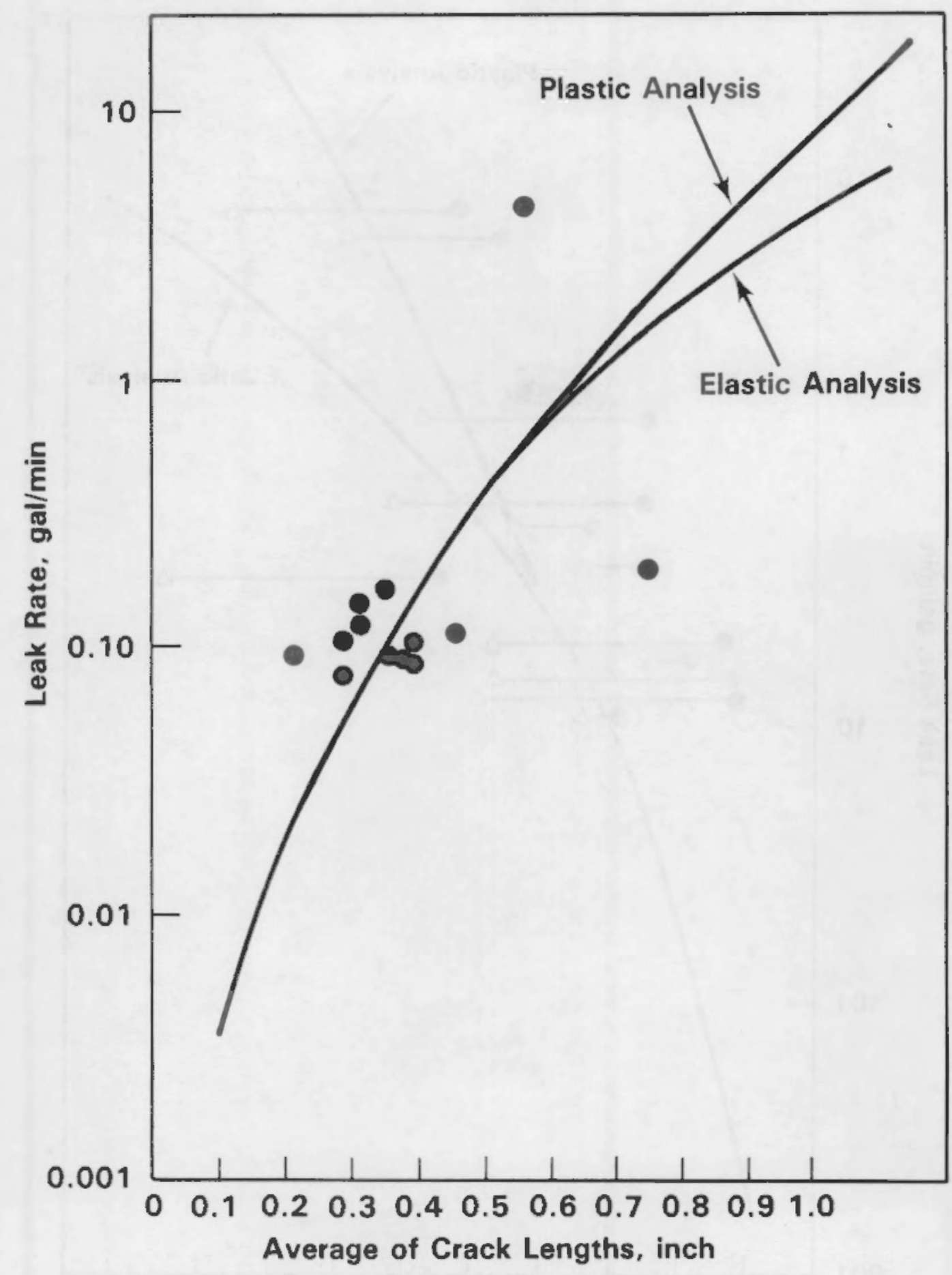

FIGURE 14. Comparison of Combustion Engineering Leak Test Data with Model Predictions, Normal Operating Condition 


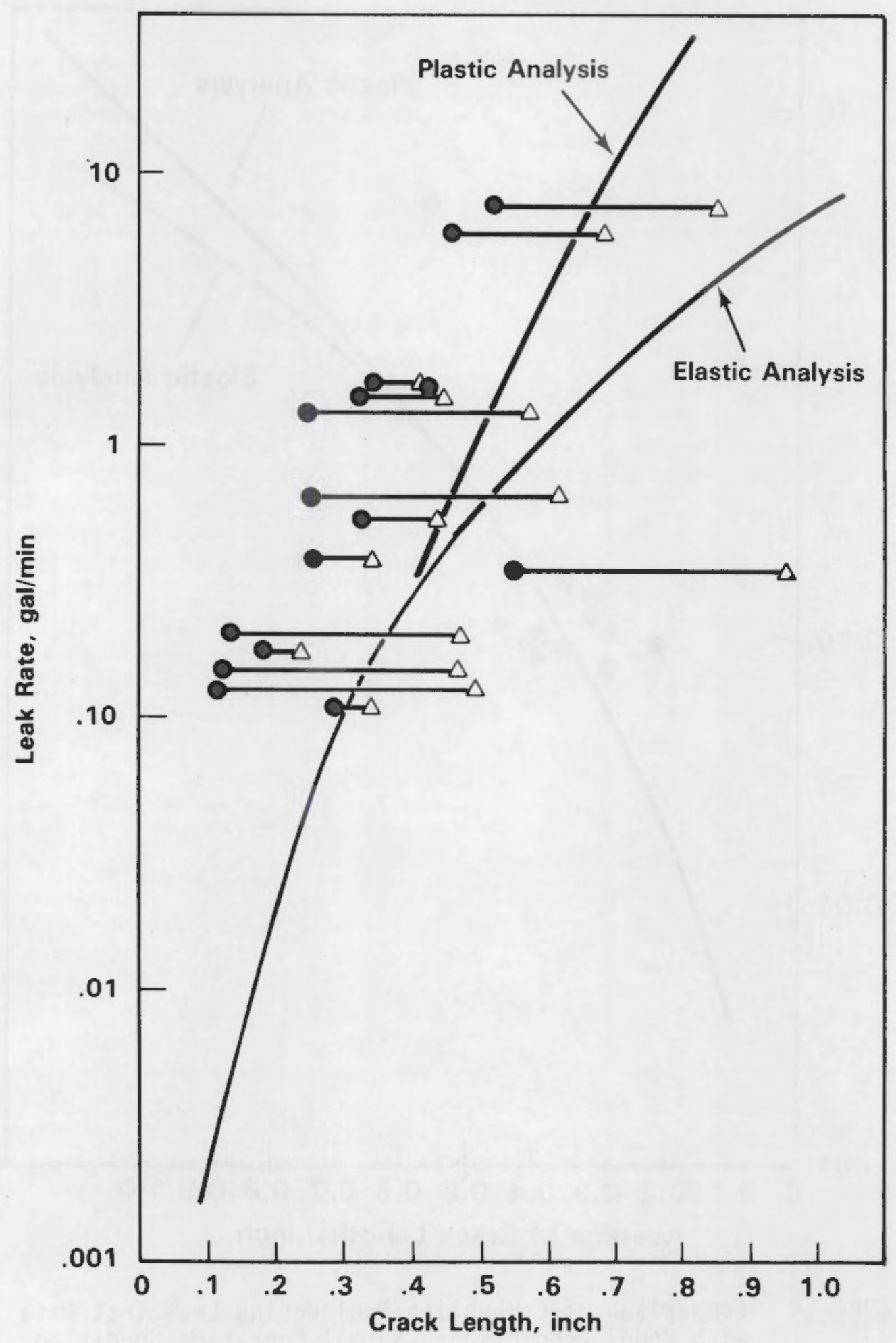

FIGURE 15. Comparison of Combustion Engineering Leak Test Data with Model Predictions, Steamline Break Condition 


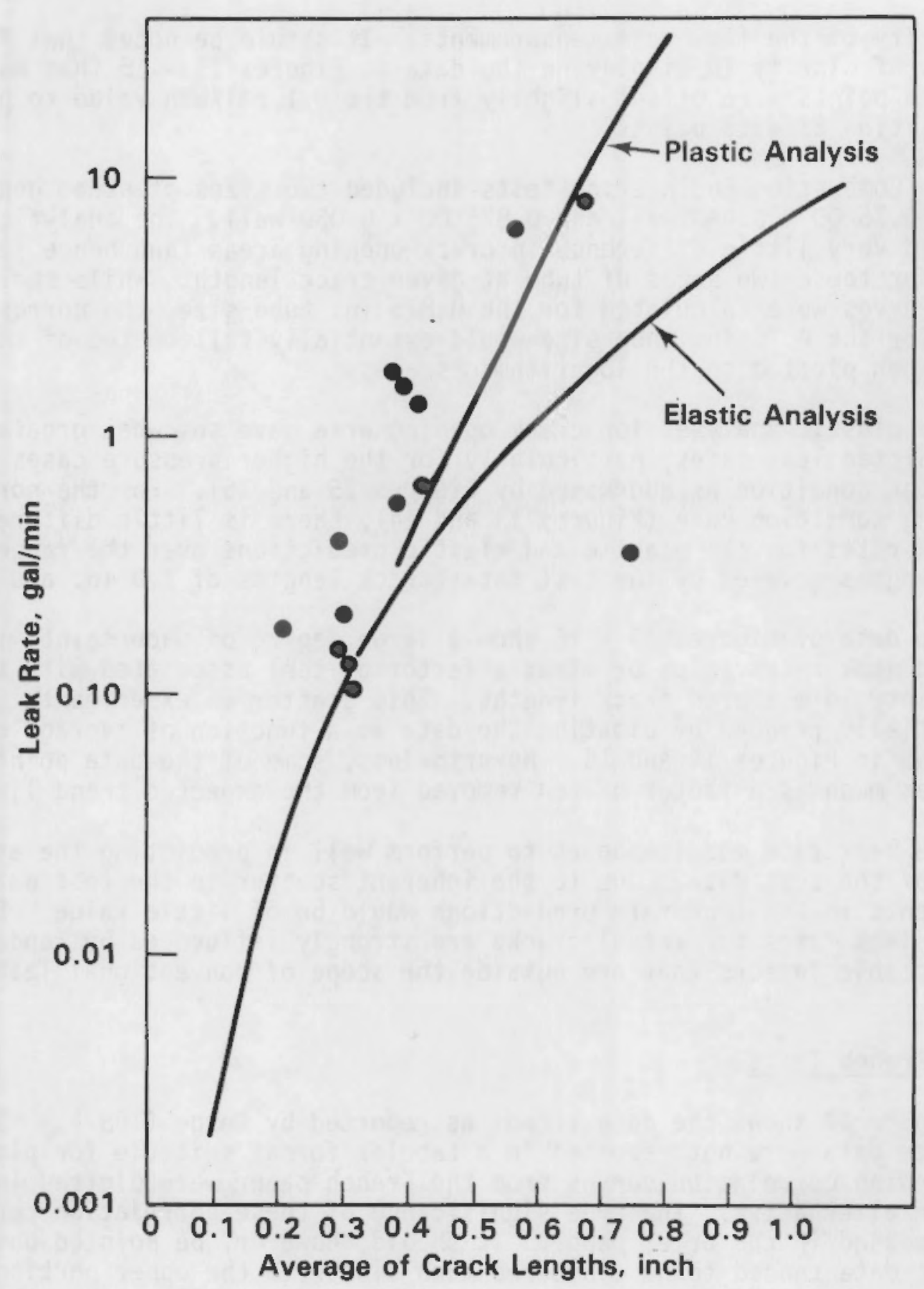

FIGURE 16. Comparison of Combustion Engineering Leak Test Data with Model Predictions, Steamline Break Condition 
sensitivity of the flow rate measurements. It should be noted that for purposes of clarity in displaying the data on Figures 13 - 16 that many of 2the data points were offset slightly from the $0.1 \mathrm{gal} / \mathrm{min}$ value to prevent superposition of data points.

The Combustion Engineering tests included two sizes of steam generator tubes $-0.7500 \times 0.043$ wall and $0.87500 \times 0.050$ wall. The analytic model predicted very little difference in crack opening areas (and hence leak rates) for these two sizes of tube at given crack length. While the predicted curves were calculated for the 0.875 in. tube size, the corresponding curves for the $0.75 \mathrm{in}$. tube size would essentially fall on top of the 0.875 curves when plotted on the logarithmic scales.

The plastic analyses for crack opening area gave somewhat greater values for predicted leak rates, particularly for the higher pressure cases (steamline break condition as addressed by Figures 15 and 16). For the normal operating condition case (Figures 13 and 14), there is little difference in the leak rates for the plastic and elastic predictions over the range of crack lengths covered by the test data (crack lengths of 1.0 in. and less).

The data of Figures 13 - 16 show a large degree of uncertainty in expected leak rates (plus or minus a factor of ten) associated with the uncertainty in measured crack lengths. This scatter in experimental data is substantially reduced by plotting the data as a function of average crack length as in Figures 14 and 16. Nevertheless, some of the data points still remain as much as a factor of ten removed from the expected trend line.

The leak rate model appears to perform well in predicting the average trends of the test data. Due to the inherent scatter in the test data, refinements in the leak rate predictions would be of little value. Evidently, leak rates for actual cracks are strongly influenced by random and unpredictable factors that are outside the scope of conventional leak rate models.

\subsubsection{French Tests}

Figure 17 shows the data trends as reported by Berge (1987). Since the leak rate data were not reported in a tabular format suitable for plotting, the bounding correlation curves from the French paper were plotted in Figure 18 as an alternative. The true significance of these correlation curves was not addressed in the brief paper. It should, however, be pointed out that the test data tended to be clustered much closer to the upper portion of the band (i.e., near the curve labeled "outside" in Figure 17) rather than being clustered near the center of the band.

Like the Combustion Engineering data, the French data showed significant scatter. Nevertheless, the overall trend of leak rate versus crack length was consistent with the leak rates predicted by the simple model. In a significant number of tests the leak rates were lower than those predicted by the model. It was observed that the French data exhibited somewhat less scatter than the Combustion Engineering data. Nevertheless, the French 
measurements of leak rates that were in some cases up to a factor of five less than predicted by the leak rate model.

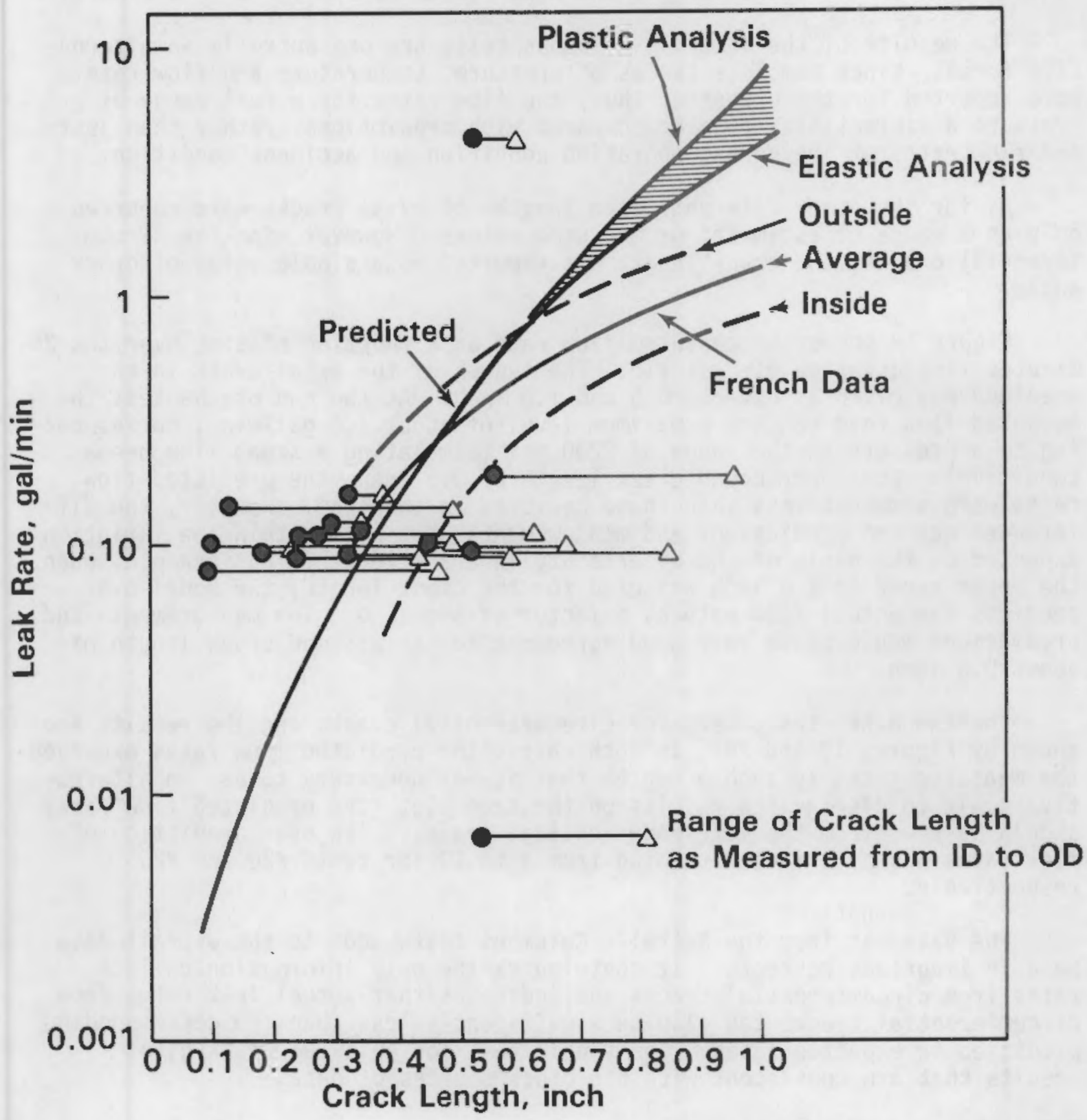

FIGURE 17. Comparison of French Leak Test Data with Model Predictions, Normal Operating Condition 


\subsubsection{Battelle Columbus Data}

The leak rate data from these tests are shown by Figures $18-20$. There were three tests of interest - tests $\# 10, \# 20$, and $\# 29$. It should be noted that two of the tests were for circumferential cracks, in contrast to the situation of axial cracks for all the other tests addressed in this report.

The results of the Battelle Columbus tests are presented in an alternative format, since complete traces of pressure, temperature and flow rate were reported for these tests. Thus, the flow rates for a full range of pressure differentials could be compared with predictions, rather than just the flow rates at the normal operation condition and accident condition.

As for the other data sets, the lengths of axial cracks were reported only as a range of estimated or measured values. However, for the circumferential cracks, the crack length was reported as a single value of crack angle.

Figure 18 shows the measured flow rate as a function of time over the 26 minutes time duration of Test \#10. The length of the axial crack in the specimen was given as between 0.5 and 1.0 inch. At the end of the test the measured flow rate reached a maximum level of about $1.6 \mathrm{gal} / \mathrm{min}$., corresponding to a pressure in the range of 2200 psi (simulating a steam line break condition). For lower bound crack length of 0.5 inch, the predicted flow rates were somewhat less than those measured in the test. However, the differences between predictions and measurements were well within the variation expected on the basis of the uncertainty in crack length. For example, when the upper bound of 1.0 inch was used for the crack length, the model over predicts the actual flow rate by a factor of about 60 . The measurements and predictions would be in very good agreement for an assumed crack length of about 0.6 inch.

The two other tests were for circumferential cracks and the results are shown by Figures 19 and 20 . In both cases, the predicted flow rates exceeded the measured rates to such a degree that it was necessary to use an alternative scale to display the results on the same plot (the predicted flow rates should be read from the left hand vertical scale). The over prediction of flow rates was by a factor ranging from 4 to 10 for tests \#20 and \#29 respectively.

The data set from the Battelle Columbus tests adds to the overall data base in important respects. It contributes the only information on leak rates from circumferential cracks and indicates that actual leak rates from circumferential cracks can also be significantly less than the corresponding predicted or expected rates. The single test for an axial crack gives results that are consistent with the other sources of data.

\subsubsection{Sources of Variability}

The data from the published leak rate tests show considerable scatter. In many cases, the measured leak rates are much less than the rates predicted 


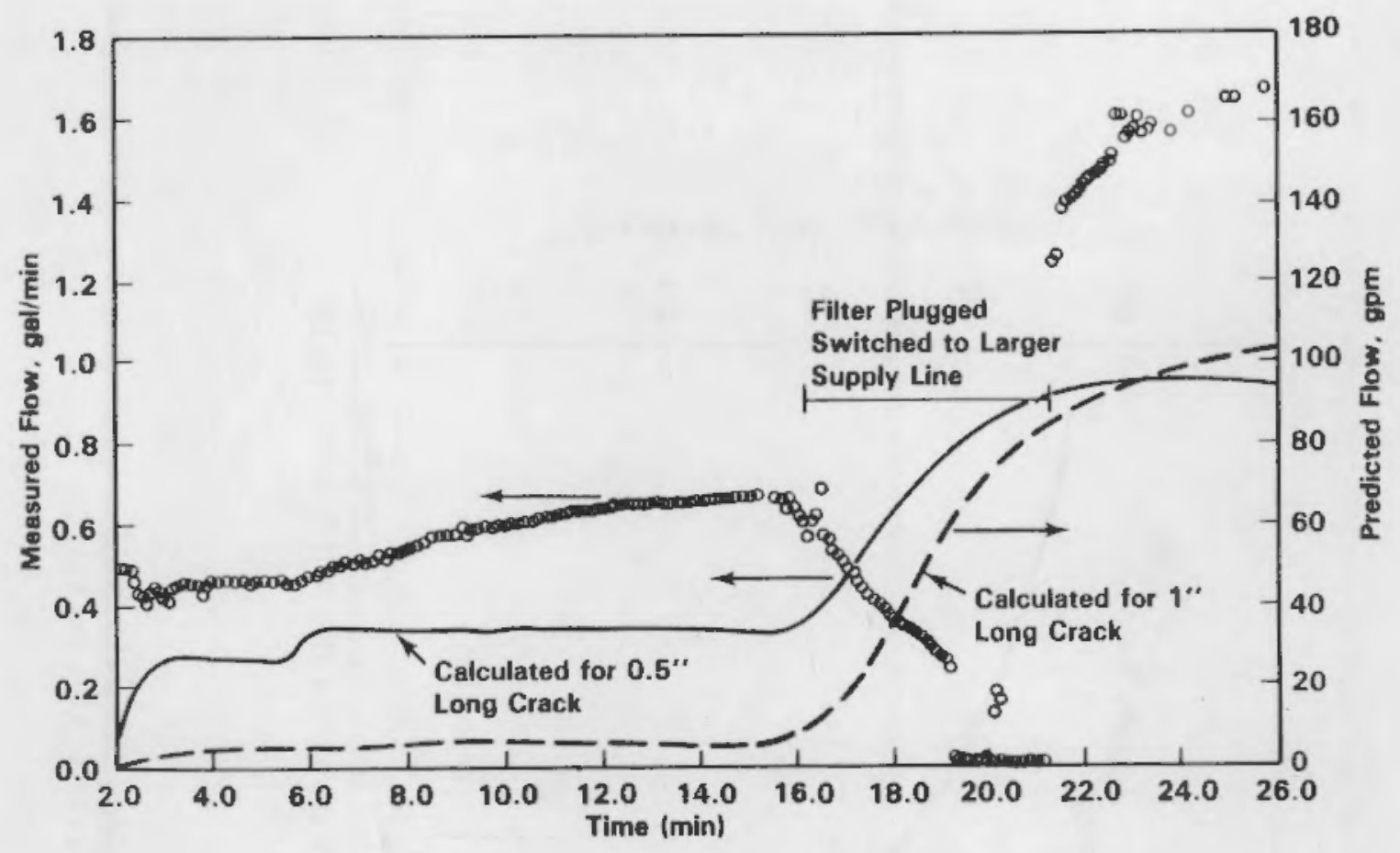

FIGURE 18. Comparison of Battelle Columbus Leak Test Data with Model Predictions, Test $\# 10$, Axial Crack

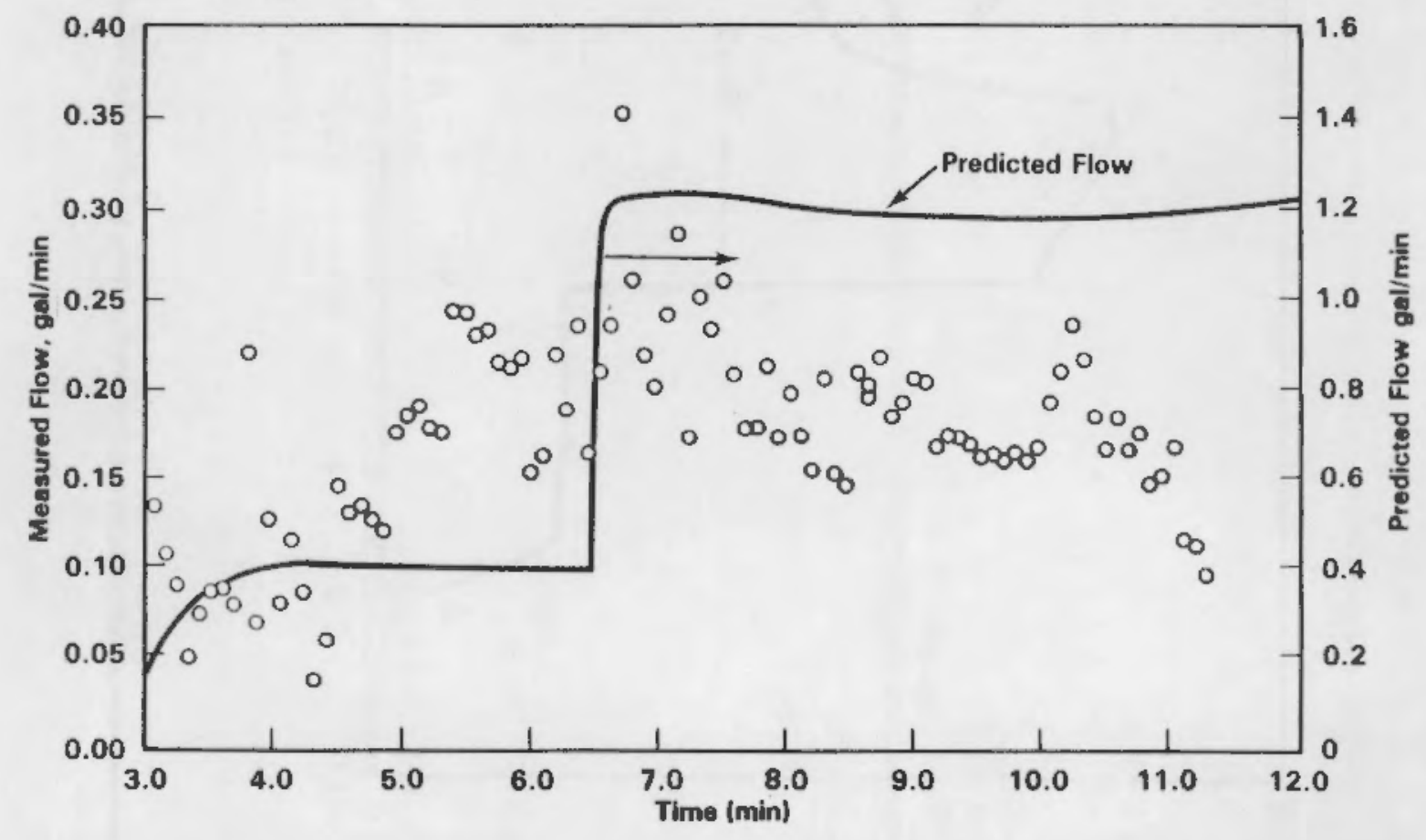

FIGURE 19. Comparison of Battelle Columbus Leak Test Data with Model Predictions, Test \#20, Circumferential Crack 


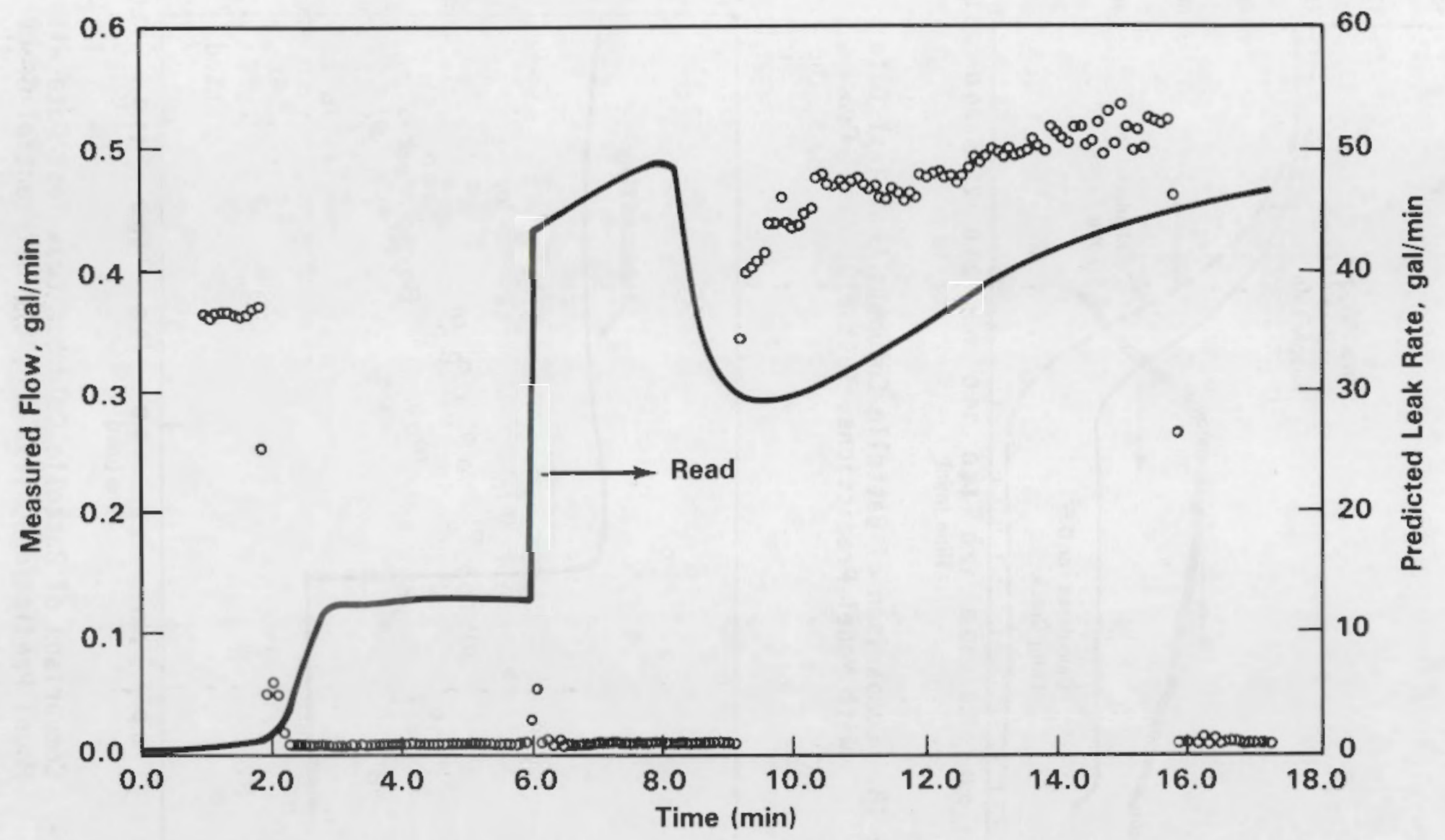

FIGURE 20. Comparison of Battelle Columbus Leak Test Data with Model Predictions Test \#29 Circumferential Crack 
by the types of mathematical models upon which leak-before-break evaluations are based. On a more positive note, many other test specimens have leaked at significantly higher rates than required to validate the conservatism of leak-before-break evaluations.

Some of the reasons for the unpredictability of leak rates should be noted. In this regard, it should be emphasized that the situation for leakage from steam generator tubes is similar to that observed for leakage from cracks in large diameter reactor piping. There are comparisons of measured and predicted leak rates through intergranular stress corrosion cracks in pipes reported by Kumar et al. (1981). These comparisons show a number of tests for which the measured leak rates are on the order of a factor of ten less than the corresponding predicted leak rates.

Some specific sources of unpredictability of leak rates are:

- Small Crack Openings - The pressures and crack lengths of interest are such that the expected pressure induced openings of the cracks are typically on the order of a few thousands of an inch or even less. Hence, uncontrolled and second order factors as listed below (plugging, crack roughness, etc.) can come to govern the leakage through the crack.

- Residual Stresses - Residual stresses from fabrication of the tubes and from the subsequent loadings used to precrack the specimens may cause the cracks to remain closed until some threshold pressure needed to initiate crack opening is applied. In other cases, the residual stress may tend to hold the crack open even when the internal pressure is reduced to zero.

- Prior Over-Pressure - In precracking of the specimens in a corrosive autoclave environment, the pressure inside the tube may have exceeded the pressure used during subsequent leak testing. Hence, it is possible that plastic deformation could have resulted in a permanent opening of some cracks. Such an effect would explain why some specimens leaked at greater than predicted rates.

- Crack Plugging - During either the autoclave process for precracking or during the leak test itself small amounts of deposits could readily restrict the flow through the narrow crack openings. Deposits could originate from impurities in the water, or the formation of corrosion products on the faces of the cracks. Tests performed to obtain data for sustained leakage from cracks in piping have been observed to show decreased and even arrested leakage due to plugging over longer time periods.

- Crack Roughness - The predictive models for leak rates include terms to predict the effects of rough crack surfaces on the leakage through the narrow slit of an open crack. Coefficients for this contribution to flow resistance can only be roughly estimated for the prototypical cracks used in the leak tests. Certainly, the 
actual roughness is subject to considerable variation, and could cause unexpected variations in leak rates.

- Uncertain Crack Lengths - The lengths of the cracks in the test specimens were reported with a wide range of uncertainty. In practice, the cracks were no doubt of complex shapes, and thus differed from the ideal through wall cracks used for the predictive models. This would effect both the length and opening behavior as they effect the flow area. Even if the crack shapes were known with improved accuracy, computational difficulties would preclude the use of such information in the simplified leak rate models.

\subsection{SUMMARY}

Data from a number of tests to measure leak rates through cracks in steam generator tubes have been reviewed. All cracks were in laboratory degraded tubes that were intended to simulate tubes with actual service induced cracks. Machined type defects were excluded from consideration, because such specimens would not properly simulate the crack opening behavior of service degraded tubing.

One objective of this evaluation was to provide a better basis for determining the reliability of the leak-before-break concept as it may be applied to the rupture of steam generator tubes. A second objective was to establish a better basis for setting leak detection requirements for steam generators, and for prescribing allowable leakage rates consistent with safe operation.

The main conclusion of the evaluation was that actual leak rates as measured during tests can be highly variable. These leak rates can be strongly influenced by "random" variables that are not addressed in the predictive models that have formed the bases of leak-before-break evaluations. Measured leak rates are often as much as a factor of ten less than the predicted rates. This suggests that a substantial level of conservatism should be applied to the predictions of leakage that are used for evaluations of leak-before-break. Such conservatism would also appear to be appropriate the for the calculations used to establish of optimal leak detection limits for detection systems.

It is concluded that the prediction of leak rates under ideal conditions of crack opening behavior is a relatively straight forward calculation. Differences in predictions from independently developed models were found to be small in comparison with the corresponding variability in the test data. Continued efforts to refine the predictive models do not appear to be warranted, since it is likely that more refined models would still not adequately treat the factors that give rise to the variability in measured leak rates in test specimens. The recommended approach would be to recognize the uncertainties in predictions of leak rates, and to use conservative margins in the application of calculated leak rates. 
The available leak rate data should also be viewed in a positive perspective, since in most (but not all) tests the measured leak rates approached or even exceeded the predicted rates. This clearly shows the value of leak detection systems as a means to detect tube degradation prior to failure of the tube by rupture. Operating histories of reactors include numerous cases of successful leak detection. On the other hand, there are documented cases of tube rupture, where tube rupture was not preceded by the detection of unacceptable leaks. The outcome of the leak rate tests provides considerable support for continued requirements for leak detection on operating reactors. The data base addressed in the present study included many tests of tubes at pressures corresponding to a steamline break accident. It is particularly encouraging to note that none of this limited sample of tubes experienced what could be called a rupture, whereas in most cases the measured leak rates at normal operating pressures would have been detectable and exceeded limits allowed in plant technical specifications.

As a conclusion, it is proposed that leak-before-break will occur with sufficient probability that leak detection requirements can significantly enhance the safe operation of steam generators. However, the level of confidence in leak-before-break is not sufficiently high to permit relaxation of other measures such as tube inspection. A particular concern is that leak-before-break concepts tend to address only tube degradation in the form of cracking, although wall thinning types of tube degradation have been of roughly equal importance to steam generator performance. In this regard wall thinning is much less likely to result in leak-before-break behavior. It is suggested that leak detection and tube inspection should be viewed as complimentary measures, that serve to offset the uncertainties and unreliability inherent in the current level of technology and in the level of understanding of tube degradation mechanisms. 



\subsection{NONDESTRUCTIVE TESTING}

An integral part of this investigation involved the single and multifrequency eddy-current inspection and evaluation of the chemically degraded tube specimens. This work was the continuation of the Phase I testing effort, where over 500 mechanically degraded specimens were eddy-current tested and evaluated. This section discusses the nondestructive evaluation of the SCC and wastage defected tubes by PNL eddy-current specialists as well as a mini-round robin conducted on a subset of the SCC tube matrix. In addition, flaw depth measurements using alternate standards are compared to the results achieved using the ASME flat-bottom hole standards.

\subsection{EDDY-CURRENT RESULTS FOR SCC AND WASTAGE DEGRADED TUBES}

Single-frequency eddy-current (EC) test results for chemically produced SCC and wastage are discussed in this section. A Zetec MIZ-7 singlefrequency EC test system was used to inspect the degraded tube segments. The system consisted of an Automation Industries EM-3300 two channel EC tester, a Gould Brush 220 two-channel strip chart recorder, a Teac A-2300SX tape recorder and a 2-coil differential wound bobbin probe of 0.750 in. diameter.

\subsubsection{Stress Corrosion Crack Specimen Results}

Table 2 (Section 2.2.2) listed the nondestructive test data for the 27 SCC defected tube segments investigated. The table provided both EC and PT data for these specimens.

The EC depth information was determined by using the signal phase angle. Only the maximum EC estimated flaw depth is reported in Table 2 . In many of these specimens the flawed area of the tube consisted of one or two major axially oriented cracks accompanied by many adjacent minor axial cracks. Many of the minor cracks (estimated at less than $30 \%$ of wall) were not detectable due to limitations in the EC sensitivity. Specimens with major cracks tended to give strong indications which often masked minor crack indications.

Bobbin-coil probes used to inspect steam generator tubing commonly have a slightly smaller diameter than that of the tube inner diameter. The ratio of the probe OD to tube ID is called the fill factor. The fill factor used for this work was 0.86 . Testing dented tubing with a reduced diameter requires smaller size probes. Thus, a fill factor of 0.62 is not uncommon when inspecting dented tubes. Because of the lower fill factor, the probe is less sensitive and has a greater tendency to wobble, thus affecting measurement repeatability and accuracy. To investigate this problem of measurement repeatability, several SCC specimens were inspected with the flawed region of the tube oriented at three different positions. Each tube was inspected with the SCC flaw facing the zenith $\left(0^{\circ}\right.$ reference position) and then rotated $90^{\circ}$ and $180^{\circ}$ from the zenith and reinspected. Figure 21 shows the dramatic change in the EC signal pattern that results from differences 
(a) SCC FLAW AT ZENITH

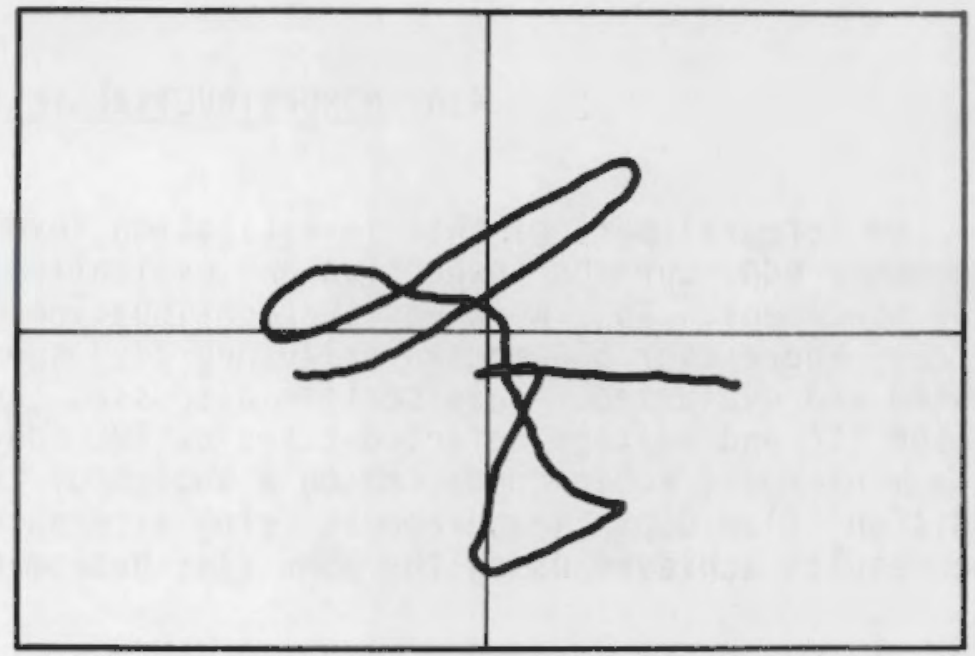

(b) SCC FLAW AT 90 DEGREES

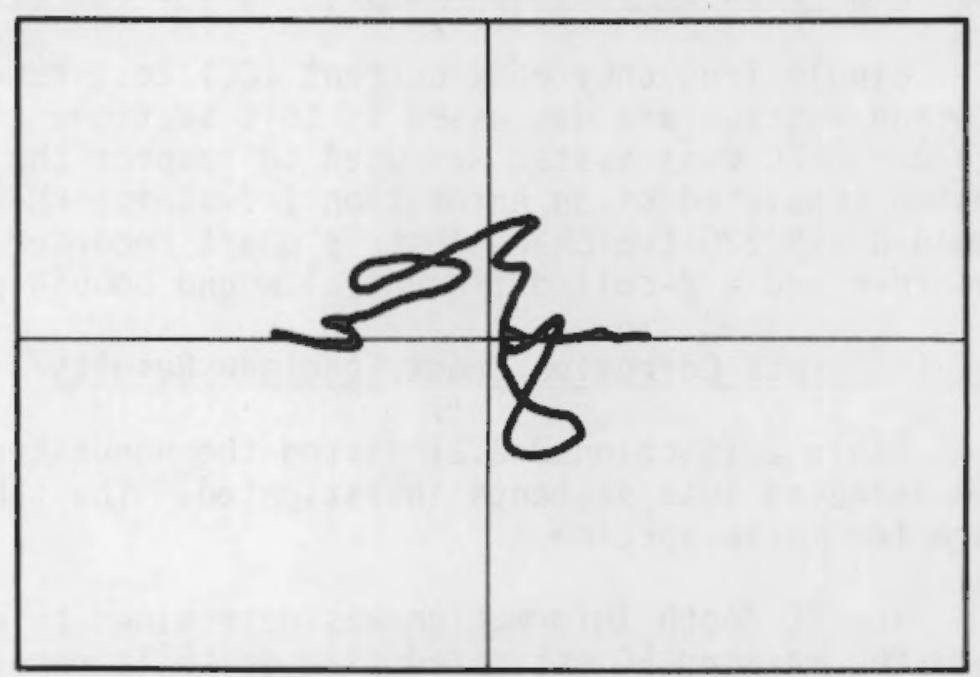

(c) SCC FLAW AT 180 DEGREES

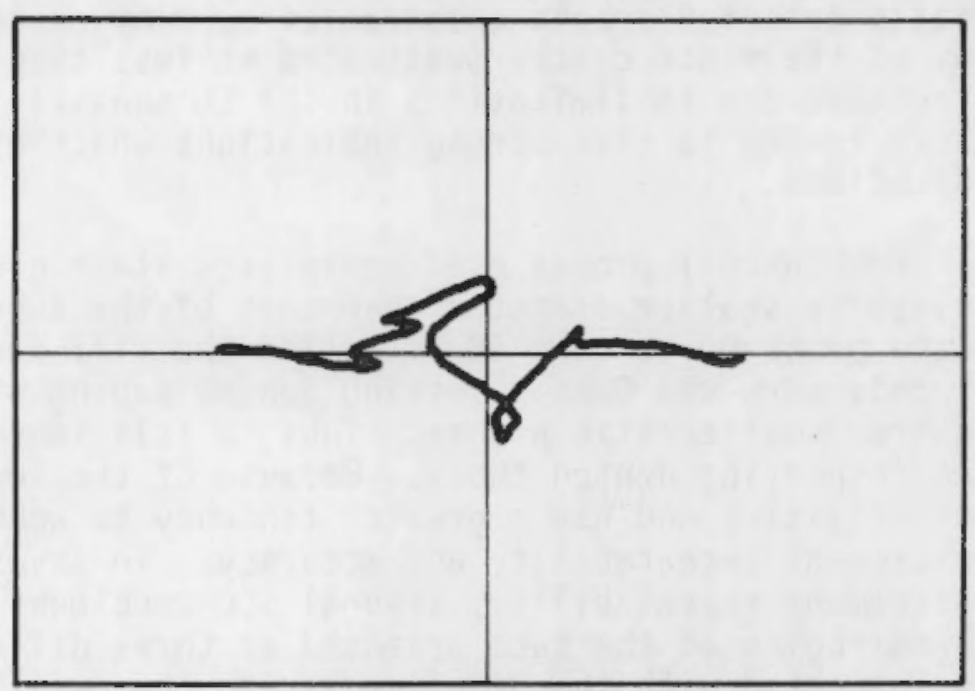

FIGURE 21. Single-Frequency Eddy-Current Signal Indications from Stress Corrosion Crack Tube No. B-1. The corrosion crack flawed area was positioned at a reference 0,90 and 180 degrees. 
between the orientation of the bobbin-coil probe in the tube, to the flaw. The data shown in Figure 21 was taken using a fill factor of 0.86 .

Figure 22 shows the EC depth sizing data for the SCC flawed tube segments. Note that there was a great deal of variability in estimating flaw depth. Even though the mean error for these data was only $-1.3 \%$ the standard deviation was fairly large at 17.1 .

\subsubsection{Wastage Specimen Results}

Figures 23 to 26 show single frequency EC differential probe results for elliptical wastage and uniform thinning type flaws. The figures show plots of the EC indicated depth versus the measured flaw depth, with flaw depth presented as a percentage of the tube wall thickness. A diagonal line is shown in each figure, and represents perfect measurement accuracy. Hence, data points above the diagonal line represent overestimates of flaw depth, while points below the diagonal indicate underestimated flaw sizing.

Figure 23 shows data for the electroetched elliptical wastage specimens. The trend of the data shows consistent underestimates of the flaw depth with a mean error of about $-5.2 \%$.

Figure 24 shows data for the IGA elliptical wastage specimens. Of the six specimens, four had wastage that varied in depth about $10 \%$ from each end of the flawed region (depth gradient). Therefore, when the data was plotted the minimum and maximum depths were used. The trend of the data shows an EC overestimate of flaw depth.

Figure 25 shows data for the electroetched uniform thinning specimens. The trend of the data depicts a consistent overestimation of flaw depth with a mean error of about $7.6 \%$.

Figure 26 gives the data for the IGA uniform thinning specimens. Again, the trend of the data reveals a consistent overestimation of flaw depth by approximately $10.4 \%$.

Table 9 summarizes the single-frequency EC measurement errors for the Phase II specimen matrix.

TABLE 9. Single-Frequency EC Flaw Depth Measurement Error

\begin{tabular}{|c|c|c|c|}
\hline $\begin{array}{l}\text { Flaw } \\
\text { Iype }\end{array}$ & $\begin{array}{l}\text { Number of } \\
\text { Specimens }\end{array}$ & $\begin{array}{l}\text { Mean Error } \\
(\% \mathrm{Wall}) \\
\end{array}$ & $\begin{array}{l}\text { Standard } \\
\text { Deviation }\end{array}$ \\
\hline $\begin{array}{l}\text { SCC } \\
\text { EW (E) } \\
\text { EW (I) } \\
\text { UT (E) } \\
\text { UT (I) }\end{array}$ & $\begin{array}{r}24 \\
13 \\
6 \\
17 \\
21\end{array}$ & $\begin{array}{r}-1.3 \\
-5.2 \\
N C \\
7.6 \\
10.4\end{array}$ & $\begin{array}{r}17.1 \\
3.8 \\
N C \\
4.2 \\
3.9\end{array}$ \\
\hline
\end{tabular}




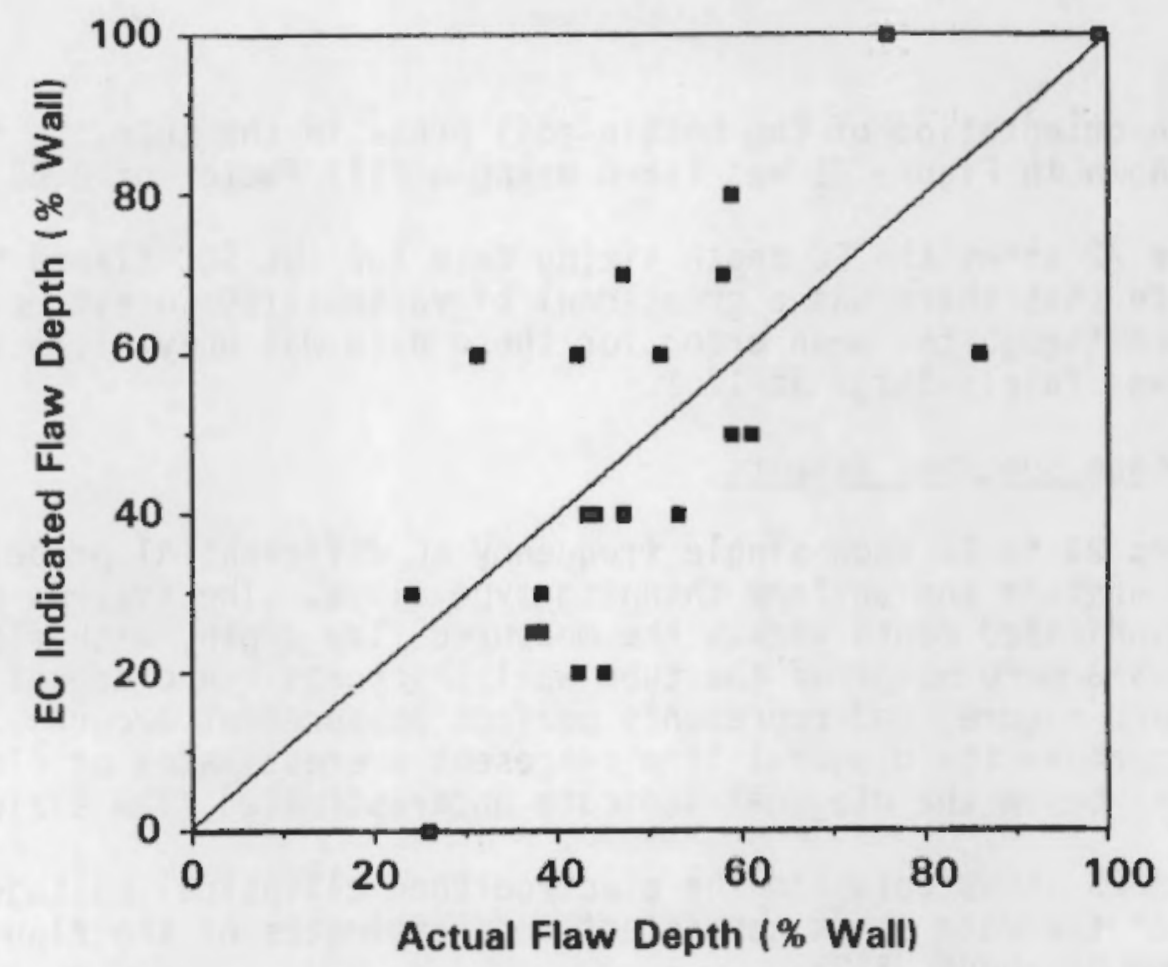

FIGURE 22. Eddy-Current Indicated Flaw Depth Versus Actual Depth for SCC Flaws

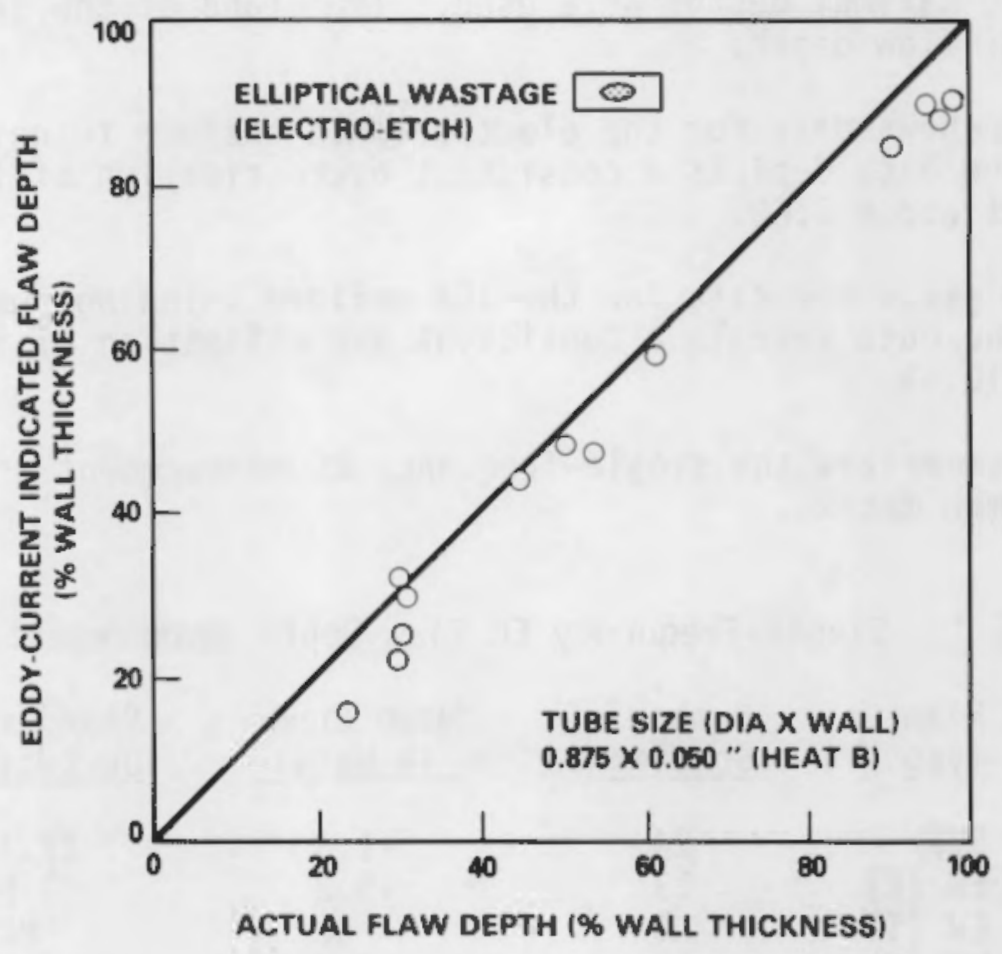

FIGURE 23. Eddy-Current Indicated Flaw Depth Versus the Actual Depth for Elliptical Wastage Flaws (electroetch) 


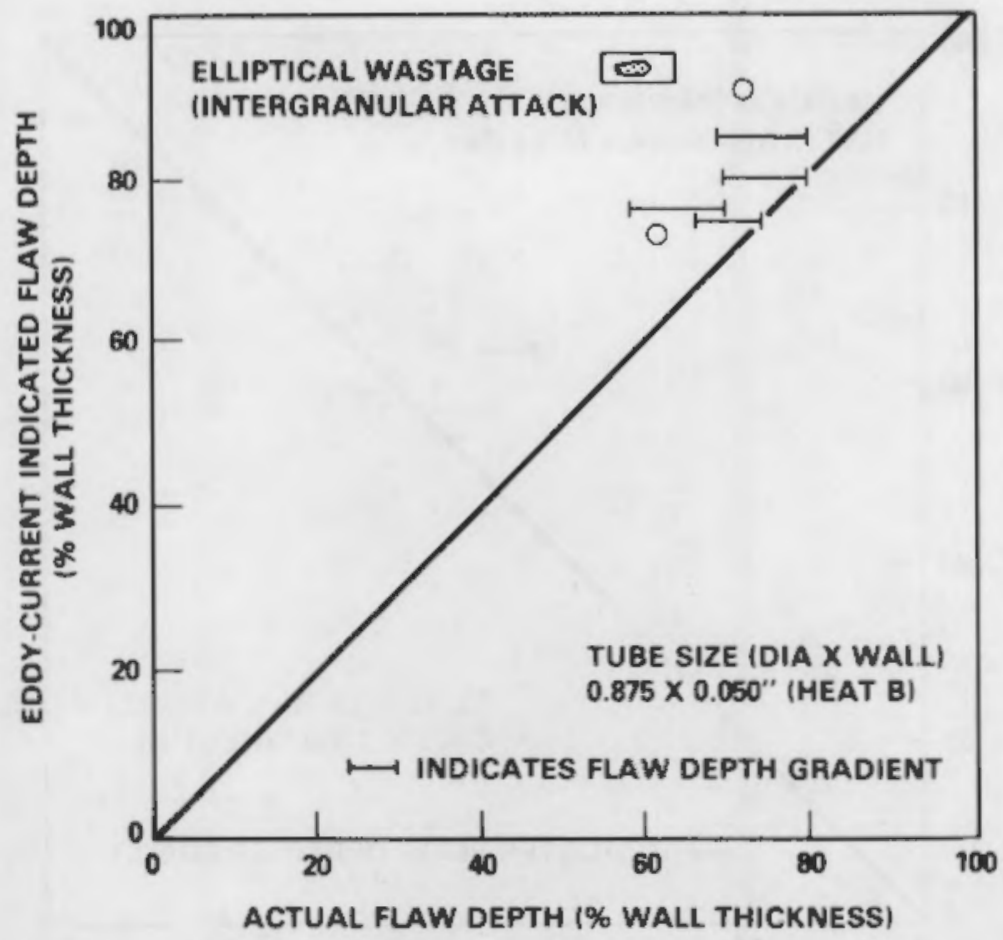

FIGURE 24. Eddy-Current Indicated Flaw Depth Versus the Actual Depth for Elliptical Wastage Flaws (intergranular attack)

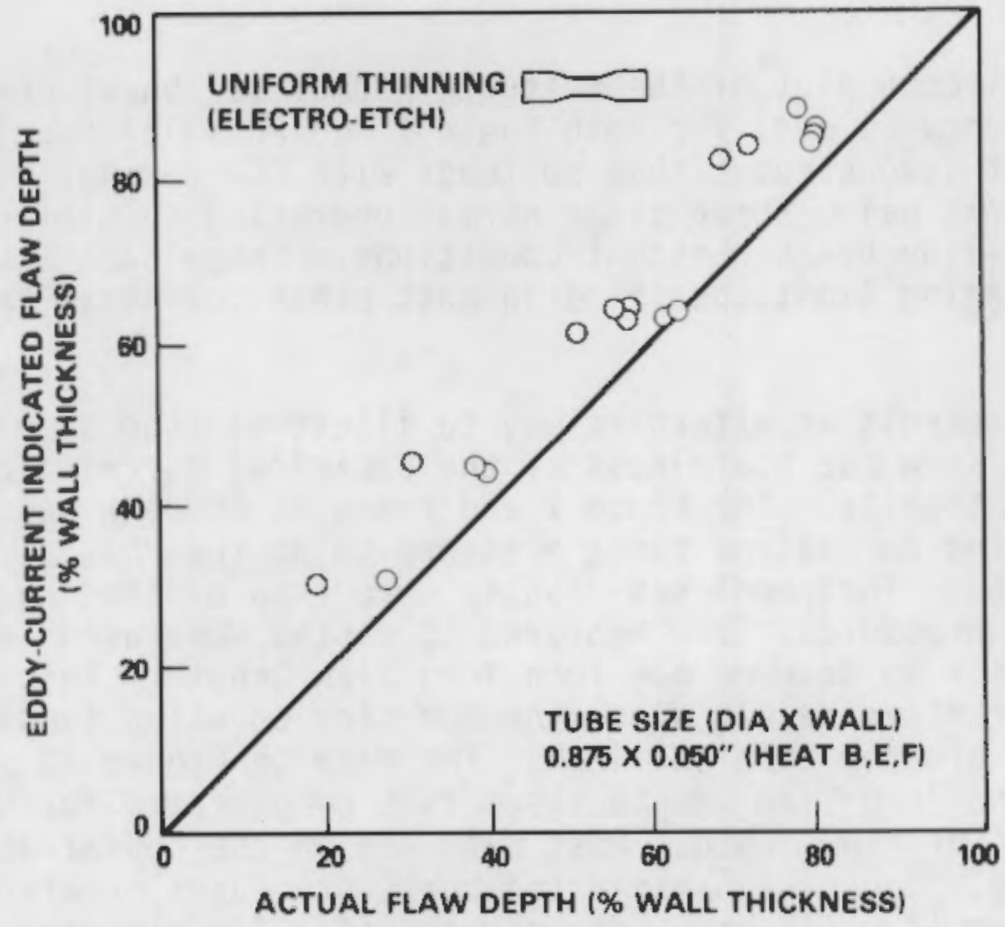

FIGURE 25. Eddy-Current Indicated Flaw Depth Versus the Actual Depth for Uniform Thinning Wastage (electroetch) 


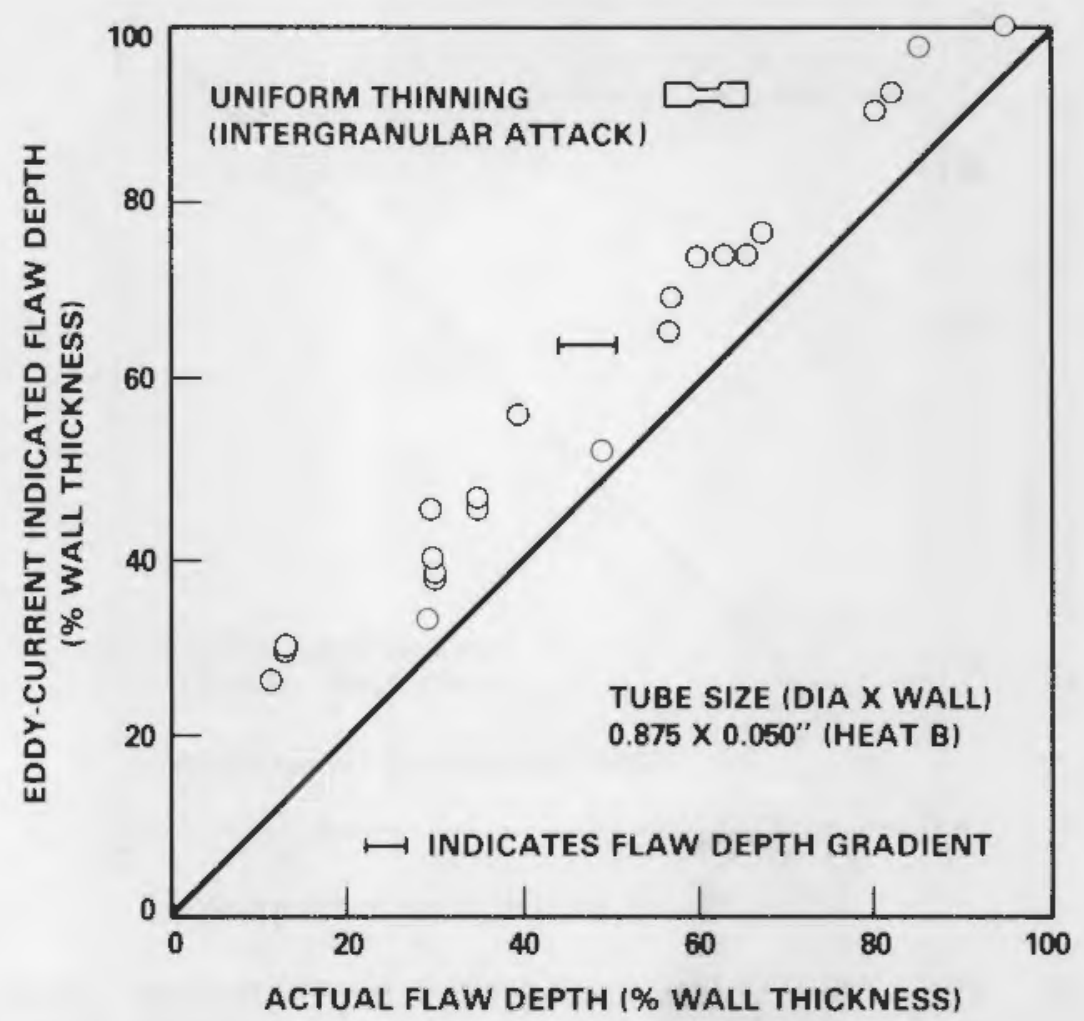

FIGURE 26. Eddy-Current Indicated Flaw Depth Versus the Actual Depth for Uniform Thinning Wastage (intergranular attack)

Figure 27 gives a plot of the measured normalized burst pressure versus the single frequency EC data for both Phase I and Phase II specimens. The data in this plot demonstrates that no tubes with EC readings less than $40 \%$ failed at pressures below three times normal operating conditions or 1.4 times main-steam-line break accident conditions. These data would suggest that the $40 \%$ plugging limit specified in most plant technical specifications is conservative.

Figure 28 presents an alternate way to illustrate the same information in Figure 27 and show the usefulness of the empirical correlations for remaining tube integrity. The Phase I and Phase II EC data was used to compute a predicted normalized burst pressure using the Phase I EDM slot empirical equation. The predicted results were then plotted against actual normalized burst pressures. The measured EC depths were used in the EDM slot equation along with an assumed one inch long flaw length. This flaw length produces a conservative result since the EDM slot equation tends to saturate for flaw lengths greater than one inch. The data in Figure 28 shows that in most instances the long flaw length assumption compensates for uncertainty in the EC estimation of flaw depth. Most data are on the conservative side of the diagonal line. Tubes with estimated burst pressures greater than measured values would still have been plugged if a $40 \%$ plugging limit were used. In Figure 28 the $40 \%$ plugging limit corresponds to a calculated burst pressure of about 0.6 (again assuming a one inch long flaw). Thus, no tubes would have gone unplugged if a $40 \%$ plugging limit had been utilized. 


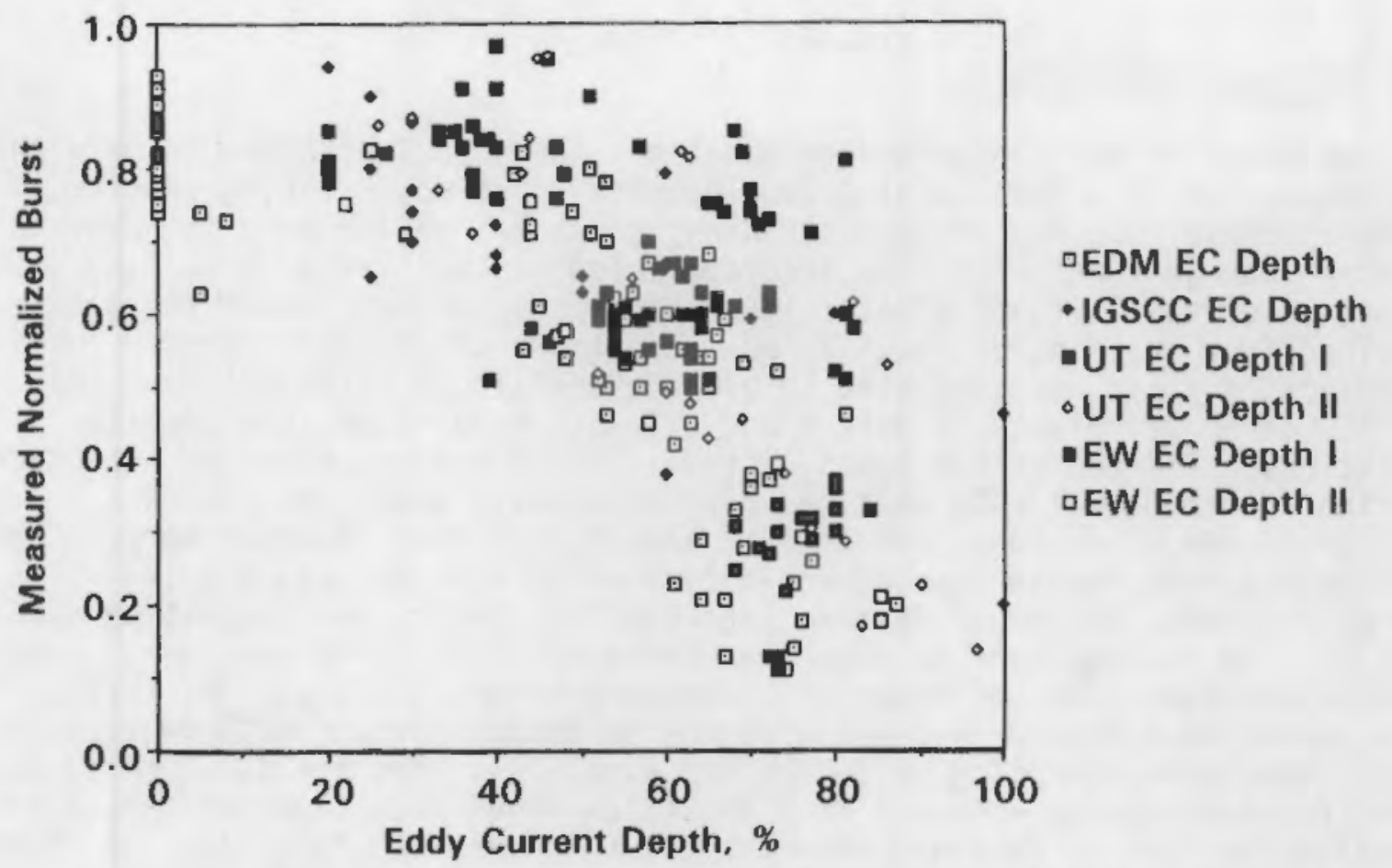

FIGURE 27. Measured Normalized Burst Pressure vs. Eddy-Current Depth for Phase I and Phase II Specimens

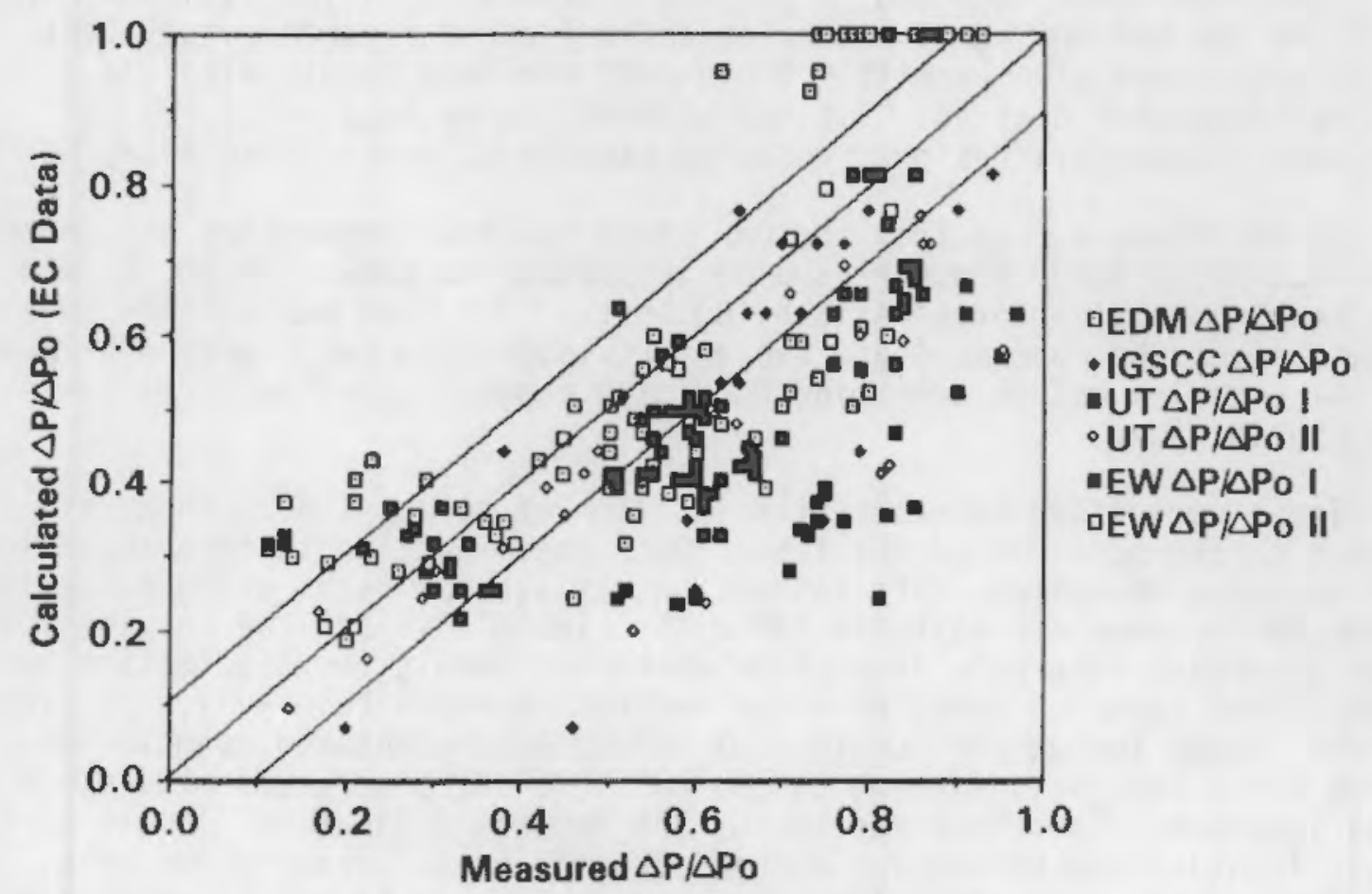

FIGURE 28. Calculated Normalized Burst Pressure from EC Data Assuming One Inch Defect Length vs. Measured Normalized Burst for Phase I and Phase II Specimens. 


\subsection{SCC MINI-ROUND ROBIN}

As shown above, plugging determinations based on laboratory EC data and the assumption of a long axial defect geometry give conservative results. However, these results can be misleading, since NDE reliability is governed by more than just defect sizing accuracy. The probability of detecting a defect is of equal if not greater importance. So, to supplement the data obtained from the single-frequency EC inspections of the SCC defected tubes, a mini-round robin was conducted to provide additional information on the ability of EC techniques to detect and size SCC under simulated service conditions. Fifteen of the tubes listed in Table 2 along with one tube containing a through-wall SCC that had been previously leak rate tested (E-01-03), one blank tube, and an ASME flat-bottom hole standard were assembled into a tube bundle and sequentially sent to the JA Jones Applied Research Center, Universal Testing Laboratories, Zetec, and Combustion Engineering. It is important to note that three of these firms routinely conduct in-service inspections of operational steam generators. Thus, the results of this round robin provide a measure of the performance that could be expected from inspectors attempting to detect and size SCC in the field. Some of the tubes had been coated with a 1 to 2 mil thick nonuniform layer of copper to simulate the type of deposits known to exist in-service, Table 10 . In other cases the cracked portion of the tube was covered either partially or completely by an $0.75 \mathrm{in}$. thick carbon steel support plate, Table 10 . For these cases the tube-to-tube support plate crevice was not filled with magnetite or other typical deposits, nor was the tube dented in any way. Each participant was required to perform a standard bobbin-coil inspection utilizing 100 and $400 \mathrm{kHz}$ frequencies and any other frequencies of their choice. Each was also permitted to inspect the tube bundle with any alternative method desired. Typical alternative methods consisted of alternate bobbin-coil designs, rotating pancake EC probes, and array coils.

In addition, a team from the Oak Ridge National Laboratory and another from Mitsubishi Heavy Industries also inspected the tubes listed in Table 10. This work was not performed as a blind test. Each team was allowed to visually inspect the specimens and use any EC inspection technique. The purpose of this exercise was to determine EC sizing capability without regard to defect detection.

Teams were asked to report the location of defect indications with respect to the open end of the tube. Both depth and length of each indication was also requested. The inspection results for teams using conventional bobbin-coil probes are given in Table 11. Table 12 lists the results for teams employing alternate inspection methods. Credit for a detection was given if the reported location of an indication was within $a \neq 1.5 \mathrm{in}$. zone centered about the actual location of the crack that caused tube failure during burst testing. In many cases, multiple calls were reported for a given specimen. For these instances, the deepest indication closest to the defect location was chosen for comparison with actual crack dimensions. Selection of the deepest indication would correspond to conservative field practice. 
TABLE 10. SCC Mini-Round Robin Defect Conditions

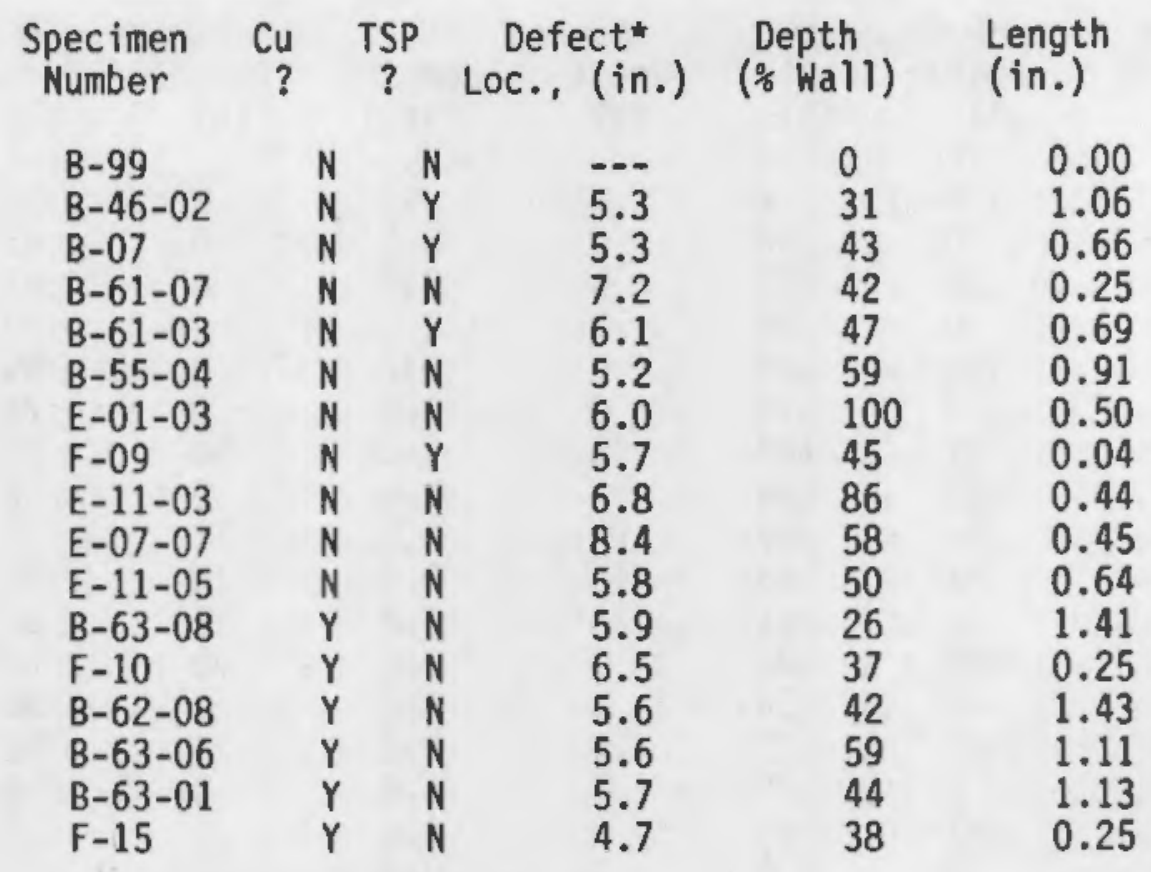

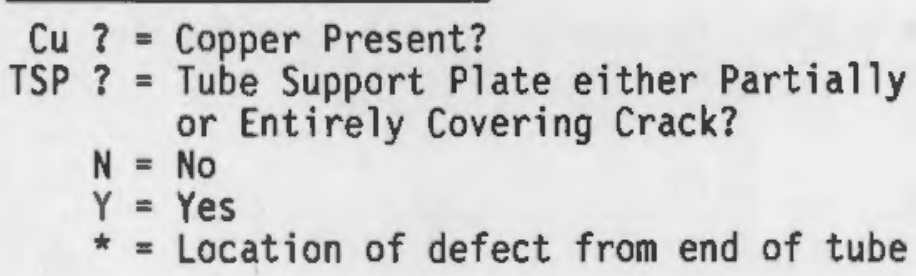

\subsection{EVALUATION OF NDE RELIABILITY FOR SCC}

The reliability of the in-service inspection of steam generators depends on the ability of the NDE technique to detect and size defects in the tubing. The mini-round robin was conducted to provide a more realistic estimate of NDE techniques to detect and size SCC compared to the single frequency EC measurements described above.

\subsubsection{Probability of Detection}

Table 13 summarizes the probability of detection (P0D) and flaw sizing statistics for the 16 teams involved in the round robin. The probe type used by each team is also included in Table 13. Due to the limited data available, no attempt was made to determine POD as a function of crack dimensions. However, it should be noted that in 12 of the 16 cracked tubes the crack depth was greater than $40 \%$ through-wall. The POD calculations were performed only for the 16 cracked tube segments. Three teams reported a number of unidentified signals. These were not counted as defect detections in the POD calculations. 
TABLE 11. SCC Mini-Round Robin Bobbin-Coil Results

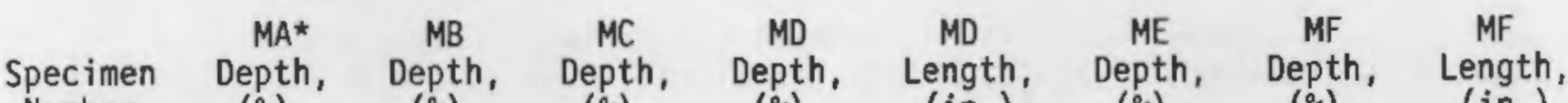
Number

$(\%)$

$(\%)$

$(\%)$

(\%)

$(\%)$

$(\%)$

(in.)

$\begin{array}{lrrrrrrrr}\text { B-99 } & \text { NI } & 0 & 0 & 0 & 0.0 & 0 & 0 & 0.0 \\ \text { B-46-02 } & 40 & 0 & 0 & 0 & 0.0 & 0 & 42 & 1.2 \\ \text { B-07 } & 23 & 96 & \text { US } & 0 & 0.0 & 0 & 37 & 0.8 \\ \text { B-61-07 } & 20 & 0 & 0 & 0 & 0.0 & 0 & 0 & 0.0 \\ \text { B-61-03 } & 30 & 100 & 53 & 0 & 0.0 & 0 & 99 & 0.7 \\ \text { B-55-04 } & 32 & 99 & 45 & 0 & 0.0 & 0 & 74 & 1.5 \\ \text { E-01-03 } & \text { NI } & 97 & 100 & 95 & 0.2 & 98 & 99 & 1.2 \\ \text { F-09 } & 24 & 88 & 39 & 0 & 0.0 & 0 & 0 & 0.0 \\ \text { E-11-03 } & 70 & 80 & 69 & 77 & 0.2 & 71 & 75 & 0.5 \\ \text { E- } 07-07 & 36 & 77 & 43 & 49 & 0.2 & 76 & 63 & 1.3 \\ \text { E-11-05 } & 37 & 0 & 41 & 34 & 0.2 & 43 & 87 & 2.2 \\ \text { B-63-08 } & 20 & 86 & \text { US } & 0 & 0.0 & 0 & 0 & 0.0 \\ \text { F-10 } & 26 & 89 & 55 & 0 & 0.0 & 79 & 86 & 1.3 \\ \text { B-62-08 } & 30 & 81 & \text { US } & 79 & 0.2 & 74 & 88 & 2.0 \\ \text { B-63-06 } & 42 & 0 & \text { US } & 0 & 0.0 & 0 & 0 & 0.0 \\ \text { B-63-01 } & 20 & 97 & \text { US } & 0 & 0.0 & 0 & 0 & 0.0 \\ \text { F-15 } & 23 & 0 & 0 & 0 & 0.0 & 0 & 0 & 0.0\end{array}$

*Team MA did not perform a blind inspection of the tube bundle.

NI $=$ Not Inspected

US = Unidentified Signal

The average POD for teams employing conventional bobbin-coil techniques was 0.50 . Surprisingly, the alternate bobbin-coil techniques performed significantly below the conventional bobbin-coil. The average alternate bobbin-coil POD was 0.27 . The best detection performance was obtained from teams that utilized rotating pancake coil (RPC) or array coil techniques either alone or as a supplemental technique for the conventional bobbin-coil. The average POD for these techniques was 0.63 .

\subsubsection{Crack Depth Sizing Analysis}

The results of the depth sizing analyses reported in Table 13 were obtained by fitting a linear model between the NDE estimated flaw size and actual values. Nondetected cracks were not included in the data set for curve fitting. A perfect sizing relationship is described by an intercept of zero and a slope of one. The correlation coefficient ( $\left.R^{2}\right)$ provides a measure of how well the model fits the data. For four of the teams an $R^{2}$ value of greater than 0.8 for the depth sizing analysis was calculated. This result is misleading, since three of these teams had an average POD of only 0.25 . Of the teams with a POD greater than or equal to 0.5 , only Team MC had intercept and slope values close to ideal. Interestingly, this team used a bobbin-coil probe. A plot of Team MC's data is shown in Figure 29. Note that except for the point at $(0,0)$ all data along the horizontal axis are 
TABLE 12. SCC Mini-Round Robin Alternate Results

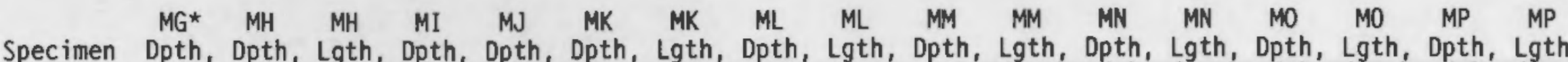
Number (\%) (\%) (in.) (\%) (\%) (\%) (in.) (\%) (in.) (\%) (in.) (\%) (in.) (\%) (in.) (\%) (in.)

\begin{tabular}{lrrrrrrrrrrrrrrrrr} 
B-99 & NI & 0 & 0.0 & \multicolumn{1}{c}{0} & 0 & 0 & 0.0 & 0 & 0.0 & 0 & 0.0 & 0 & 0.0 & 0 & 0.0 & 0 & 0.0 \\
B-46-02 & 50 & 0 & 0.0 & US & US & 0 & 0.0 & 0 & 0.0 & 0 & 0.0 & 0 & 0.0 & 0 & 0.0 & -- & 1.1 \\
B-07 & 76 & 39 & 0.8 & 82 & 100 & 0 & 0.0 & 0 & 0.0 & 0 & 0.0 & 0 & 0.0 & 0 & 0.0 & -- & 0.6 \\
B-61-07 & 34 & 0 & 0.0 & 73 & 100 & 0 & 0.0 & 0 & 0.0 & 99 & 0.2 & 0 & 0.0 & 0 & 0.0 & 100 & --- \\
B-61-03 & 84 & 93 & 0.4 & 30 & 50 & 0 & 0.0 & 0 & 0.0 & 100 & 0.2 & 0 & 0.0 & 0 & 0.0 & -- & 0.6 \\
B-55-04 & 100 & 93 & 0.8 & 66 & 100 & 100 & 0.3 & 0 & 0.0 & 0 & 0.0 & 0 & 0.0 & 20 & 0.6 & -- & 0.9 \\
E-01-03 & NI & 98 & 1.0 & 89 & 100 & 100 & 0.3 & 98 & 0.2 & 0 & 0.0 & 98 & 0.3 & 24 & 0.5 & -- & 0.9 \\
F-09 & 64 & 93 & 0.4 & 20 & 39 & 0 & 0.0 & 0 & 0.0 & 0 & 0.0 & 0 & 0.0 & 0 & 0.0 & 0 & 0.0 \\
E-11-03 & 100 & 74 & 0.4 & 59 & 69 & 60 & 0.2 & 63 & 0.2 & 0 & 0.0 & 64 & 0.2 & 33 & 0.2 & -- & 0.5 \\
E-07-07 & 100 & 79 & 1.3 & 37 & 43 & 46 & 0.2 & 29 & 0.2 & 87 & 0.2 & 45 & 0.3 & 29 & 1.1 & -- & 1.3 \\
E-11-05 & 88 & 91 & 1.9 & 89 & 100 & 62 & 0.2 & 35 & 0.2 & 0 & 0.0 & 0 & 0.0 & 20 & 1.8 & -- & 2.0 \\
B-63-08 & 28 & 0 & 0.0 & US & US & 0 & 0.0 & 0 & 0.0 & 0 & 0.0 & 0 & 0.0 & 20 & 0.7 & 0 & 0.0 \\
F-10 & 60 & 46 & 0.8 & US & US & 0 & 0.0 & 0 & 0.0 & 85 & 0.2 & 0 & 0.0 & 0 & 0.0 & -- & 1.0 \\
B-62-08 & 98 & 87 & 0.5 & 48 & 48 & 0 & 0.0 & 38 & 0.2 & 0 & 0.0 & 0 & 0.0 & 20 & 0.4 & -- & 0.0 \\
B-63-06 & 80 & 0 & 0.0 & US & US & 0 & 0.0 & 0 & 0.0 & 0 & 0.0 & 0 & 0.0 & 0 & 0.0 & 0 & 0.0 \\
B-63-01 & 78 & 0 & 0.0 & US & US & 0 & 0.0 & 0 & 0.0 & 0 & 0.0 & 0 & 0.0 & 20 & 1.2 & 0 & 0.0 \\
F-15 & 68 & 0 & 0.0 & 0 & 0 & 0 & 0.0 & 0 & 0.0 & 0 & 0.0 & 0 & 0.0 & 0 & 0.0 & -- & 4.0
\end{tabular}

*Team MG did not perform a blind inspection of the tube bundle.

NI = Not Inspected

US = Unidentified Signal 


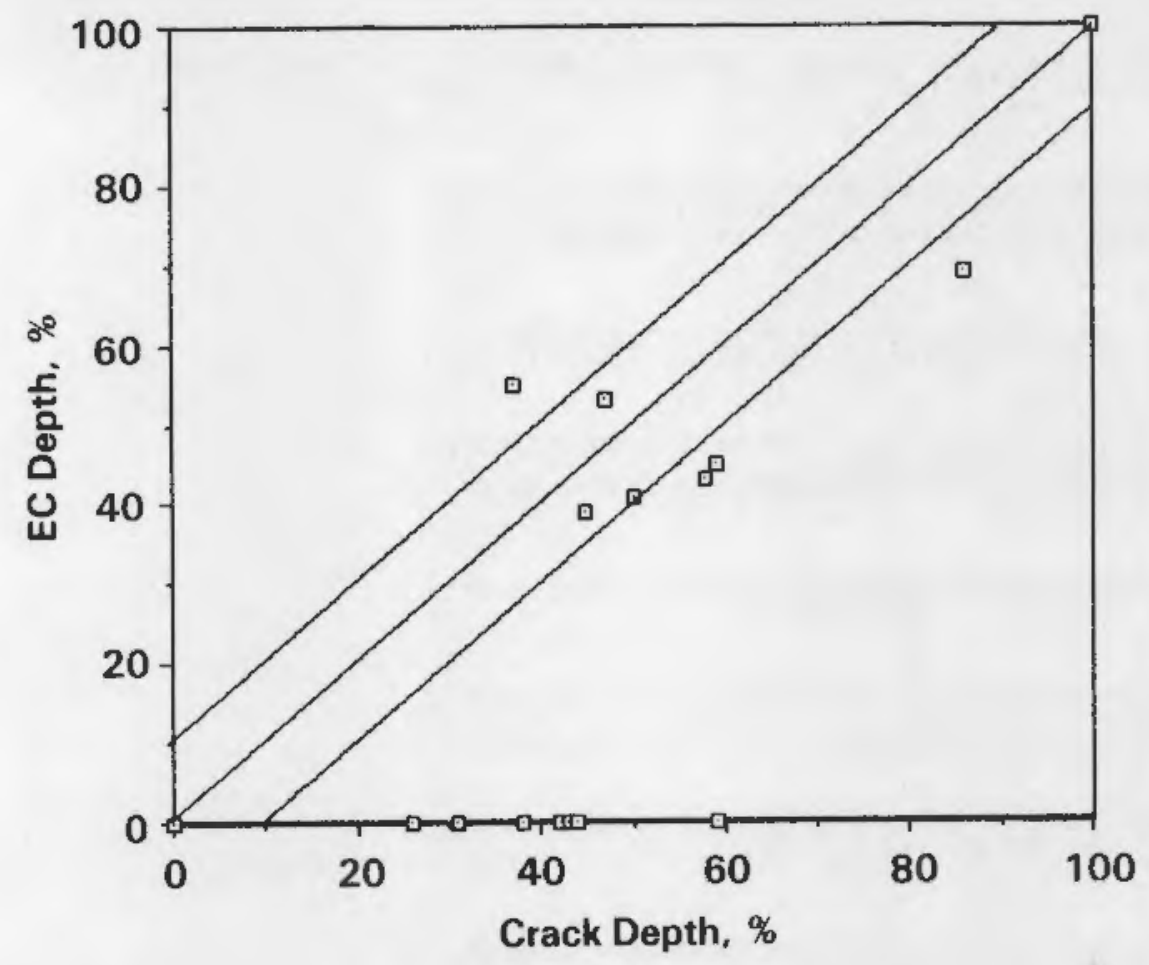

FIGURE 29. Eddy-Current Estimated vs. Actual SCC Depth for Team MC

nondetections. Most of the data falls in a group near the middle of the plot with the two data points at zero and $100 \%$ through-wall strongly influencing the resulting correlation. The other three bobbin-coil teams generally overestimated crack depth. A typical example of these results is shown in Figure 30, which presents the data for Team MF. The one bobbin-coil team (Team MA) that did not perform a blind inspection of the tube bundle had reasonable slope, intercept and $\mathrm{R}^{2}$ values, but tended to underestimate the crack depth. A plot of this team's data is presented in Figure 31.

The alternate technique results did not display improved crack depth sizing capability. To illustrate, plots of EC estimated versus actual crack depth for Teams MH, MI and MO are shown in Figures 32-33. These plots indicate significant crack depth sizing variation from one alternate technique team to the next. Team MH tended to overestimate crack depth considerably, whereas the Team MI results showed a great deal of scatter and no clearly defined trend. At the other end of the spectrum, Team MO seriously underestimated crack depth. Team MO results display almost no capability to discriminate crack size. The one alternate team that utilized an eddy-current reflection probe (Team MG) did not perform a blind inspection of the tube bundle. This team consistently overestimated the crack depth, as shown in Figure 35. A statistical test was performed to determine if the presence of the copper coating or support plate on some tubes had an affect on inspection performance. The results of these calculations indicated that there was no statistically significant effect created by these extraneous conditions. 
TABLE 13 Probability of Detection, Depth Sizing and Length

Sizing Analyses for SCC Mini-Round Robin Teams

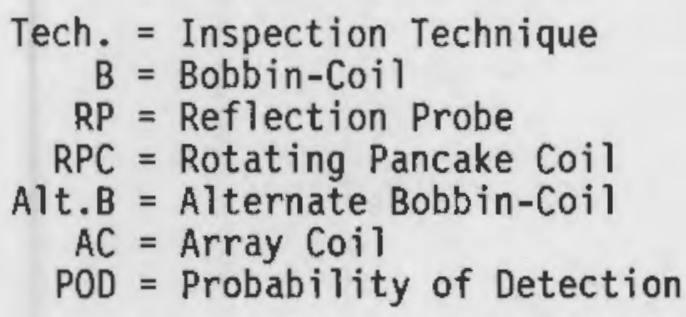

\subsubsection{Crack Length Sizing Analysis}

As illustrated in Section 2.0 of this report, the flaw length can significantly impact remaining tube integrity. To estimate NDE performance for crack length measurement, linear models were fit to the length sizing information. As with the depth sizing analysis, nondetected cracks were excluded from the data set for curve fitting. The results of these calculations are given in Table 13. Only two bobbin-coil inspection teams reported crack lengths, whereas most of the alternate inspection teams provided this information. Note that for any given team (regardless of the NDE technique used) the $R^{2}$ value for the depth sizing was always greater than the corresponding value for length sizing. This suggests that EC techniques were more effective at crack depth determination. 


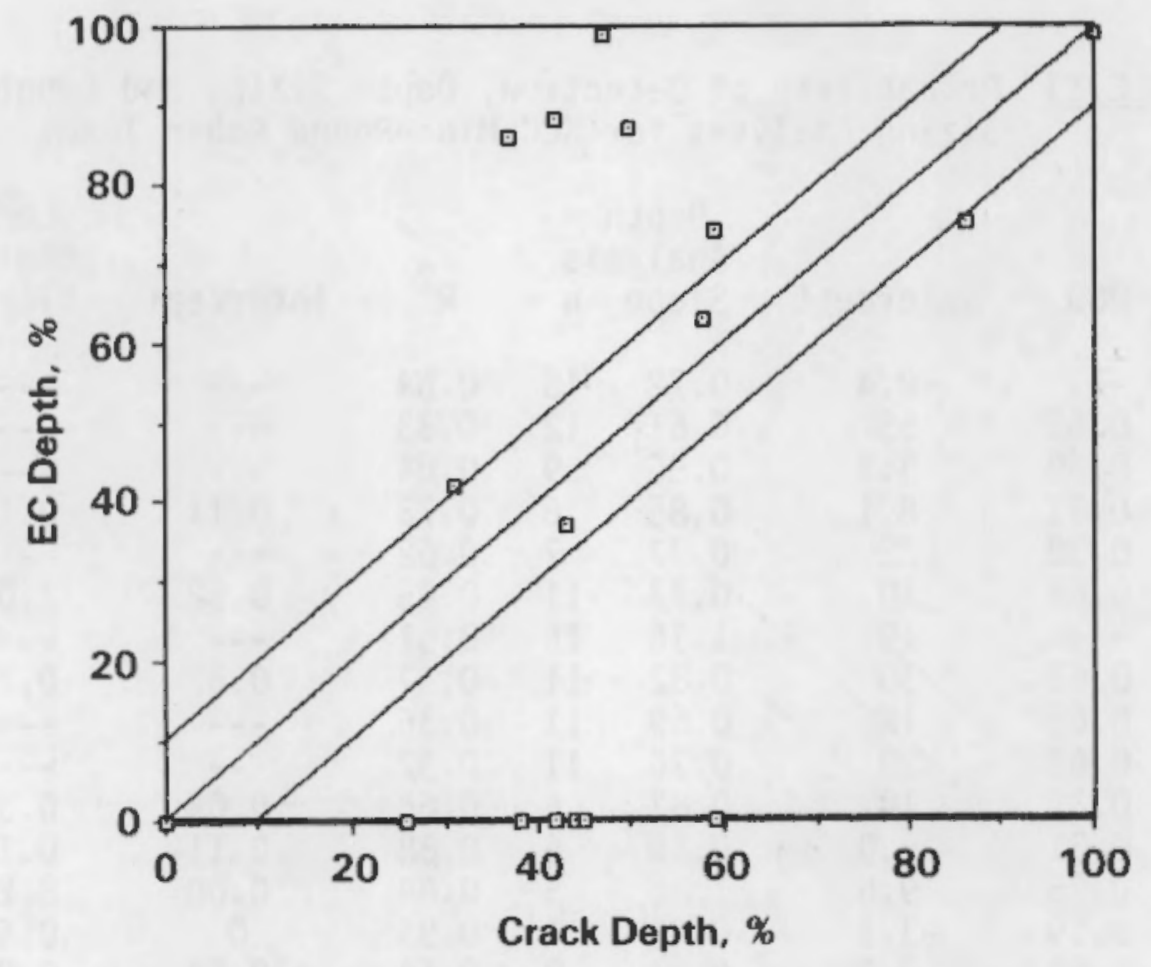

FIGURE 30. Eddy-Current Estimated vs. Actual SCC Depth for Team MF

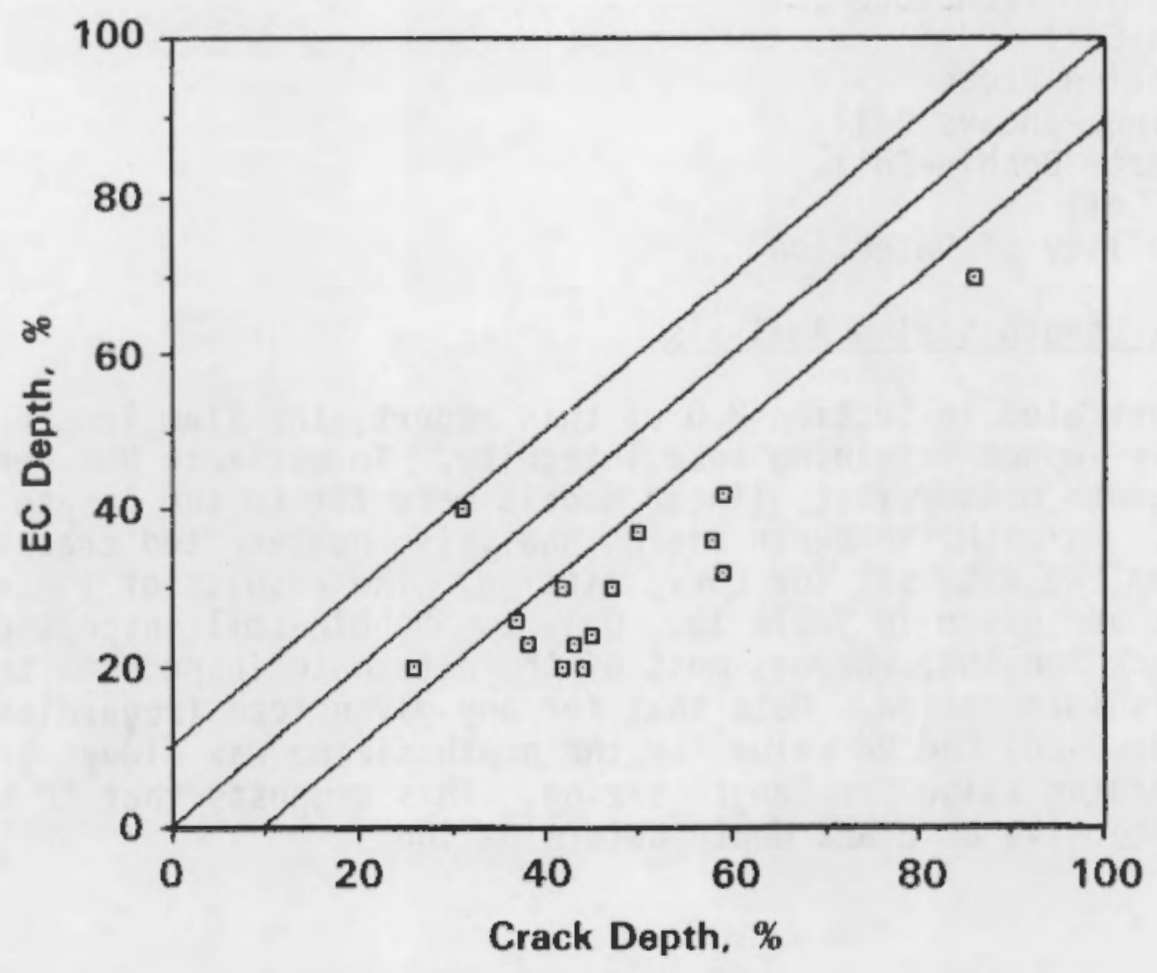

FIGURE 31. Eddy-Current Estimated vs. Actual SCC Depth for Team MA 


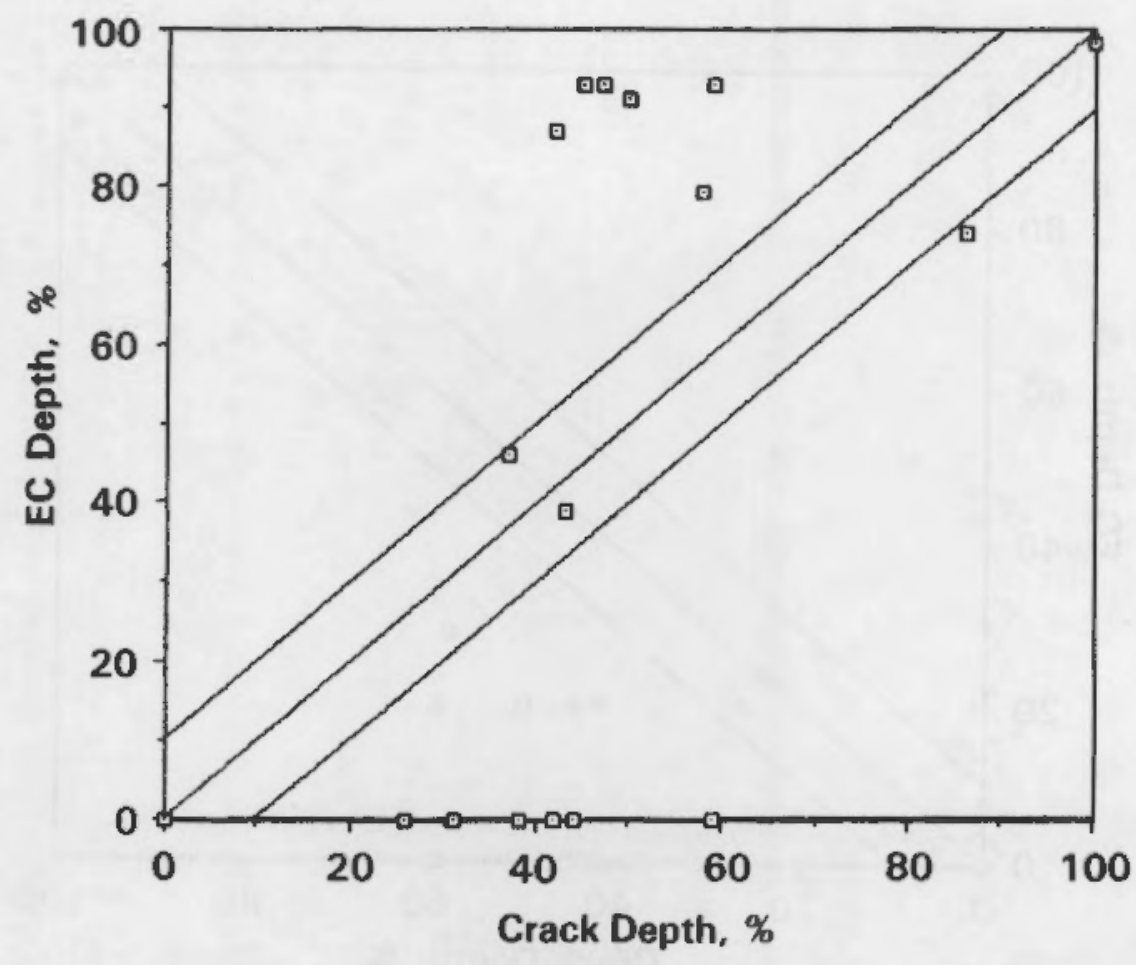

FIGURE 32. Eddy-Current Estimated vs. Actual SCC Depth for Team MH

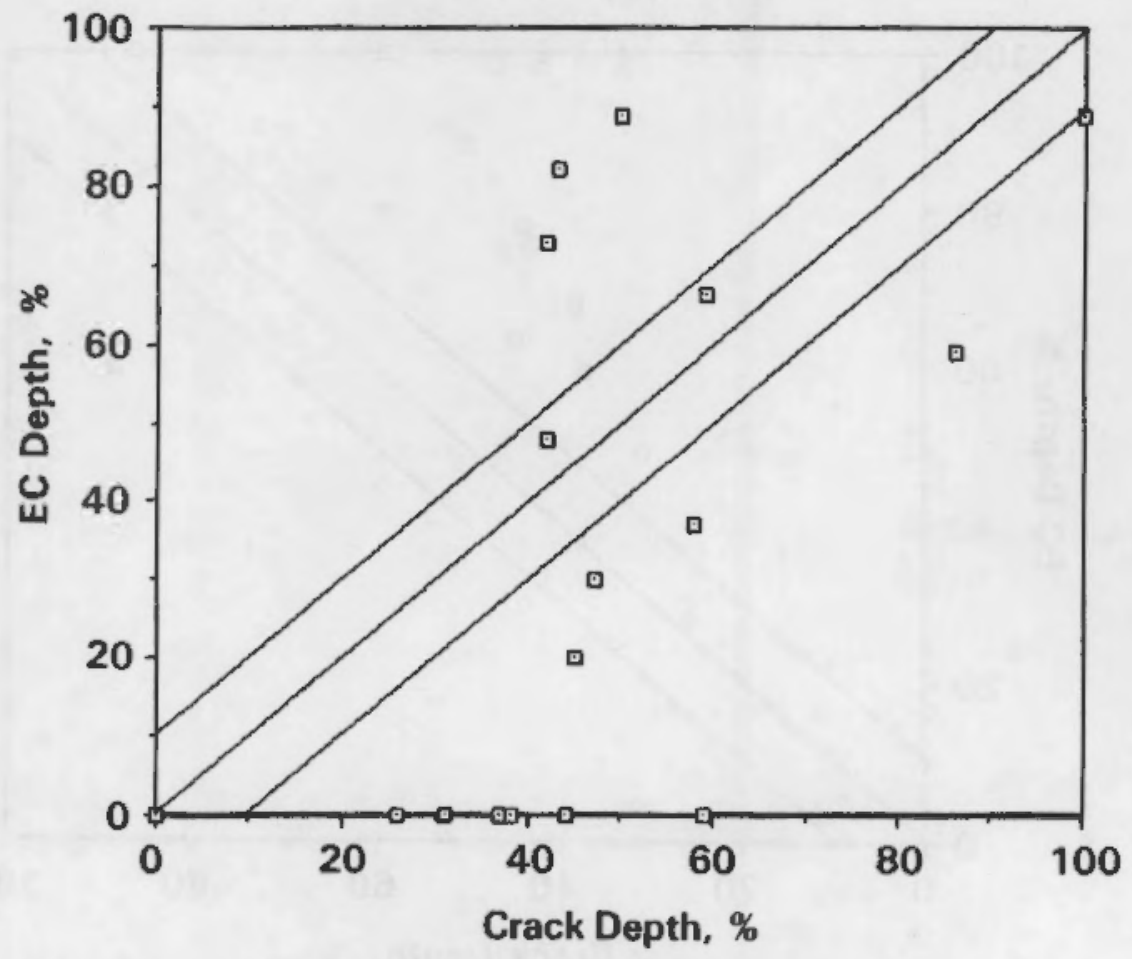

FIGURE 33. Eddy-Current Estimated vs. Actual SCC Depth for Team MI 


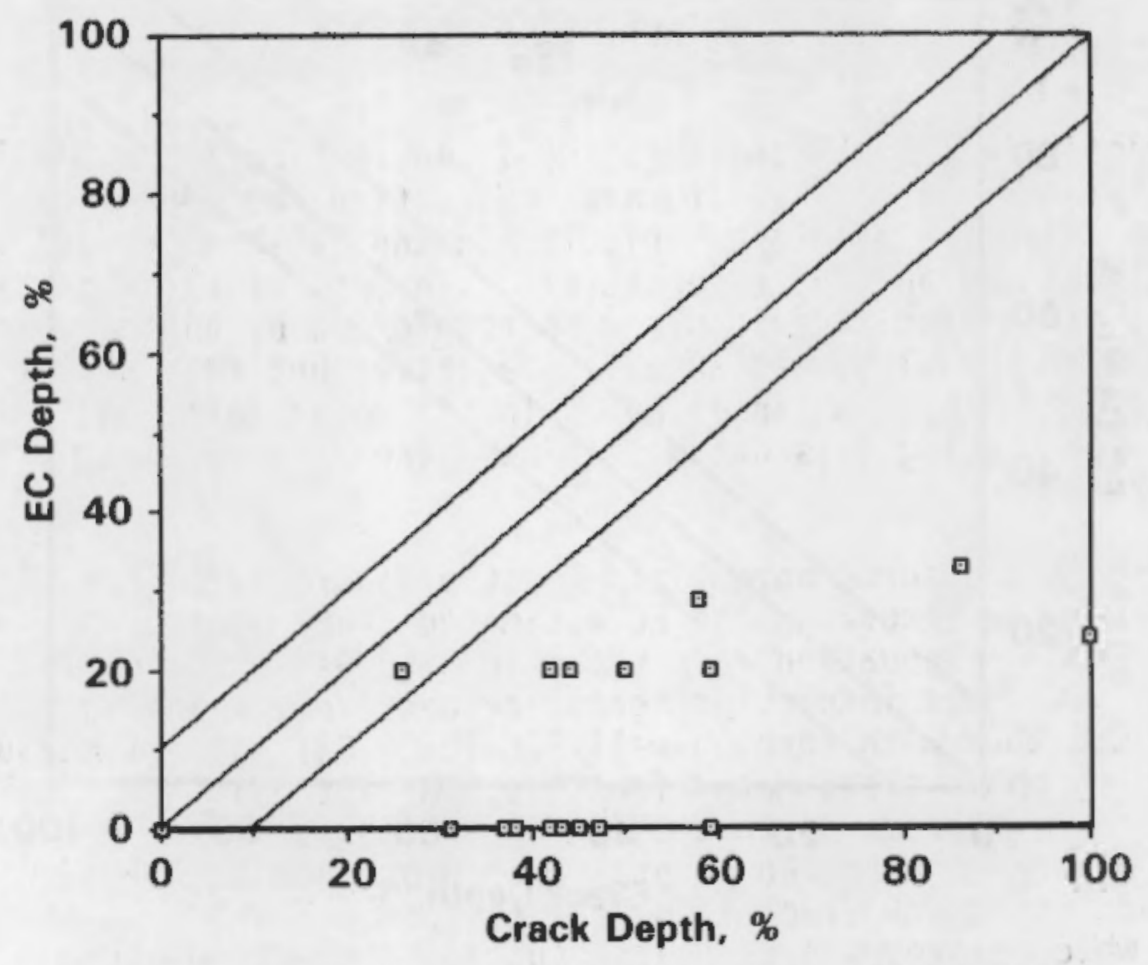

FIGURE 34. Eddy-Current Estimated vs. Actual SCC Depth for Team MO

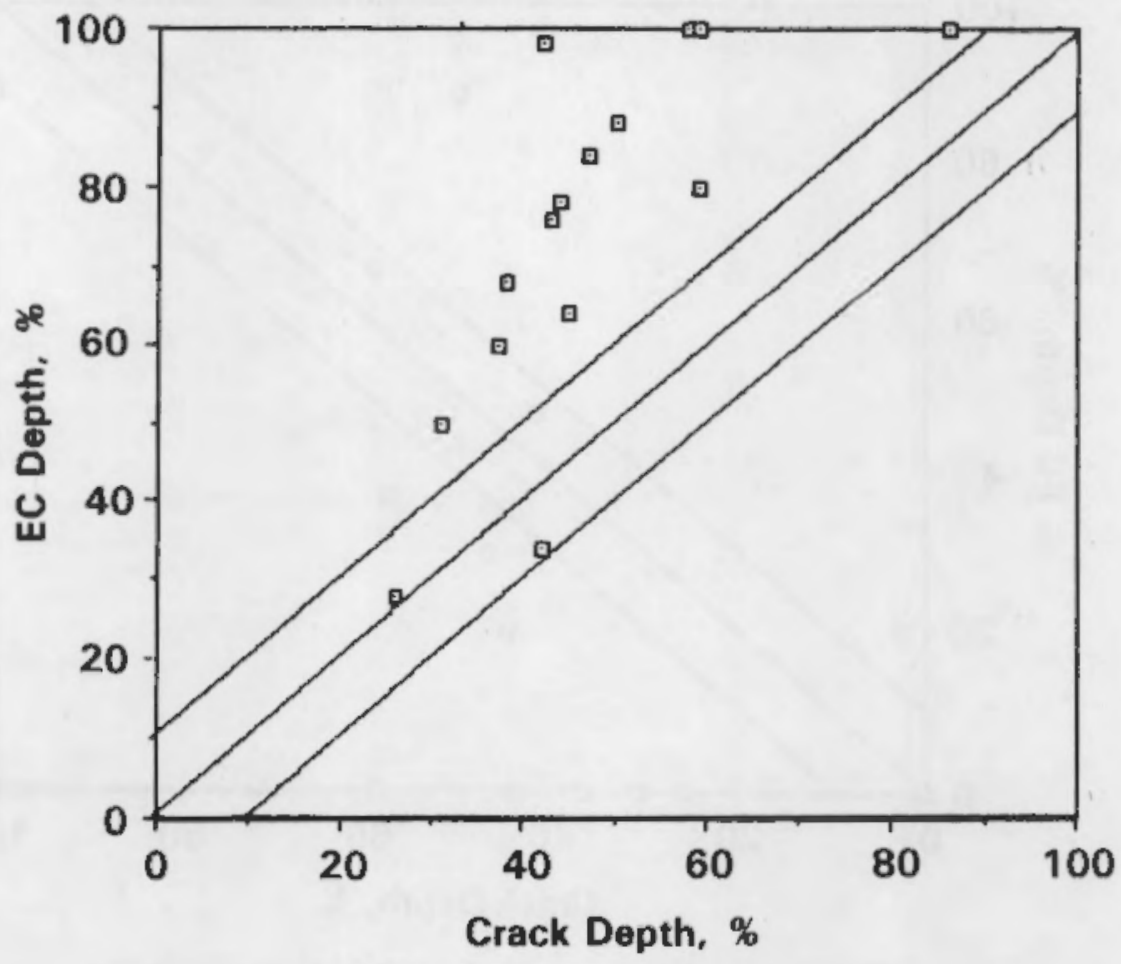

FIGURE 35. Eddy-Current Estimated vs. Actual SCC Depth for Team MG 
Considering the bobbin-coil results, Team MD significantly underestimated crack length, as shown in Figure 36. In contrast, Team MF substantially overestimated crack length, as depicted in Figure 37. Analogous to the depth sizing results, the alternate inspection techniques did not yield improved length sizing accuracy. Figures 38 and 39 show typical plots of RPC results for Teams MH and MP, respectively. In both of these cases a great deal of data dispersion is evident, also reinforced by the very low values of $\mathrm{R}^{2}$. For Team MP the slope was actually negative, but this result was strongly influenced by the single point in the upper left hand corner of Figure 39. Eliminating this datum from the linear curve fit shifts the slope to a positive value.

Plots of the measured normalized burst pressure versus calculated values, obtained by inserting the EC estimated crack depths and lengths into the Phase I EDM slot equation, are shown in Figures 40 and 41 for two bobbincoil and two alternate inspection teams, respectively. The normalized burst pressure of the tube with through-wall SCC (E-01-03) was not measured experimentally, but was estimated from the EDM slot equation. Only teams that estimated both crack depth and length are shown in Figures 40 and 41 . Data points along the upper horizontal axis represent instances when a team did not detect the crack (except for the one point plotted in the upper right hand corner which represents the blank tube). The shaded portion of each plot defines a region bounded by a $40 \%$ plugging limit $(\triangle P / \triangle P O=0.6)$ and three times the operating pressure differential $(\sim \Delta P / \Delta P O=0.4)$. Predicted failure pressures falling within this region would be considered nonconservative. The results demonstrate that a few estimates of failure pressure were somewhat less conservative than required by current regulations. This was caused by unreliability in crack sizing and suggests that the results for the laboratory inspections presented in Figure 28 may not be fully indicative of field NDE performance.

\subsubsection{Summary}

Although the amount of data collected during the mini-round robin exercise is limited, several trends are evident. First, the results indicated that detection of SCC by both conventional bobbin-coil and alternate inspection techniques was low. Second, the reliability of EC for estimating crack depth and length was very uncertain. Third, EC inspection techniques appear to be more effective at determining crack depth rather than crack length. Fourth, the alternate inspection techniques investigated did not offer improved depth or length sizing for SCC. Lastly, unreliability in the EC determined crack size led to a few estimates of remaining tube integrity that had less margin-to-failure than specified by current regulations. This suggests that conservative upwards adjustment of EC crack size estimates would be warranted. This last conclusion especially applies for the estimate of flaw length, which is the flaw dimension that dominates tube burst strength. 


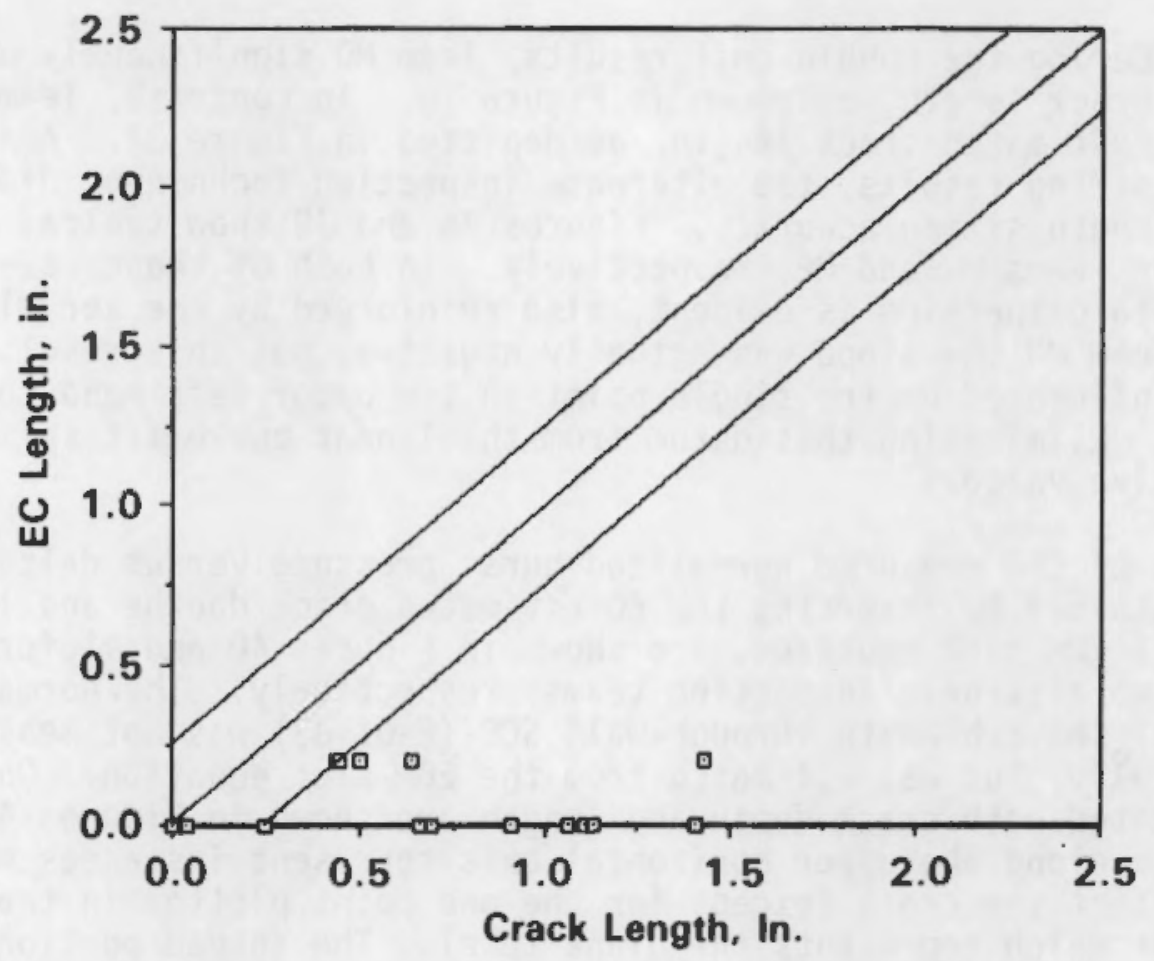

FIGURE 36. Eddy-Current Estimated vs. Actual SCC Length for Team MD

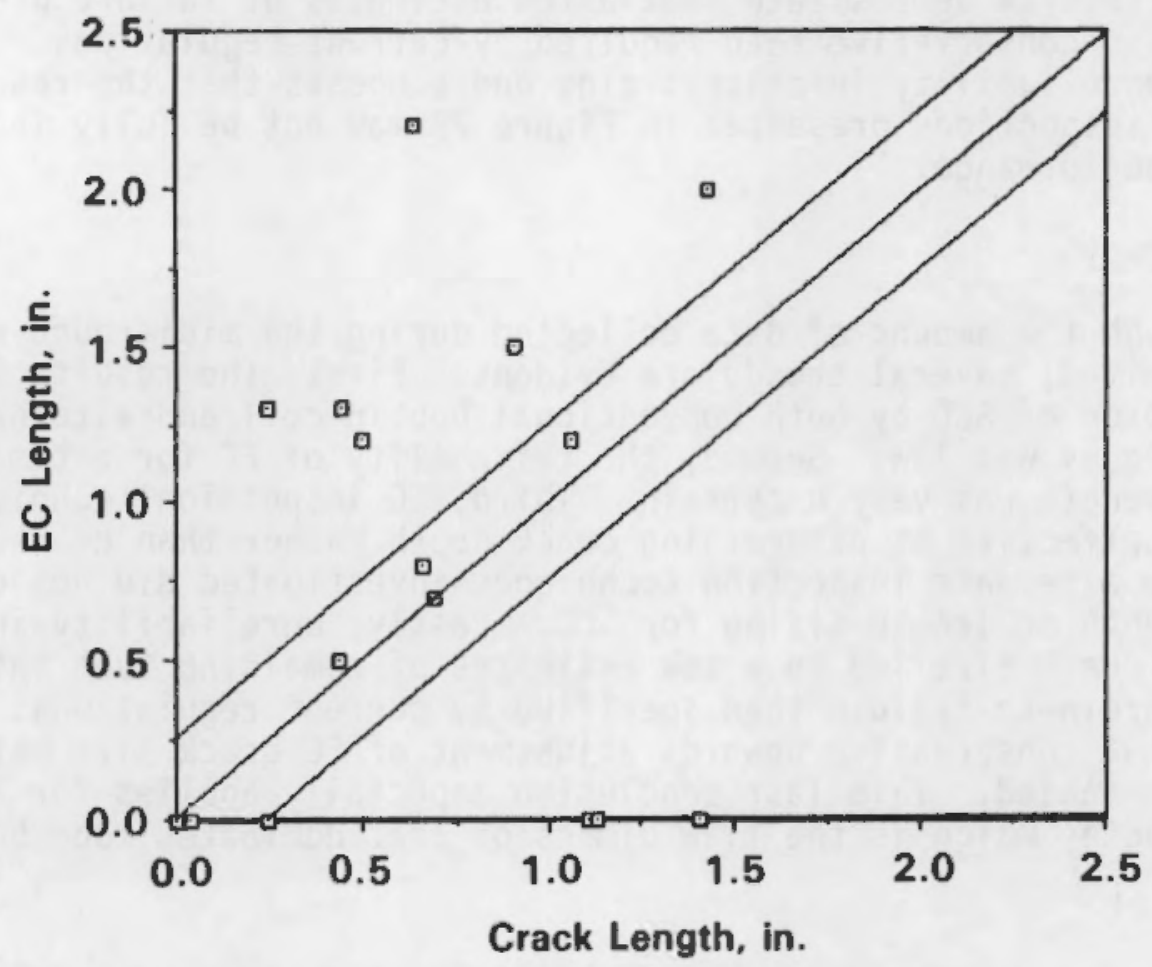

FIGURE 37. Eddy-Current Estimated vs. Actual SCC Length for Team MF 


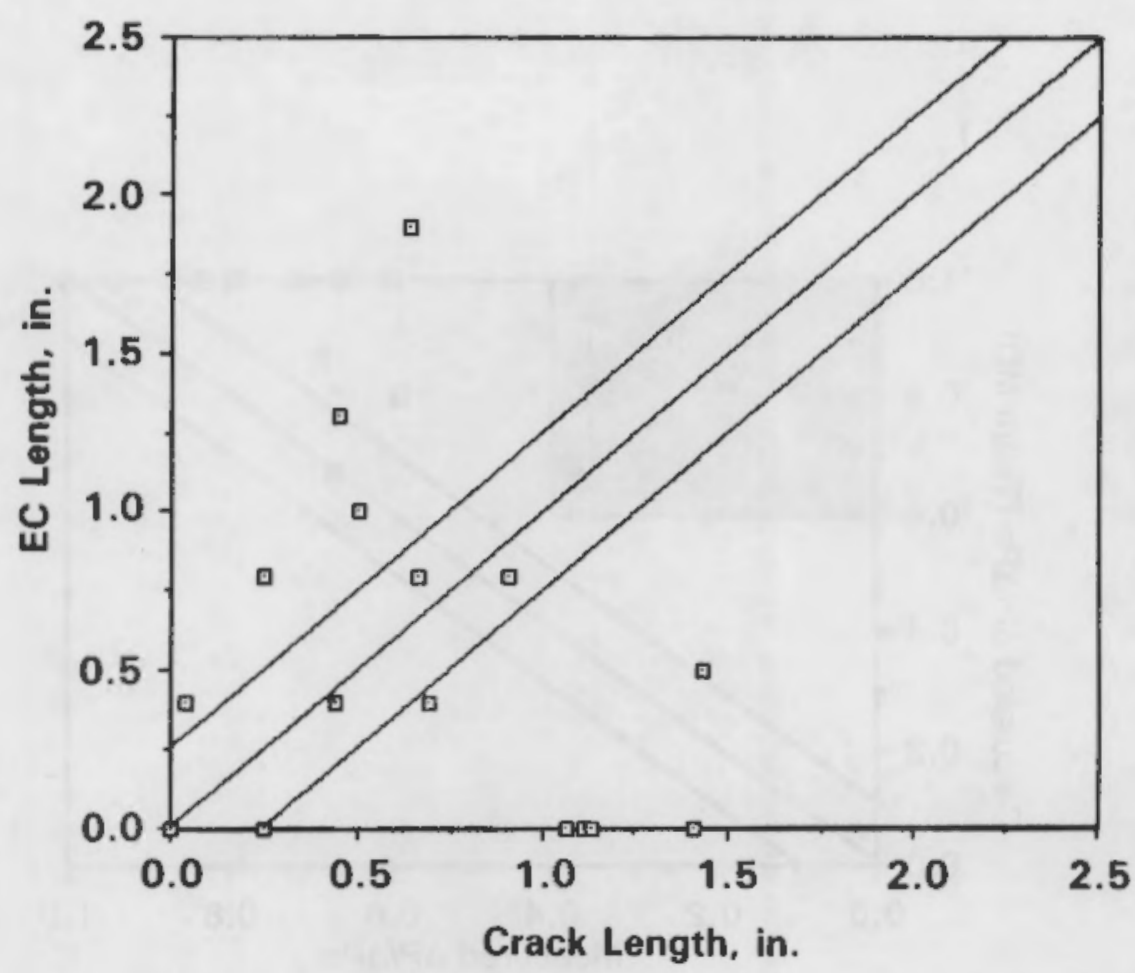

FIGURE 38. Eddy-Current Estimated vs. Actual SCC Length for Team MH

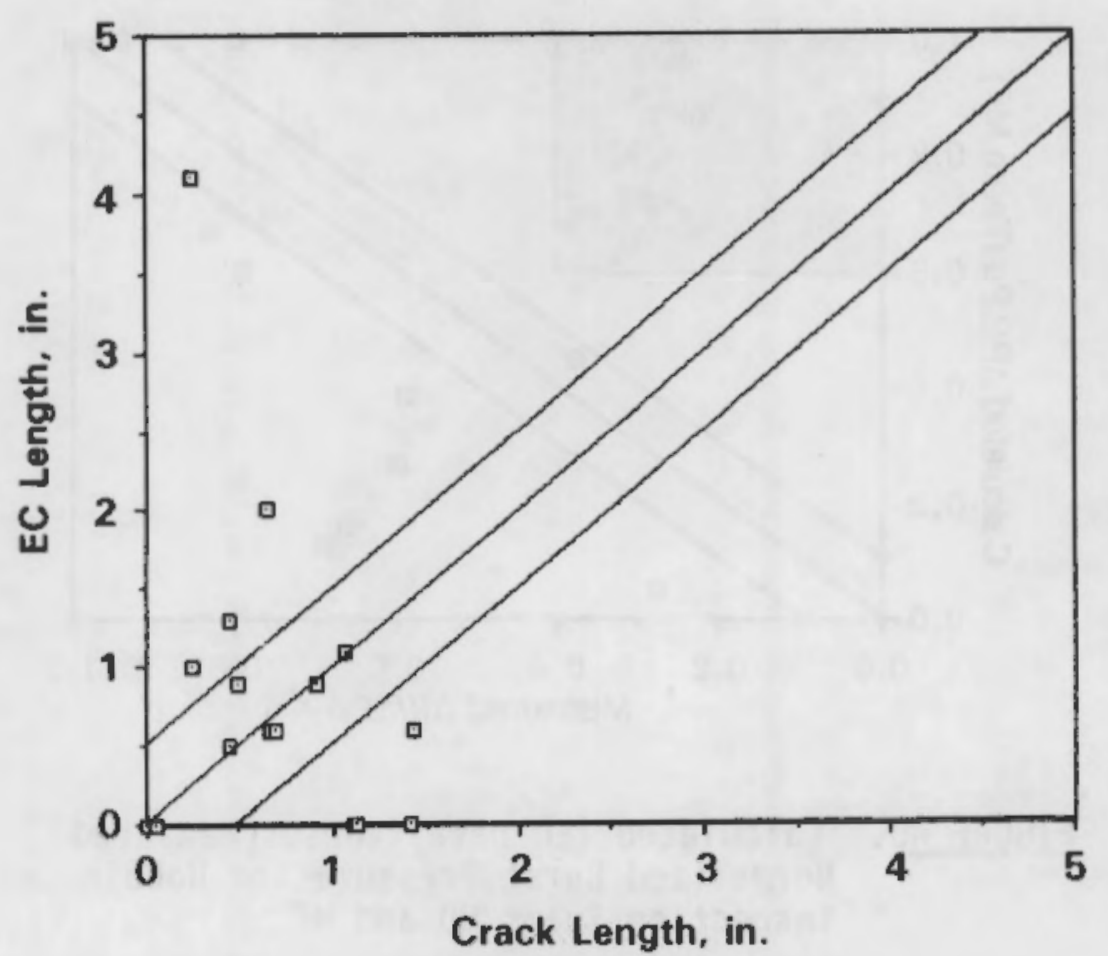

FIGURE 39. Eddy-Current Estimated vs. Actual SCC Length for Team MP 

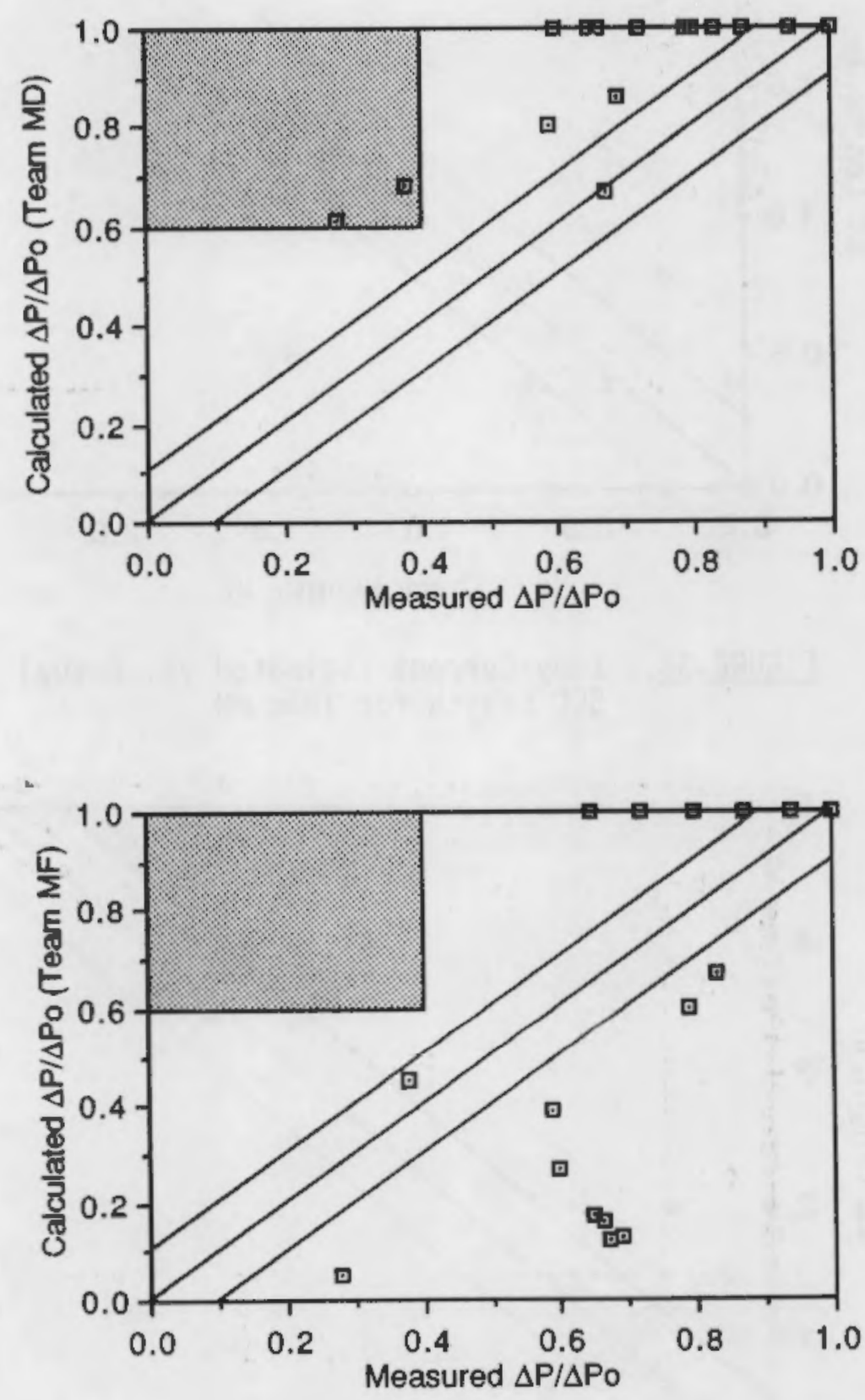

FIGURE 40. Calculated (EC Data) versus Measured Normalized Burst Pressure for Bobbin-Coil Inspection Teams MD and MF 

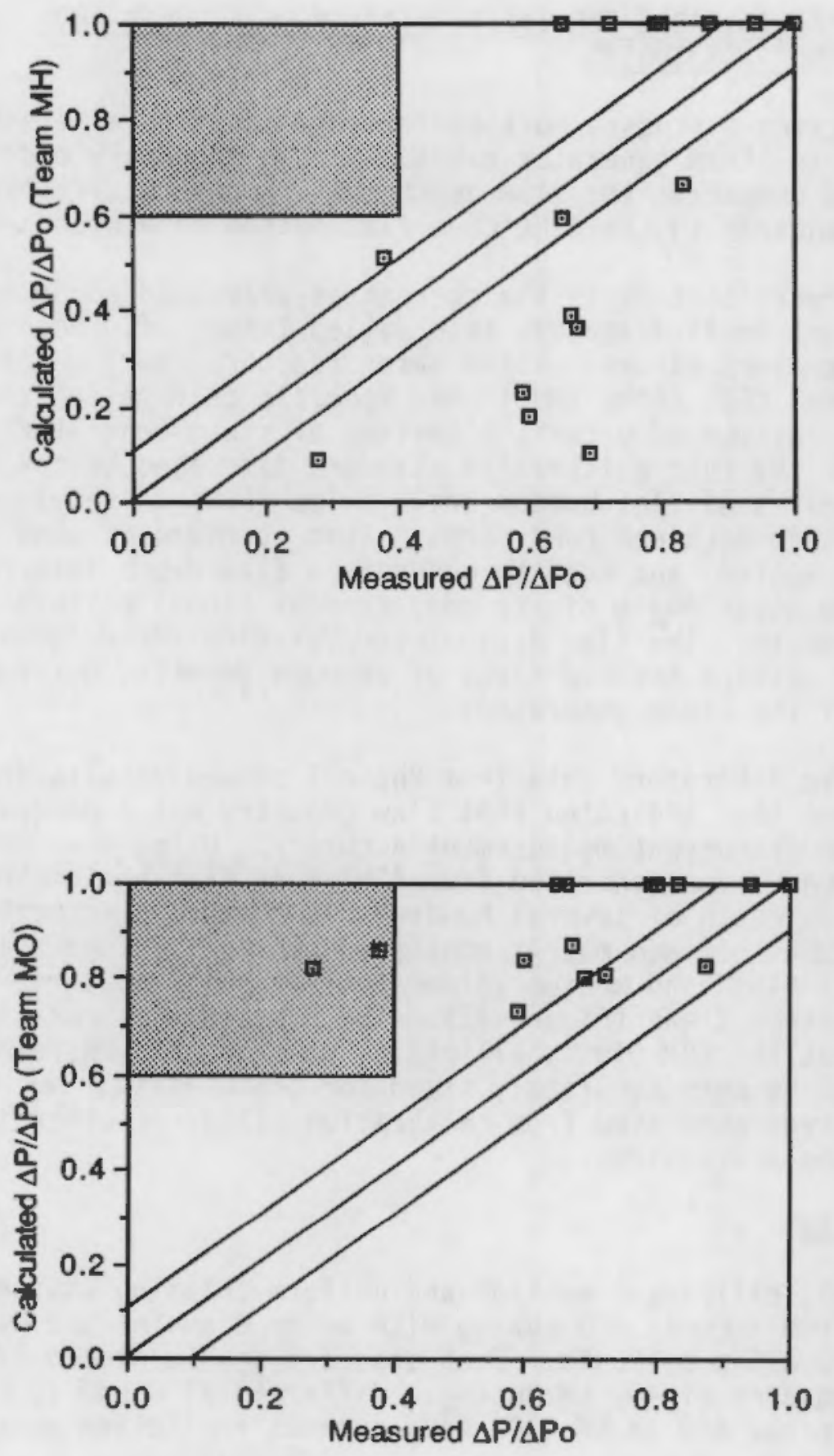

FIGURE 41. Calculated (EC Data) versus Measured Normalized Burst Pressure for Alternate Inspection Teams MO and MH 


\subsection{ALTERNATE STANDARDS FOR INTERPRETATION OF EC DATA FROM STEAM GENERATOR TUBING}

This section discusses work performed to develop alternate standards for sizing flaws in steam generator tubes. Single-frequency eddy-current results are presented comparing the flaw depth measurement results obtained using the alternate standards to the ASME Code flat-bottom hole standard.

Eddy-current testing is the current as-practiced nondestructive method used to inspect small diameter, thin walled Inconel 600 heat exchanger tubes in steam generators of pressurized water reactors (PWR). The ASME Boiler and Pressure Vessel Code (ASME 1986) has specific calibration and procedure requirements for the eddy-current testing of steam generator tubes. Specifically, the tube calibration standard described by the ASME Code contains a series of flat-bottom drill holes (FBH) of varying diameters and depths and other machined conditions. This standard is used to calibrate the eddy-current system, and used to generate a flaw depth interpretation curve to relate the phase angle of the eddy-current signal pattern to the flatbottom hole depth. The flaw depth interpretation curve is used to determine the depth of service induced flaws of unknown geometry during in-service inspection of the steam generator.

Extensive laboratory data from Phase I showed results for mechanically defected tubes that indicated that flaw geometry was a dominant factor in determining eddy-current measurement accuracy. Using flaw depth interpretation curves generated from ASME Code flat-bottom hole calibration standards, the depth of several hundred flawed tube specimens was determined. The flawed tube specimen matrix consisted of small volume electrodischarged machine (EDM) slots and medium volume (elliptical) and large volume (uniform thinning) wastage flaws (Figure 42). The eddy-current results from Phase I suggested that the EDM slots, elliptical wastage, and uniform thinning defects could be more accurately sized for depth using flaw depth interpretation curves generated from calibration standards other than the ASME flat-bottom hole standards.

\subsubsection{Results}

EDM slot, elliptical wastage and uniform thinning wastage standards were fabricated from Inconel 600 tubing with outer diameter and wall thickness dimensions, $0.875 \times 0.050 \mathrm{in}$. Each standard was inspected in the laboratory at a set frequency of $400 \mathrm{kHz}$ using a differential wound (2 coil) eddy-current bobbin probe and an EM-3300 eddy-current excitation generator.

Figure 43 shows a plot of the interpretation curves for EDM slot, elliptical wastage, uniform thinning and ASME FBH standards. These curves show the relationship between the eddy-current pattern phase angle and true flaw depth, as determined by optical and mechanical gauging techniques. Figure 43 shows that the EDM slot and uniform thinning wastage curves exhibit a different relationship between pattern phase angle and flaw depth compared to the ASME FBH curve. The elliptical wastage curve closely approximates the ASME FBH curve. 

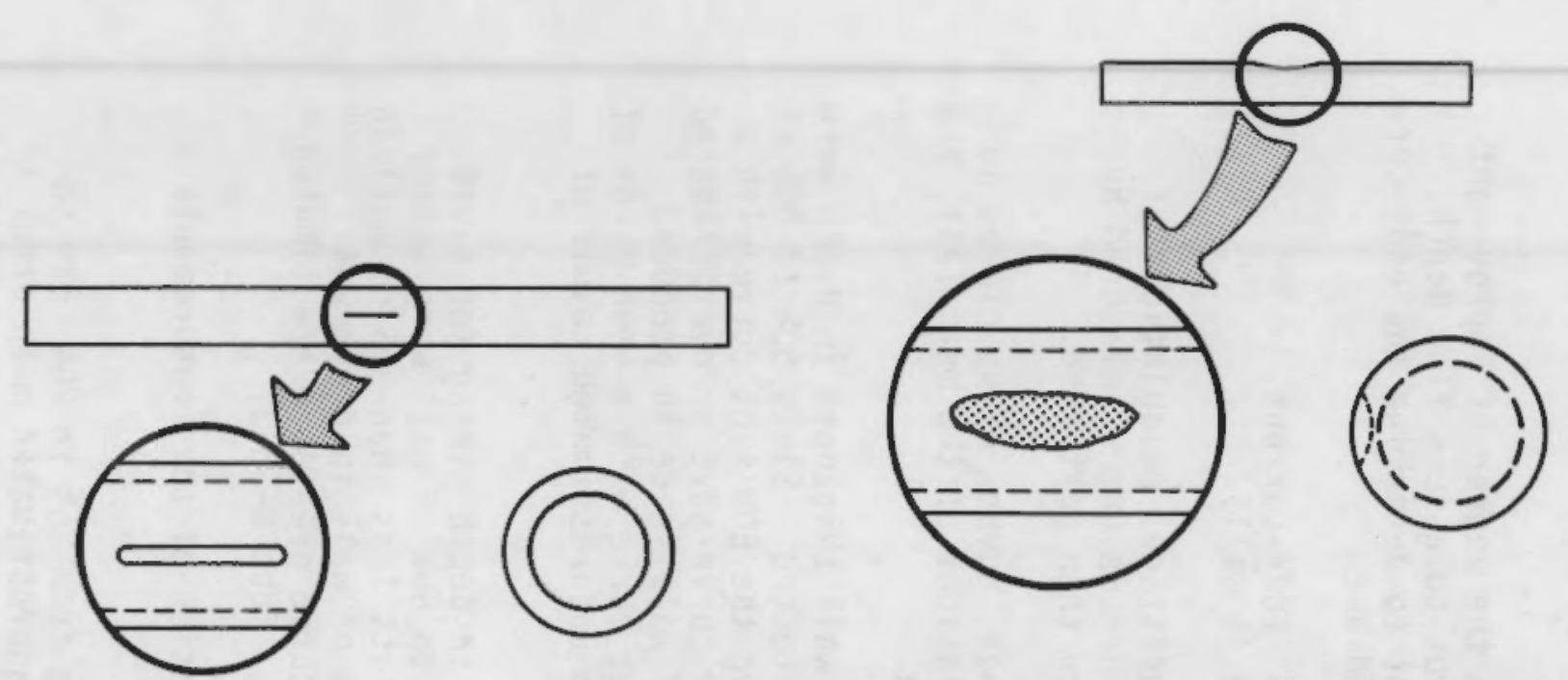

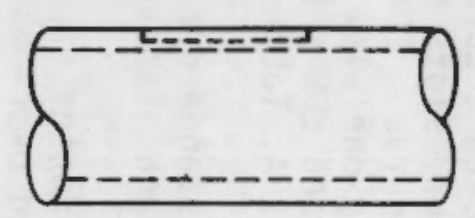

(a) EDM SLOT
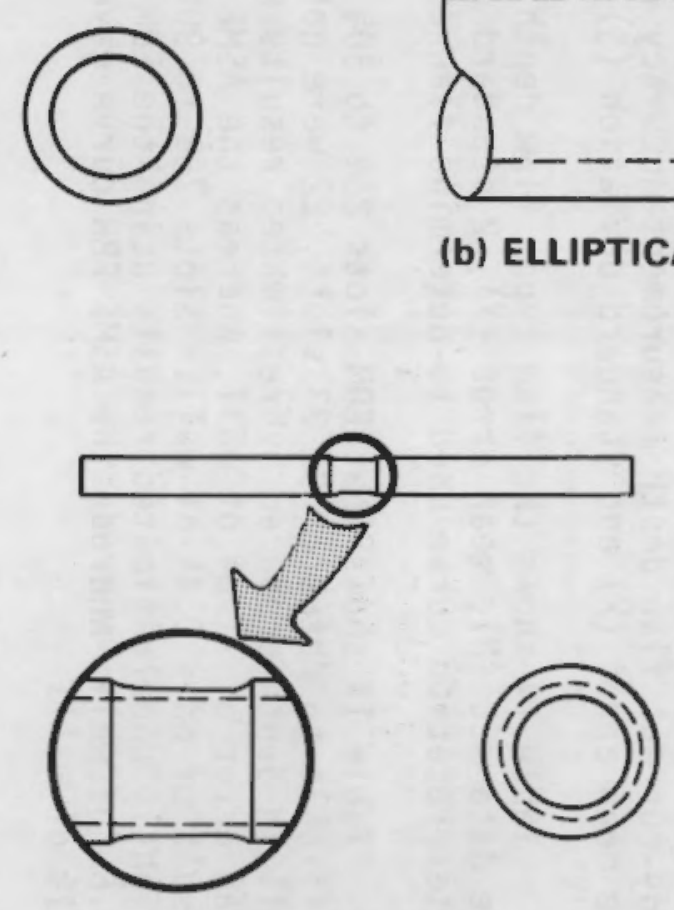

(c) UNIFORM THINNING

FIGURE 42. EDM Slots, Elliptical Wastage, and Uniform Thinning Wastage Flaw Specimens 
The eddy-current data from Phase I was re-evaluated using the new interpretation curves of Figure 43. Figures 44,45 , and 46 show the eddy-current indicated depth for EDM slots, elliptical wastage, and uniform thinning wastage plotted against the actual depth of the flaw; both depths are presented as a percentage of wall thickness. The solid line represents the linear relationship that would result if there were no eddy-current measurement error. The figures show that the data exhibits different trends for each flaw type at a given flaw depth.

The objective of this study was to determine the degree of improvement that may result with the use of alternate standards to assess flaw depth. The analysis approach taken in the study was first to determine the eddy-current flaw depth measurement error which is defined as:

Flaw Depth Measurement Error ( $\%$ wall thickness) = Eddy-current indicated flaw depth (\% wall) - Actual Flaw Depth (\% wall)

for each depth measurement (see Appendix A). Statistical calculations of eddy-current flaw depth measurement accuracy and precision, as measured by the mean error $(\bar{X})$ and standard deviation $(S)$ were then performed.

Table 14 shows the flaw type, flaw depth range, number of specimens in the data set $(\mathrm{N})$, mean error ( $\mathrm{X}), 2$ standard deviations of the mean (2S), and interpretation curve used to determine flaw depth.

Table 14 shows that EDM slots $25 \%$ to $30 \%$ of wall thickness in depth were difficult to detect. Of 23 slots, 22 were not detected. Slots $50 \%$ to $60 \%$ of wall in depth produced overestimated results using the EDM slot curve with a mean error of $11.6 \%$ of wall, whereas the ASME FBH curve gave an overestimated result of only $2.4 \%$ of wall. Slots $78 \%$ to $90 \%$ of wall in depth produced slightly underestimated results using the EDM slot curve with a mean error of $-0.6 \%$ of wall, whereas the ASME FBH curve gave an underestimated result of $-11 \%$ of wall.

The EDM slot results show improved accuracy in depth sizing for slots $78 \%$ to $90 \%$ of wall in depth. However, slots $50 \%$ to $60 \%$ of wall were better sized for depth using the ASME FBH curve. EDM slots less than $30 \%$ of wall in depth are difficult to detect. Only one slot 25\% of wall in depth was detected. Both the ASME FBH curve and EDM slot curve greatly overestimated the depth of this slot (see Appendix A, Table A-1, Tube B-38-3).

Table 14 data showed that the standard deviation of the measurements essentially remained constant for each standard.

Elliptical wastage flaws with depths ranging from $25 \%$ to $28 \%, 53 \%$ to $57 \%$, and $82 \%$ to $86 \%$ of wall produced over- and underestimated mean error results of $-1.0 \%, 2.3 \%$, and $-5.7 \%$ of wall thickness, respectively. Correspondingly the mean errors were $6.2 \%, 4.7 \%$, and $-6.8 \%$ of wall, respectively, for the ASME FBH curve. The elliptical wastage results showed improved accuracy in flaw depth sizing with the use of the elliptical wastage standard. Table 14 data show that the standard deviation of the measurements 


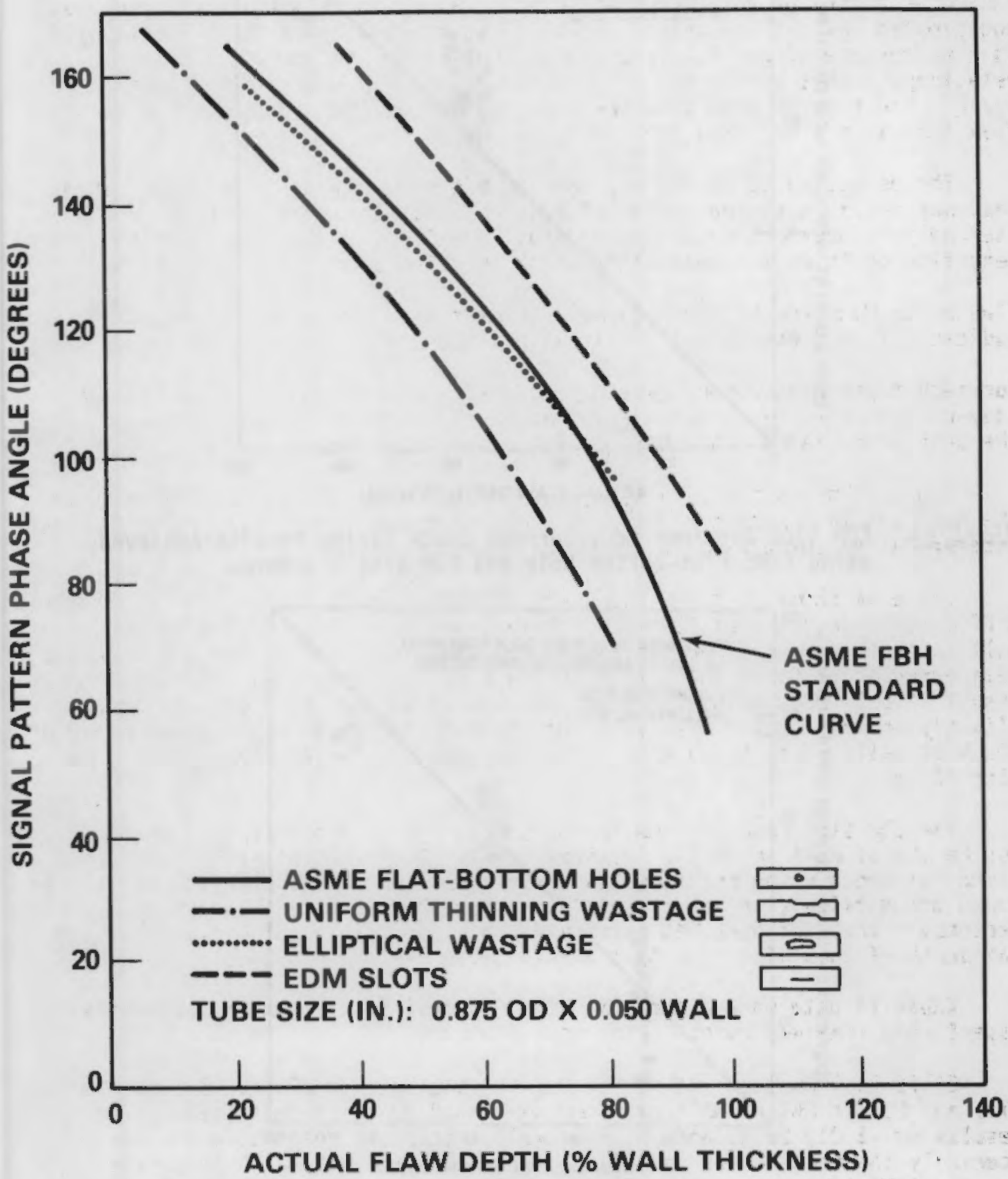

FIGURE 43. Single-Frequency Eddy-Current Interpretation Curves Generated from ASME-FBH, EDM Slot, Elliptical Wastage, and Uniform Thinning Wastage Standards 


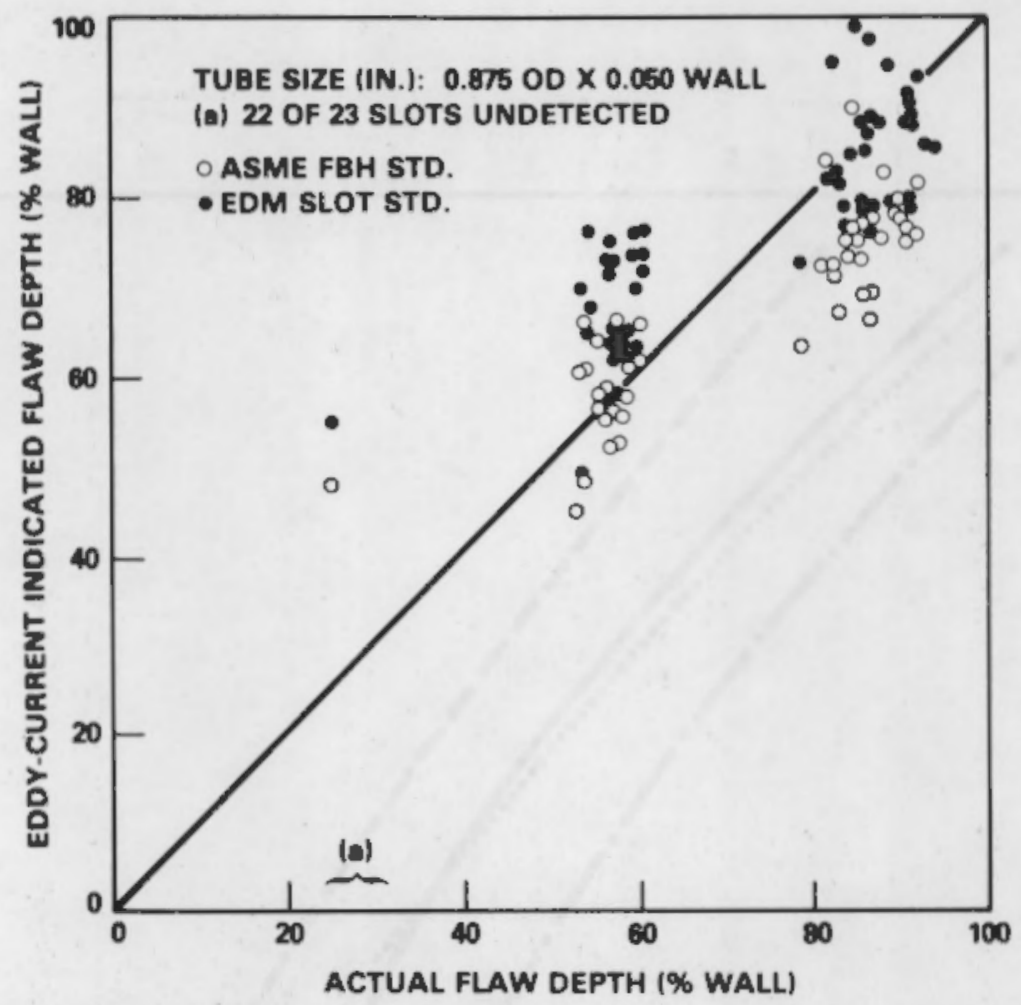

FIGURE 44. EDM Slot Specimen Eddy-Current Depth Sizing Results Achieved using ASME Flat-Bottom Hole and EDM Slot Standards

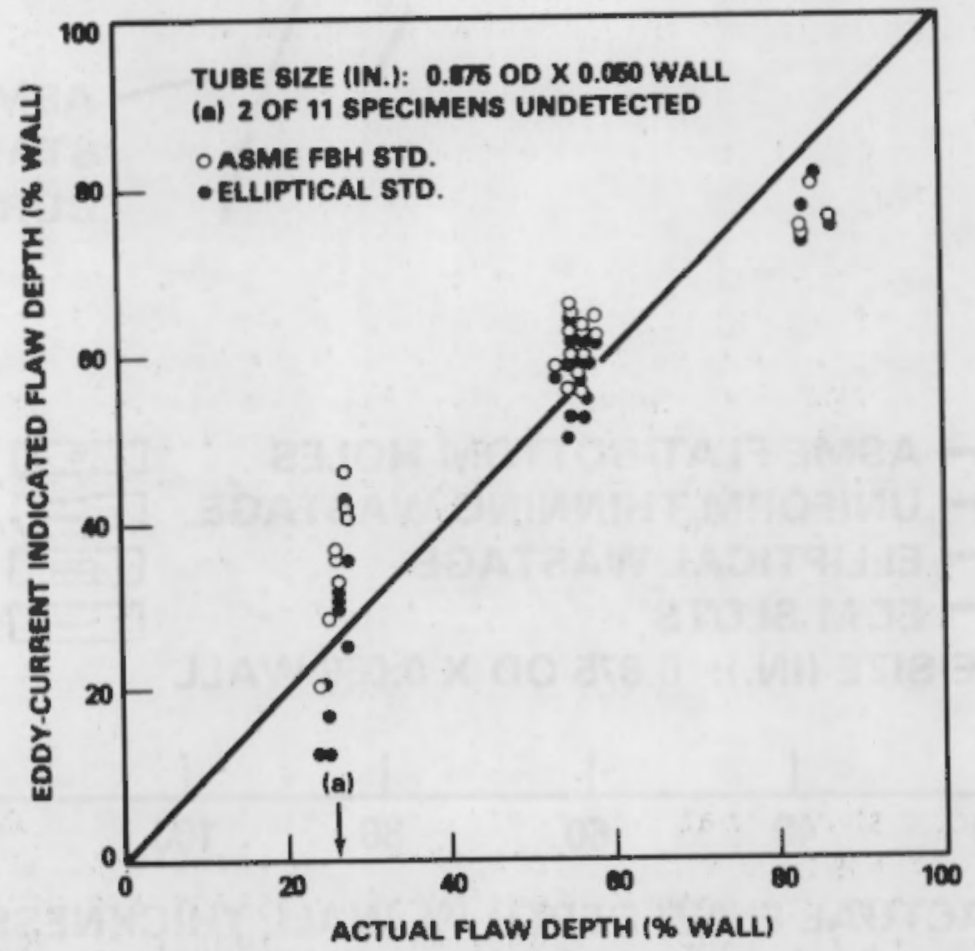

FIGURE 45. Elliptical Hastage Specimen Eddy-Current Depth Sizing Results Achieved using ASME Flat-Bottom Hole and Elliptical Wastage Standards 


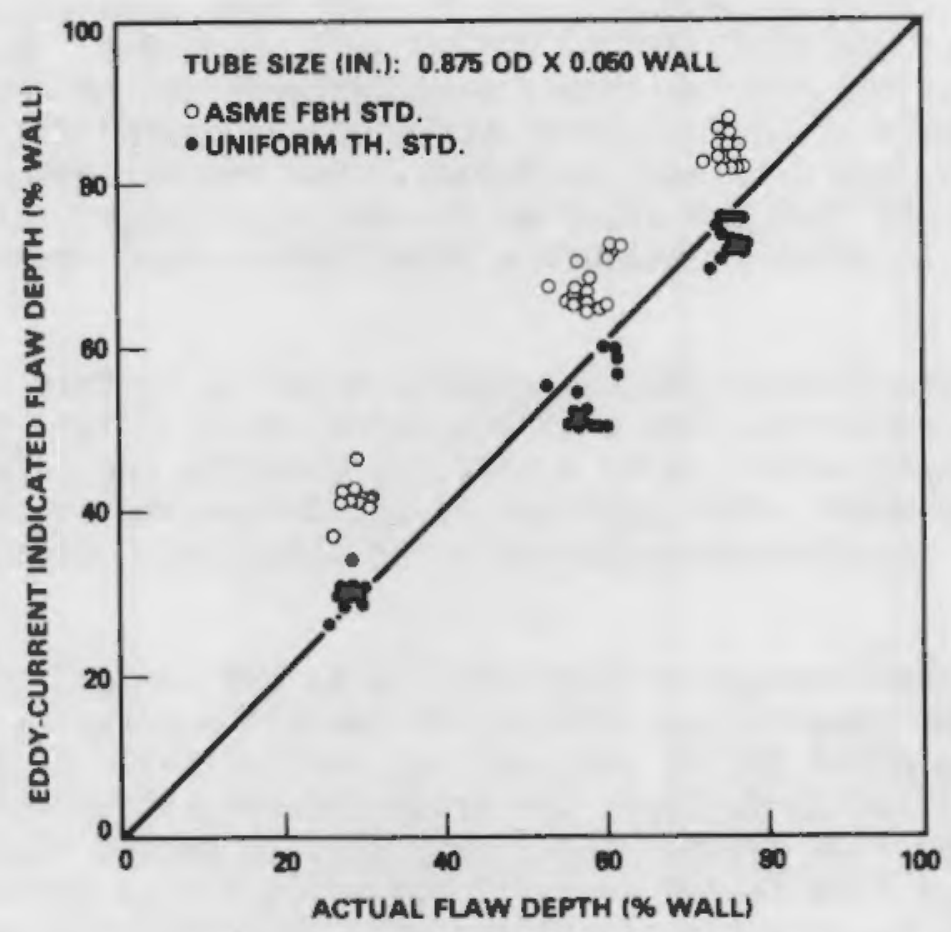

FIGURE 46. Uniform Thinning Wastage Specimen Eddy-Current Depth Sizing Results Achieved using ASME Flat-Bottom Hole and Uniform Thinning Wastage Standards

essentially remained constant for each standard for elliptical wastage greater than $50 \%$ deep.

Uniform thinning specimens with depths ranging from $25 \%$ to $28 \%, 51 \%$ to $60 \%$, and $72 \%$ to $76 \%$ of wall produced slightly over- and underestimated mean error results of $1.8 \%,-4.0 \%$ and $-2.0 \%$ of wall thickness, respectively. Correspondingly, the ASME FBH curve produced overestimated mean error results of $13.7 \%, 9.8 \%$, and $7.8 \%$ of wall thickness. The uniform thinning wastage results show that there is a dramatic improvement in measurement accuracy for the depth sizing of uniform thinning wastage specimens with the use of uniform thinning wastage standards. Table 14 data reveal that the standard deviation of the measurements essentially remained constant for each standard.

\subsubsection{Summary}

This study has shown that alternate tube standards with mechanically produced elliptical wastage and uniform thinning flaws resulted in a more accurate determination of depth for elliptical wastage and uniform thinning specimens compared to the ASME flat-bottom hole standards. However, the improved accuracy in measuring flaw depth has not decreased the standard deviation (i.e., increased the precision). 
The EDM slot standard produced results that were more accurate in determining the depth of EDM slots $78 \%$ to $90 \%$ of wall thickness. However, EDM slots $50 \%$ to $60 \%$ of the wall thickness were better sized in depth using the ASME flat-bottom hole standard. Axial EDM slots of depth less than $30 \%$ of the wall thickness, are difficult to detect. For depths less than $30 \%$ of the wall thickness, slots that are wider at the surface (larger volume slots) would be required in order to produce a detectable eddy-current signal indication.

The reader should note that the results reported in this study were based upon curves generated from a single one-of-a-kind standard. The interpretation curves were drawn giving a best fit curve to the data points generated from each standard. This approach is not unique and is the same method used to construct interpretation curves using ASME flat-bottom hole standards.

The investigators recognize that the key to the use and application of alternate standards requires the ability to correctly classify and accurately interpret (pattern phase angle) eddy-current indications. If flaws are incorrectly classified as to type, the wrong interpretation curve would be chosen to determine flaw depth. The interpretation curves of Figure 43 show that if an EDM slot flaw (known depth at $80 \%$ wall) with a pattern phase angle of 120 degrees, is incorrectly classified as a uniform thinning wastage flaw, the slot depth would be assessed using the uniform thinning curve, at 55\% of the wall thickness. Whereas, the EDM slot curve would have sized the slot to be $75 \%$ of the wall in depth. The incorrect classification of the flaw has inadvertently resulted in a substantial flaw depth measurement error of $25 \%$ of the wall thickness. 
TABLE 14. Statistical Data for EDM Slot, Elliptical Wastage, Uniform Thinning Wastage and Flat-Bottom Hole Standards(a)

\begin{tabular}{|c|c|c|c|c|c|}
\hline Flaw Type & $\begin{array}{l}\text { Flaw } \\
\text { Depth } \\
\text { (\% Wall) }\end{array}$ & $\begin{array}{l}\text { No. } \\
\text { Specimens } \\
\text { (N) }\end{array}$ & $\begin{array}{l}\text { Mean } \\
\text { Error } \\
\text { (\% Wall) }\end{array}$ & $\begin{array}{l}2 \text { Standard } \\
\text { Deviation } \\
\text { (\% Wall) }\end{array}$ & $\begin{array}{l}\text { Interpretation } \\
\text { Curve } \\
\text { (re: Figure 44) }\end{array}$ \\
\hline EDM Slot & $\begin{array}{l}25-30 \\
50-60 \\
50=60 \\
78=90 \\
78=90\end{array}$ & $\begin{array}{l}23 \\
25 \\
25 \\
33 \\
33\end{array}$ & $\begin{array}{r}(\mathrm{b}) \\
2.4 \\
11.6 \\
-11.0 \\
-0.6\end{array}$ & $\begin{array}{l}-- \\
10.4 \\
12.0 \\
11.2 \\
13.8\end{array}$ & $\begin{array}{l}-- \\
\text { ASME } \\
\text { EDM } \\
\text { ASME } \\
\text { EDM }\end{array}$ \\
\hline $\begin{array}{l}\text { Elliptical } \\
\text { Wastage }\end{array}$ & $\begin{array}{l}25-28 \\
25=28 \\
53=57 \\
53-57 \\
82-86 \\
82-86\end{array}$ & $\begin{array}{r}9 \\
9 \\
18 \\
18 \\
4 \\
4\end{array}$ & $\begin{array}{r}6.2 \\
-1.0 \\
4.7 \\
2.3 \\
-6.8 \\
-5.7\end{array}$ & $\begin{array}{r}16.6 \\
20.6 \\
7.2 \\
8.4 \\
4.0 \\
6.0\end{array}$ & $\begin{array}{c}\text { ASME } \\
\text { ELLIPTICAL } \\
\text { ASME } \\
\text { ELLIPTICAL } \\
\text { ASME } \\
\text { ELLIPTICAL }\end{array}$ \\
\hline $\begin{array}{l}\text { Uniform } \\
\text { Thinning }\end{array}$ & $\begin{array}{l}25-28 \\
25=28 \\
51-60 \\
51=60 \\
72=76 \\
72-76\end{array}$ & $\begin{array}{l}14 \\
14 \\
18 \\
18 \\
16 \\
16\end{array}$ & $\begin{array}{r}13.7 \\
1.8 \\
9.8 \\
-4.0 \\
7.9 \\
-2.0\end{array}$ & $\begin{array}{l}4.3 \\
4.4 \\
5.1 \\
6.0 \\
4.4 \\
3.5\end{array}$ & $\begin{array}{c}\text { ASME } \\
\text { UNIFORM } \\
\text { ASME } \\
\text { UNIFORM } \\
\text { ASME } \\
\text { UNIFORM }\end{array}$ \\
\hline
\end{tabular}

(a) Tube size (in.): $0.875 \times 0.050$ wall thickness.

(b) 22 of 23 EDM slots undetected. 


\subsection{CONCLUSIONS}

1. Phase II stress corrosion cracked specimens burst at pressures about $10 \%$ greater, on the average, than the EDM notch defected tubes of Phase I.

2. Phase II uniform thinning and elliptical wastage specimens burst and collapsed at pressures slightly less than $10 \%$ below the similarly defected Phase I specimens.

3. The Phase I empirical relationships adequately predicted the burst pressure of SCC defected specimens without modification, but for uniform thinning and elliptical wastage defects the Phase I equations predicted failure pressures about $10 \%$ less than measured from the Phase II specimens. This would suggest additional conservatism may be appropriate for evaluating these types of defects.

4. Measured leak rates for SCC type defects were observed to be highly variable when compared to analytical predictions. In some cases, measured leak rates were as much as a factor of ten less than the predicted rates. This suggests that a substantial level of conservatism should be applied to predictions of leakage that are used for evaluations of leak-before-break. Such conservatism would also appear appropriate for establishing leak detection limits for detection systems. Most of the limited sample of tubes leaked at detectable rates for normal operation conditions and then did not burst for accident conditions. The test data suggest that leak-before-break will occur with sufficient probability that leak detection requirements add to steam generator safety. However, the confidence in leak-before-break is not sufficiently high to permit relaxation of in-service inspection requirements or increasing of leak detection limits.

5. Laboratory EC measurements of SCC depth indicated these types of defects were, on the average, undersized. Data scatter for this defect type was found to be large. Elliptical wastage and uniform thinning defects were more accurately sized and with much less data scatter. Sizing accuracy increased as the volume of material removed by the defecting process increased.

6. Correlation of burst pressure with laboratory EC flaw depth estimates demonstrated that the present plugging limit is conservative, but this conclusion must be viewed with caution, since results from the miniround robin conducted with SCC defected tubes suggests that EC sizing errors could lead to determinations of remaining tube integrity with less margin-to-failure than prescribed by current regulations.

7. Laboratory EC measurements of defect depth combined with the Phase I empirical equations of tube burst provided a conservative assessment of when to plug a degraded tube if the defect length was assumed to be long $(>1$ in.). 
8. The average POD of SCC defects by conventional bobbin-coil and alternate inspection techniques was low. The best average performance was 0.63 .

9. The reliability of the various NDE techniques to determine SCC length and depth was very uncertain. Alternate inspection techniques did not provide improved sizing capability compared to conventional bobbin-coil techniques.

10. Eddy-current inspection techniques appeared to be more effective at sizing SCC depth rather than length.

11. Alternate machined standards for calibrating eddy-current inspection equipment resulted in limited improvement of defect depth sizing for machined elliptical wastage and uniform thinning specimens compared to the ASME flat-bottom hole standard. However, no improvement in measurement precision was noted for these defect types.

12. An alternate machined standard for sizing EDM slots resulted in more accurate depth estimates for EDM slots $78 \%$ to $90 \%$ of wall thickness, but shallower EDM slots were better sized in depth by the ASME standard. Use of alternate standards for calibrating in-service inspection equipment could result in substantial sizing errors if the defect type is not known. 


\subsection{REFERENCES}

Alzheimer, J. M. et al. 1979. Steam Generator Tube Integrity Program - Phase I Report, NUREG/CR-0718, Pacific Northwest Laboratory, Richland, Washington.

American Society of Mechanical Engineer's Boiler and Pressure Vessel Code. Section XI Rules for In-Service Inspection of Nuclear Power Plant Components. 1986 Edition. ASME, New York, New York.

Clark, R. A. and R. L. Burr. 1980. "A Method for Controlled Stress Corrosion Cracking in Nonsensitized Inconel 600 Tubing," Corrosion, $36(7): 382-383$.

Griesbach, T., R. Cipolla, and J. Lang. 1985. "Analysis Methods for Evaluating Leak-Before-Break in U-Tube Steam Generators," Proceedings ASME Winter Meeting, Miami Beach, Florida.

Kumar, V., M. D. German, and C. F. Shih. 1981. An Engineering Approach for Elastic-Plastic Fracture Analysis, EPRI NP-1931, Electric Power Research Institute, Palo Alto, California.

Norris, D. et al. 1984. PICEP: Pipe Crack Evaluation Program, EPRI NP-3596-SR, Electric Power Research Institute, Palo Alto, California.

Powell, D. E. and J. F. Hall. 1987. "Experimental Measurements of Leak Rates and Burst Pressures for Cracked Alloy 600 Tubes Under Steam Generator Conditions." In Proceedings: 1985 Workshop on Primary-Side Corrosion Cracking of PWR Steam Generator Tubing, EPRI NP-5158, Electric Power Research Institute, Palo Alto, California.

Berge, P. 1987. "Overview of Primary Side Stress Corrosion Cracking SG Tubes of Electricite de France," ibid.

Simonen, F. A. et al. 1986. Reactor Pressure Vessel Failure Probability Following Through-Wall Cracks Due to Pressurized Thermal Shock Events, NUREG/CR-4483, Pacific Northwest Laboratory, Richland, Washington. 

APPENDIX A

EDDY-CURRENT FLAW DEPTH MEASUREMENTS 
TABLE A.1. Phase I - SGTI Program Eddy-Current Data EDM Slot (Heats $B, E$, and F)

Eddy-Current

\begin{tabular}{|c|c|c|c|c|c|c|}
\hline $\begin{array}{l}\text { Specimen } \\
\text { Number }\end{array}$ & $\begin{array}{l}\text { Defect } \\
\text { Length } \\
\text { (in.) }\end{array}$ & $\begin{array}{c}\text { Actual } \\
\text { Flaw Depth } \\
(\% \text { Wall) } \\
\end{array}$ & $\begin{array}{c}\text { Indicate } \\
\text { ASME FBH } \\
\text { Curve } \\
\text { (\% Wall) }\end{array}$ & $\begin{array}{c}\text { law Depth } \\
\text { EDM Slot } \\
\text { Curve } \\
(\% \text { Wall) }\end{array}$ & $\begin{array}{c}\text { Measureme } \\
\text { ASME FBH } \\
\text { Curve } \\
(\% \text { Wall })\end{array}$ & $\begin{array}{c}\text { Error (b) } \\
\text { EOM Slot } \\
\text { Curve } \\
(\% \text { Wall) }\end{array}$ \\
\hline 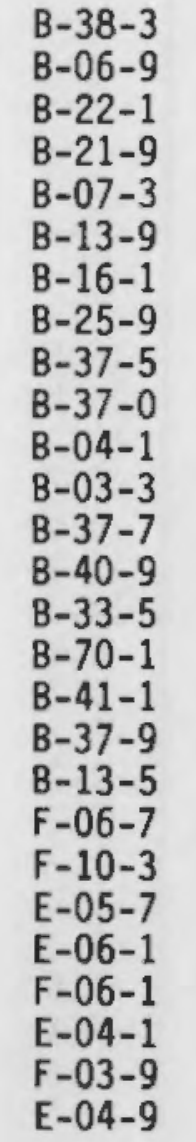 & $\begin{array}{l}0.250 \\
0.496 \\
0.255 \\
1.480 \\
1.485 \\
0.255 \\
0.500 \\
1.493 \\
1.498 \\
0.255 \\
0.502 \\
0.500 \\
0.500 \\
0.495 \\
1.505 \\
0.999 \\
1.505 \\
0.250 \\
0.253 \\
0.501 \\
0.500 \\
0.495 \\
0.495 \\
0.504 \\
0.505 \\
0.499 \\
0.505\end{array}$ & $\begin{array}{l}25.0 \\
25.3 \\
25.9 \\
26.6 \\
29.8 \\
30.2 \\
30.7 \\
52.5 \\
53.6 \\
55.6 \\
57.9 \\
58.7 \\
78.5 \\
82.0 \\
83.7 \\
84.0 \\
84.9 \\
86.2 \\
91.4 \\
57.3 \\
57.5 \\
58.7 \\
58.7 \\
85.0 \\
89.1 \\
89.6 \\
91.1\end{array}$ & $\begin{array}{l}48 \\
(\mathrm{a}) \\
(\mathrm{a}) \\
(\mathrm{a}) \\
(\mathrm{a}) \\
(\mathrm{a}) \\
(\mathrm{a}) \\
43 \\
57 \\
56 \\
55 \\
57 \\
63 \\
72 \\
90 \\
76 \\
87 \\
66 \\
81 \\
52 \\
55 \\
63 \\
65 \\
68 \\
77 \\
77 \\
75\end{array}$ & $\begin{array}{l}55 \\
(a) \\
(a) \\
(a) \\
(a) \\
(a) \\
(a) \\
49 \\
65 \\
63 \\
62 \\
65 \\
73 \\
83 \\
100(c) \\
88 \\
98 \\
76 \\
94 \\
64 \\
63 \\
74 \\
76 \\
79 \\
88 \\
88 \\
86\end{array}$ & $\begin{array}{r}23.0 \\
-. \\
-- \\
-- \\
-- \\
-- \\
-- \\
-9.5 \\
3.4 \\
0.6 \\
-2.9 \\
-1.7 \\
-15.5 \\
-10.0 \\
6.3 \\
-8.0 \\
2.1 \\
-20.2 \\
-10.4 \\
-5.3 \\
-2.5 \\
4.3 \\
6.3 \\
-17.0 \\
-12.1 \\
-12.6 \\
-16.1\end{array}$ & $\begin{array}{r}30.0 \\
-.- \\
-.- \\
-. \\
-- \\
-- \\
-3.5 \\
11.4 \\
7.4 \\
4.1 \\
6.3 \\
-5.5 \\
1.0 \\
16.3 \\
4.0 \\
15.1 \\
-10.2 \\
0.6 \\
6.7 \\
5.5 \\
15.3 \\
17.3 \\
-6.0 \\
-1.1 \\
-1.6 \\
-5.1\end{array}$ \\
\hline
\end{tabular}
(a) Undetectable.
(b) Measurement error ( $\%$ wall) $=$ Eddy-current indicated depth (\% wall) - actual flaw depth ( $\%$ wall).
(c) Interpretation based upon extrapolated curve. 
IABLE A.2. Phase I - SGTI Program Eddy-Current Data EDM Slot (Heats $B, E$, and F)

Eddy-Current

\begin{tabular}{|c|c|c|c|c|c|c|}
\hline $\begin{array}{l}\text { Specimen } \\
\text { Number }\end{array}$ & $\begin{array}{l}\text { Defect } \\
\text { Length } \\
\text { (in.) }\end{array}$ & $\begin{array}{l}\text { Actual } \\
\text { Flaw Depth } \\
(\% \text { Wall) }\end{array}$ & $\begin{array}{c}\text { Indicated } \\
\text { ASME FBH } \\
\text { Curve } \\
(\% \text { Wall) }\end{array}$ & $\begin{array}{c}\text { law Depth } \\
\text { EDM Slot } \\
\text { Curve } \\
(\% \text { Wall) }\end{array}$ & $\begin{array}{c}\text { Measureme } \\
\text { ASME FBH } \\
\text { Curve } \\
(\% \text { Wall) }\end{array}$ & $\begin{array}{c}\text { Error (b) } \\
\text { EOM Slot } \\
\text { Curve } \\
(\% \text { Wall) }\end{array}$ \\
\hline $\begin{array}{l}\text { E-04-5 } \\
\text { F-09-3 } \\
\text { F- } 09-9 \\
\text { E-03-7 } \\
\text { B-29-7 } \\
\text { B-42-5 } \\
\text { B-38-5 } \\
\text { B-48-9 } \\
\text { B-75-3 } \\
\text { B-43-5 } \\
\text { B-60-3 } \\
\text { F- } 06-7 \\
\text { F-10-3 } \\
\text { E- } 05-7 \\
\text { E- } 06-1 \\
\text { B-27-7 } \\
\text { B-13-1 } \\
\text { B-21-5 } \\
\text { B-11-9 } \\
\text { B-32-1 } \\
\text { B-75-5 } \\
\text { F- } 06-1 \\
\text { E-04-1 } \\
\text { F-03-9 } \\
\text { E- } 04-9\end{array}$ & $\begin{array}{l}0.500 \\
0.496 \\
0.498 \\
0.496 \\
1.510 \\
1.504 \\
0.502 \\
0.501 \\
1.503 \\
0.505 \\
0.503 \\
0.501 \\
0.500 \\
0.495 \\
0.495 \\
1.502 \\
0.499 \\
1.490 \\
0.503 \\
0.249 \\
0.260 \\
0.504 \\
0.505 \\
0.499 \\
0.505\end{array}$ & $\begin{array}{l}26.3 \\
27.7 \\
27.7 \\
28.3 \\
24.1 \\
26.8 \\
27.2 \\
28.0 \\
53.1 \\
56.4 \\
58.9 \\
57.3 \\
57.5 \\
58.7 \\
58.7 \\
81.1 \\
81.7 \\
82.7 \\
83.0 \\
85.2 \\
90.7 \\
85.0 \\
89.1 \\
89.6 \\
91.1\end{array}$ & $\begin{array}{l}\text { (a) } \\
\text { (a) } \\
(a) \\
(a) \\
(a) \\
(a) \\
(a) \\
(a) \\
61 \\
63 \\
61 \\
52 \\
55 \\
63 \\
65 \\
71 \\
70 \\
67 \\
73 \\
73 \\
76 \\
68 \\
77 \\
77 \\
75\end{array}$ & $\begin{array}{l}\text { (a) } \\
\text { (a) } \\
(a) \\
(a) \\
(a) \\
(a) \\
(a) \\
(a) \\
70 \\
73 \\
70 \\
64 \\
63 \\
74 \\
76 \\
82 \\
81 \\
77 \\
85 \\
85 \\
88 \\
79 \\
88 \\
88 \\
86\end{array}$ & $\begin{array}{r}-- \\
-- \\
-- \\
-- \\
-- \\
-- \\
-- \\
-- \\
7.9 \\
6.6 \\
2.1 \\
-5.3 \\
-2.5 \\
4.3 \\
6.3 \\
-10.1 \\
-11.7 \\
-15.7 \\
-10.0 \\
-12.2 \\
-14.7 \\
-17.0 \\
-12.1 \\
-12.6 \\
-16.1\end{array}$ & $\begin{array}{r}-. \\
-- \\
-- \\
-- \\
-- \\
-- \\
-- \\
16.9 \\
16.6 \\
11.1 \\
6.7 \\
5.5 \\
15.3 \\
17.3 \\
0.9 \\
-0.7 \\
-5.7 \\
2.0 \\
0.2 \\
-2.7 \\
-6.0 \\
-1.1 \\
-1.6 \\
-5.1\end{array}$ \\
\hline
\end{tabular}

\footnotetext{
(a) Undetectable.

(b) Measurement error ( $\%$ wall) $=$ Eddy-current indicated depth (\% wall) actual flaw depth (\% wall).
} 


\section{TABLE A.3. Phase I - SGTI Program Eddy-Current Data} EDM Slot (Heats E and F)

\begin{tabular}{|c|c|c|c|c|c|c|}
\hline $\begin{array}{l}\text { Specimen } \\
\text { Number }\end{array}$ & $\begin{array}{l}\text { Defect } \\
\text { Length } \\
\text { (in.) }\end{array}$ & $\begin{array}{c}\text { Actual } \\
\text { Flaw Depth } \\
(\% \text { Wall) } \\
\end{array}$ & $\begin{array}{c}\text { Eddy } \\
\text { Indicate } \\
\text { ASME FBH } \\
\text { Curve } \\
(\% \text { Wall })\end{array}$ & $\begin{array}{l}\text { law Depth } \\
\text { EDM Slot } \\
\text { Curve } \\
\text { (\% Wall) }\end{array}$ & $\begin{array}{c}\text { Measurem } \\
\text { ASME FBH } \\
\text { Curve } \\
(\% \text { Wall })\end{array}$ & $\begin{array}{c}\text { Error (b) } \\
\text { EDM Slot } \\
\text { Curve } \\
(\% \text { Wall })\end{array}$ \\
\hline $\begin{array}{l}E-05-1 \\
E-03-5 \\
E-04-7 \\
E-02-3 \\
F-08-9 \\
F-04-9 \\
F-01-5 \\
F-01-7 \\
F-06-5 \\
F-10-9 \\
F-03-5 \\
F-01-3 \\
E-14-6 \\
E-15-1 \\
E-09-1 \\
E-05-9 \\
F-07-5 \\
F-03-3 \\
F-08-1 \\
E-15-3 \\
F-04-5 \\
F-09-5 \\
F-07-3 \\
E-03-3 \\
E-09-5 \\
E-14-8 \\
E-09-7 \\
E-14-9\end{array}$ & $\begin{array}{l}0.500 \\
0.490 \\
1.493 \\
1.495 \\
1.490 \\
0.496 \\
1.525 \\
0.498 \\
1.488 \\
0.504 \\
0.499 \\
1.525 \\
0.503 \\
1.490 \\
0.490 \\
1.495 \\
0.499 \\
1.505 \\
1.498 \\
0.503 \\
0.499 \\
0.246 \\
0.248 \\
1.506 \\
0.247 \\
0.249 \\
0.498 \\
1.505\end{array}$ & $\begin{array}{l}25.3 \\
25.3 \\
26.3 \\
26.3 \\
26.7 \\
26.9 \\
27.3 \\
28.0 \\
53.8 \\
55.6 \\
55.8 \\
56.5 \\
56.7 \\
56.7 \\
57.7 \\
60.7 \\
81.0 \\
83.7 \\
85.0 \\
85.0 \\
85.7 \\
87.0 \\
87.0 \\
87.0 \\
89.1 \\
89.1 \\
89.1 \\
89.1\end{array}$ & $\begin{array}{l}(a) \\
(a) \\
(a) \\
(a) \\
(a) \\
(a) \\
(a) \\
(a) \\
60 \\
57 \\
65 \\
62 \\
56 \\
63 \\
63 \\
62 \\
83 \\
74 \\
74 \\
77 \\
77 \\
75 \\
75 \\
82 \\
77 \\
74 \\
75 \\
79\end{array}$ & $\begin{array}{l}(a) \\
(a) \\
(a) \\
(a) \\
(a) \\
(a) \\
a) \\
a) \\
68 \\
65 \\
75 \\
72 \\
63 \\
73 \\
73 \\
72 \\
97(c) \\
79 \\
79 \\
89 \\
89 \\
80 \\
80 \\
96 \\
89 \\
79 \\
80 \\
92\end{array}$ & $\begin{array}{r}-. \\
-- \\
-. \\
-- \\
-. \\
-- \\
-- \\
6.2 \\
1.4 \\
9.2 \\
5.5 \\
-0.7 \\
6.3 \\
5.3 \\
1.3 \\
2.0 \\
-9.7 \\
-11.0 \\
-8.0 \\
-8.7 \\
-12.0 \\
-12.0 \\
-5.0 \\
-12.1 \\
-15.1 \\
-14.1 \\
-10.1\end{array}$ & \begin{tabular}{r}
-- \\
-- \\
-- \\
-- \\
-- \\
-- \\
-- \\
\multicolumn{1}{c}{-} \\
14.2 \\
9.4 \\
19.2 \\
15.5 \\
6.3 \\
16.3 \\
15.3 \\
11.3 \\
16.0 \\
-4.7 \\
-6.0 \\
4.0 \\
3.3 \\
-7.0 \\
-7.0 \\
9.0 \\
-0.1 \\
-10.1 \\
-9.1 \\
2.9
\end{tabular} \\
\hline
\end{tabular}
(a) Undetectable.
(b) Measurement error (\% wall) = Eddy-current indicated depth (\% wal1) - actual flaw depth (\% wall).
(c) Interpretation based upon extrapolated curve. 
IABLE A.4. Phase I - SGTI Program Eddy-Current Data Elliptical Wastage (Heat B)

Eddy-Current

\begin{tabular}{|c|c|c|c|c|c|c|c|}
\hline $\begin{array}{l}\text { Specimen } \\
\text { Number }\end{array}$ & $\begin{array}{l}\text { Cutter } \\
\text { Radius } \\
\text { (in.) }\end{array}$ & $\begin{array}{c}\text { Wrap } \\
\text { Angle } \\
\text { (degrees) } \\
\end{array}$ & $\begin{array}{l}\text { Actual } \\
\text { Flaw Depth } \\
(\% \text { Wall) } \\
\end{array}$ & $\begin{array}{l}\text { Indicated } \\
\text { ASME FBH } \\
\text { Curve } \\
(\% \text { Wall) }\end{array}$ & $\begin{array}{l}\text { Flaw Depth } \\
\text { Elliptical } \\
\text { Curve } \\
\text { ( } \% \text { Wall) }\end{array}$ & $\begin{array}{c}\text { Measureme } \\
\text { ASME FBH } \\
\text { Curve } \\
(\% \text { Wall) }\end{array}$ & $\begin{array}{c}\text { nt Error(b) } \\
\text { Elliptical } \\
\text { Curve } \\
(\% \text { Wall }) \\
\end{array}$ \\
\hline $\begin{array}{l}\text { B-48-3 } \\
\text { B-48-7 } \\
\text { B-36-1 } \\
\text { B-22-7 } \\
\text { B-53-4 } \\
\text { B-31-5 } \\
\text { B-53-3 } \\
\text { B-09-10 } \\
\text { B-53-10 } \\
\text { B-07-10 } \\
\text { B-09-4 } \\
\text { B-43-7 } \\
\text { B-28-7 } \\
\text { B-40-3 } \\
\text { B-53-7 } \\
\text { B-52-5 } \\
\text { B-31-3 } \\
\text { B-54-7 } \\
\text { B-54-3 }\end{array}$ & $\begin{array}{r}24 \\
24 \\
24 \\
24 \\
24 \\
24 \\
24 \\
6 \\
6 \\
6 \\
6 \\
6 \\
12 \\
12 \\
12 \\
12 \\
12 \\
12 \\
6 \\
6 \\
6\end{array}$ & $\begin{array}{r}0 \\
0 \\
45 \\
45 \\
135 \\
135 \\
135 \\
135 \\
135 \\
45 \\
45 \\
45 \\
45 \\
125 \\
0 \\
0 \\
135 \\
0 \\
0\end{array}$ & $\begin{array}{l}26.1 \\
26.1 \\
26.3 \\
26.9 \\
27.0 \\
27.2 \\
28.0 \\
55.0 \\
55.0 \\
53.8 \\
55.4 \\
55.4 \\
55.4 \\
56.0 \\
56.0 \\
56.9 \\
57.4 \\
82.7 \\
85.6\end{array}$ & $\begin{array}{l}\text { (a) } \\
(a) \\
27 \\
35 \\
33 \\
36 \\
46 \\
62 \\
61 \\
59 \\
63 \\
66 \\
64 \\
64 \\
58 \\
62 \\
64 \\
76 \\
77\end{array}$ & $\begin{array}{l}\text { (a) } \\
\left(\begin{array}{l}a \\
16\end{array}(\mathrm{c})\right. \\
30 \\
28 \\
31 \\
43 \\
62 \\
60 \\
57 \\
62 \\
65 \\
62 \\
62 \\
56 \\
62 \\
62 \\
78 \\
77\end{array}$ & $\begin{array}{r}-- \\
-. \\
0.7 \\
8.1 \\
6.0 \\
8.8 \\
18.0 \\
7.0 \\
6.0 \\
5.2 \\
7.6 \\
10.6 \\
8.6 \\
8.0 \\
2.0 \\
5.1 \\
6.6 \\
-6.7 \\
-8.6\end{array}$ & $\begin{array}{c}-. \\
-10.3(c) \\
3.4 \\
1.0 \\
3.8 \\
17.0 \\
7.0 \\
5.0 \\
3.2 \\
6.6 \\
9.6 \\
6.6 \\
6.0 \\
0.0 \\
5.1 \\
4.6 \\
-8.6 \\
-8.6\end{array}$ \\
\hline
\end{tabular}

(a) Undetectable.

(b) Measurement error (\% wall) = Eddy-current indicated depth (\% wall) actual flaw depth ( $\%$ wall).

(c) Interpretation based upon extrapolated curve. 
IABLE A.5. Phase I - SGTI Program Eddy-Current Data Elliptical Wastage (Heats $B, E$, and F)

\begin{tabular}{|c|c|c|c|c|c|c|c|}
\hline $\begin{array}{l}\text { Specimen } \\
\text { Number }\end{array}$ & $\begin{array}{l}\text { Cutter } \\
\text { Radius } \\
\text { (in.) }\end{array}$ & $\begin{array}{c}\text { Wrap } \\
\text { Angle } \\
\text { (degrees) } \\
\end{array}$ & $\begin{array}{c}\text { Actual } \\
\text { Flaw Depth } \\
(\% \text { Wall) } \\
\end{array}$ & $\begin{array}{l}\text { Eddy- } \\
\text { Indicatec } \\
\text { ASME FBH } \\
\text { Curve } \\
(\% \text { Wall) } \\
\end{array}$ & $\begin{array}{l}\text { Current } \\
\text { Flaw Depth } \\
\text { Elliptical } \\
\text { Curve } \\
(\% \text { Wall) }\end{array}$ & $\begin{array}{c}\text { Measureme } \\
\text { ASME FBH } \\
\text { Curve } \\
(\% \text { Wal1) }\end{array}$ & $\begin{array}{c}\text { nt Error(a) } \\
\text { Elliptical } \\
\text { Curve } \\
(\% \text { Wall) } \\
\end{array}$ \\
\hline $\begin{array}{l}B-36-5 \\
B-27-1 \\
B-06-3 \\
B-29-9 \\
B-29-5 \\
B-39-3 \\
B-40-7 \\
B-39-9 \\
E-14-3 \\
F-09-1 \\
F-08-5 \\
E-06-9 \\
B-35-5 \\
B-53-1\end{array}$ & $\begin{array}{r}24 \\
24 \\
24 \\
24 \\
12 \\
12 \\
12 \\
12 \\
12 \\
12 \\
12 \\
12 \\
6 \\
6\end{array}$ & $\begin{array}{r}0 \\
0 \\
135 \\
135 \\
0 \\
0 \\
135 \\
135 \\
0 \\
0 \\
0 \\
0 \\
0 \\
0\end{array}$ & $\begin{array}{l}25.3 \\
26.1 \\
28.2 \\
28.4 \\
54.9 \\
55.0 \\
56.0 \\
57.4 \\
54.7 \\
55.3 \\
56.3 \\
56.7 \\
82.7 \\
84.0\end{array}$ & $\begin{array}{l}20 \\
20 \\
40 \\
42 \\
55 \\
62 \\
62 \\
63 \\
55 \\
57 \\
55 \\
55 \\
75 \\
80\end{array}$ & $\begin{array}{l}12 \\
12 \\
25 \\
35 \\
50 \\
60 \\
60 \\
59 \\
53 \\
55 \\
53 \\
53 \\
75 \\
82\end{array}$ & $\begin{array}{r}-5.3 \\
-6.1 \\
11.8 \\
13.6 \\
0.1 \\
7.0 \\
6.0 \\
5.6 \\
0.3 \\
1.7 \\
-1.3 \\
-1.7 \\
-7.7 \\
-4.0\end{array}$ & $\begin{array}{r}-13.5 \\
-14.1 \\
-3.2 \\
6.6 \\
-4.9 \\
5.0 \\
4.0 \\
1.6 \\
-1.7 \\
-0.3 \\
-3.3 \\
-3.7 \\
-7.7 \\
-2.0\end{array}$ \\
\hline
\end{tabular}

(a) Measurement error (\% wall) = Eddy-current indicated depth $(\%$ wall) actual flaw depth (\% wall). 
TABLE A.6. Phase I - SGTI Program Eddy-Current Data Uniform Thinning (Heats $B, E$, and F)

\begin{tabular}{|c|c|c|c|c|c|c|}
\hline $\begin{array}{l}\text { Specimen } \\
\text { Number } \\
\end{array}$ & $\begin{array}{l}\text { Defect } \\
\text { Length } \\
\text { (in.) } \\
\end{array}$ & $\begin{array}{c}\text { Actual } \\
\text { Flaw Depth } \\
(\% \text { Wall }) \\
\end{array}$ & $\begin{array}{r}\text { Edd } \\
\text { Indicat } \\
\text { ASME FBH } \\
\text { Curve } \\
(\% \text { Wal1) } \\
\end{array}$ & $\begin{array}{l}\text {-Current } \\
\text { d Flaw Depth } \\
\text { Uniform Thin } \\
\text { Curve } \\
(\% \text { Wall }) \\
\end{array}$ & $\begin{array}{c}\text { Measurer } \\
\text { ASME FBH } \\
\text { Curve } \\
(\% \text { Wall) }\end{array}$ & $\begin{array}{c}\text { ent Error(a) } \\
\text { Uniform Thin } \\
\text { Curve } \\
(\% \text { Wall }) \\
\end{array}$ \\
\hline $\begin{array}{l}\text { B-60-1 } \\
\text { B-23-5 } \\
\text { B-03-8 } \\
\text { B-32-8 } \\
\text { B-60-5 } \\
\text { B-08-9 } \\
\text { B-60-7 } \\
\text { B-35-3 } \\
\text { B-25-1 } \\
\text { B-19-7 } \\
\text { B-40-5 } \\
\text { B-60-9 } \\
\text { B-23-9 } \\
\text { B-16-5 } \\
\text { B-12-5 } \\
\text { B-08-3 } \\
\text { F- 06-9 } \\
\text { E-02-9 } \\
\text { E-06-5 } \\
\text { B-19-9 } \\
\text { B-35-7 } \\
\text { B-36-7 } \\
\text { B-09-5 } \\
\text { B-31-7 } \\
\text { B-18-3 } \\
\text { B-18-1 } \\
\text { B-21 - } 3\end{array}$ & $\begin{array}{l}0.384 \\
1.510 \\
0.195 \\
0.195 \\
0.752 \\
0.375 \\
0.755 \\
1.581 \\
0.380 \\
0.760 \\
0.182 \\
0.380 \\
1.513 \\
0.755 \\
1.496 \\
0.187 \\
0.375 \\
0.380 \\
0.380 \\
0.185 \\
0.182 \\
0.378 \\
0.750 \\
0.378 \\
0.750 \\
1.500 \\
1.495\end{array}$ & $\begin{array}{l}24.6 \\
26.1 \\
26.9 \\
27.0 \\
27.5 \\
27.7 \\
28.0 \\
28.2 \\
51.0 \\
54.5 \\
55.0 \\
55.6 \\
56 \\
56.5 \\
57.4 \\
58.0 \\
57.3 \\
58.7 \\
58.7 \\
72.4 \\
73.0 \\
73.5 \\
73.9 \\
74.9 \\
74.9 \\
74.9 \\
75.7\end{array}$ & $\begin{array}{l}36 \\
40 \\
46 \\
40 \\
40 \\
40 \\
39 \\
40 \\
66 \\
64 \\
68 \\
65 \\
63 \\
64 \\
63 \\
69 \\
67 \\
72 \\
71 \\
81 \\
82 \\
80 \\
80 \\
81 \\
80 \\
80 \\
80\end{array}$ & $\begin{array}{l}25 \\
27.8 \\
33.5 \\
27 \\
27.8 \\
27 \\
27 \\
27.8 \\
54 \\
49.5 \\
53.5 \\
52 \\
49 \\
48.8 \\
49 \\
58 \\
51 \\
58 \\
57 \\
68.5 \\
69.5 \\
71 \\
71 \\
72 \\
72 \\
72 \\
72\end{array}$ & $\begin{array}{r}11.4 \\
13.9 \\
19.1 \\
13.0 \\
12.5 \\
12.3 \\
11.0 \\
11.8 \\
15.0 \\
9.5 \\
13.0 \\
9.4 \\
7.0 \\
7.5 \\
5.6 \\
11.0 \\
9.7 \\
13.3 \\
12.3 \\
8.6 \\
9.0 \\
6.5 \\
6.1 \\
6.1 \\
5.1 \\
5.1 \\
4.3\end{array}$ & $\begin{array}{r}0.4 \\
1.7 \\
7.6 \\
0.0 \\
0.3 \\
0.7 \\
-1.0 \\
0.6 \\
3.0 \\
-5.0 \\
-1.5 \\
-3.6 \\
-7.0 \\
-5.7 \\
-8.4 \\
0.0 \\
-6.3 \\
-0.7 \\
-1.7 \\
-3.9 \\
-3.5 \\
-2.5 \\
-2.9 \\
-2.9 \\
-2.9 \\
-2.9 \\
-3.7\end{array}$ \\
\hline
\end{tabular}

(a) Measurement error ( $\&$ wall) $=$ Eddy-current indicated depth ( $\&$ wall) actual flaw depth (\% wall). 
IABLE A.7. Phase I - SGTI Program Eddy-Current Data Uniform Thinning (Heat B)

\begin{tabular}{|c|c|c|c|c|c|c|}
\hline $\begin{array}{l}\text { Specimen } \\
\text { Number }\end{array}$ & $\begin{array}{l}\text { Defect } \\
\text { Length } \\
\text { (in.) }\end{array}$ & $\begin{array}{c}\text { Actual } \\
\text { Flaw Depth } \\
\text { (\% Wall) }\end{array}$ & $\begin{array}{r}\text { Eddy } \\
\text { Indicate } \\
\text { ASME FBH } \\
\text { Curve } \\
(\% \text { Wall) } \\
\end{array}$ & $\begin{array}{l}\text {-Current } \\
\text { Flaw Depth } \\
\text { Uniform Thin } \\
\text { Curve } \\
(\% \text { Wall) } \\
\end{array}$ & $\begin{array}{l}\text { Measurem } \\
\text { ASME FBH } \\
\text { Curve } \\
(\% \text { Wall }) \\
\end{array}$ & $\begin{array}{c}\text { ent Error(a) } \\
\text { Uniform Thin } \\
\text { Curve } \\
(\% \text { Wall }) \\
\end{array}$ \\
\hline $\begin{array}{l}\text { B-39-7 } \\
\text { B-56-3 } \\
\text { B-03-7 } \\
\text { B-32-7 } \\
\text { B-28-3 } \\
\text { B-56-9 } \\
\text { B-75-9 } \\
\text { B-06-1 } \\
\text { B-29-3 } \\
\text { B-18-9 } \\
\text { B-23-7 } \\
\text { B-12-1 } \\
\text { B-70-1 } \\
\text { B-7D-5 } \\
\text { B-08-5 } \\
\text { B-42-7 } \\
\text { B-42-9 } \\
\text { B-40-1 } \\
\text { B-04-7 } \\
\text { B-48-5 }\end{array}$ & $\begin{array}{l}1.580 \\
0.370 \\
0.370 \\
0.765 \\
0.755 \\
1.550 \\
0.375 \\
0.750 \\
0.370 \\
0.775 \\
1.580 \\
1.560 \\
0.755 \\
0.875 \\
1.496 \\
0.184 \\
0.378 \\
1.500 \\
0.399 \\
0.760\end{array}$ & $\begin{array}{l}25.1 \\
25.3 \\
26.9 \\
27.0 \\
27.2 \\
27.2 \\
54.1 \\
54.5 \\
54.9 \\
56.0 \\
56.0 \\
56.5 \\
73.4 \\
73.4 \\
73.9 \\
74.7 \\
74.7 \\
75.0 \\
75.3 \\
75.3\end{array}$ & $\begin{array}{l}41 \\
40 \\
40 \\
42 \\
40 \\
42 \\
64 \\
64 \\
66 \\
63 \\
64 \\
63 \\
83 \\
85 \\
83 \\
86 \\
84 \\
83 \\
83 \\
84\end{array}$ & $\begin{array}{l}29 \\
28 \\
28 \\
29.8 \\
28 \\
29.8 \\
50 \\
50 \\
52 \\
49 \\
50 \\
49 \\
74.5 \\
73 \\
74.5 \\
74 \\
71.5 \\
74.5 \\
74.5 \\
71.5\end{array}$ & $\begin{array}{r}15.9 \\
14.7 \\
13.1 \\
15.0 \\
12.8 \\
14.8 \\
9.9 \\
9.5 \\
11.1 \\
7.0 \\
8.0 \\
6.5 \\
9.6 \\
11.6 \\
9.1 \\
11.3 \\
9.3 \\
8.0 \\
7.7 \\
8.7\end{array}$ & $\begin{array}{r}3.9 \\
3.3 \\
1.1 \\
2.8 \\
0.8 \\
2.6 \\
-4.1 \\
-4.5 \\
-2.5 \\
-7.0 \\
-6.0 \\
-7.5 \\
1.1 \\
-0.4 \\
0.6 \\
0.7 \\
-3.2 \\
-0.5 \\
-0.8 \\
-3.8\end{array}$ \\
\hline
\end{tabular}

(a) Measurement error $(\%$ wall) $=$ Eddy-current indicated depth ( $\%$ wall) actual flaw depth ( $\%$ wall). 

NUREG/CR-2336

PNL -4008

R5

\section{DISTRIBUTION}

No. of

Copies

\section{$\underline{\text { OFFSITE }}$}

2 Dr. Joseph Muscara

Materials Branch

Div. of Engineering Safety

Nuclear Regulatory Commission

Mail Stop NL-007

Washington, DC 20555

Dr. C. Y. Cheng

Office of Nuclear Regulatory Research

Nuclear Regulatory Commission

Washington, DC 20555

Mr. C. McCracken

Office of Nuclear Regulatory Research

Nuclear Regulatory Commission

Washington, DC 20555

Mr. H. Conrad

Office of Nuclear Regulatory Research

Nuclear Regulatory Commission Washington, DC 20555

Mr. E. Murphy

Office of Nuclear Regulatory Research

Nuclear Regulatory Commission

Washington, DC 20555

$\mathrm{Mr}$. K. Wichman

Office of Nuclear Regulatory Research

Nuclear Regulatory Commission

Washington, DC 20555
No. of

Copies

4 Mr. C. S. Welty

Electric Power Research

Institute

3412 Hillview Avenue

P.0. Box 10412

Palo Alto, CA 94303

5 Mr. H. S. McKay

Virginia Electric Power Co.

P.0. Box 26666

Richmond, VA 23261

3 Dr. R. A. Clark

Failure Analys is Associates 22122 20th Avenue SE

Bothe11, WA 98201

Mr. M. Anderson

Northern States Power

414 Nicolett Mall

Minneapolis, MN 55401

Mr. A. E. Curtis, III

Rochester Gas \& Electric Corp.

89 East Avenue

Rochester, NY 14649

Ms. D. Currier

Florida Power \& Light

$9250 \mathrm{~W}$. Flagler

Miami, FL 33120

Mr. D. Halama

New York Power Authority

123 Main Street

White Plains, NY 10601

Mr. J. Haning, DMT-6C

Houston Lighting \& Power Co.

P.0. Box 1700

Houston, TX 77001 
No. of Copies

Mr. C. W. Hendrix, Jr.

Duke Power Company

Nuclear Production Dept.

P.0. Box 33189

Charlotte, NC 28242

Mr. K. Hoffman

Baltimore Gas \& Electric Co.

Calvert Cliffs Nuclear Power Plant

Lusby, MD 20657

Mr. J. Kang

Pacific Gas \& Electric Co.

Dept. of Eng. Research

3400 Crow Canyon Rd.

San Ramon, CA 94583

Mr. A. Matheny

Southern California Edison

P.0. Box 128

San Clemente, CA 92672

Mr. G. Severance

Consumers Power Co.

1945 W. Parnall Road

Jackson, MI 49201

Mr. J. Benson, Assoc. Eng.

Northeast Utilities

P.0. Box 270

Hartford, CT 06101

Mr. T. Fauble, Engineer

SMUD/Rancho Seco

14440 Twin Cities Road

Herald, CA 95638

Mr. D. L. Sessler

Tennessee Valley Authority

1735 Chestnut St. Towers II

Chattanooga, TN 37401
No. of

Copies

Mr. D. L. Smith

Virginia Electric \& Power Co.

P.0. Box 26666

1 James River Plaza

Richmond, VA 23261

Dr. Costis Spalaris

Quadrex Corporation

1700 Dell Avenue

Campbel1, CA 95008

Mr. Thomas Beeman

London Nuclear Services, Inc.

2 Buffalo Avenue

Niagara Falls, NY 14303

Mr. Ernest Hayden

Westinghouse Electric Corp.

Steam Generator Services

P.0. Box 2728

Pittsburgh, PA 15230

\section{Foreign}

4

Dr. J. L. Campan

Department Manager

Water Reactor Service

C.E.A./Cadarache B.P. No. 1

13115 Saint Paul Lez Durance

Cadarache, FRANCE

Mr. C. Birac

DAS/STAS/SAM

Commissariat a l'Energie Atomique

CEN/FAR

B.P. No. 6

92265 Fontenay-aux-Roses

FRANCE

$4 \mathrm{Mr}$. M. Oishi, Director

Steam Generator Project NUPEC

Shuwa Kamiya-Cho Bldg.

3-13, 4-Chome, Toranomon,

Minato-Ku, Tokyo 105

JAPAN 
No. of

Copies

4 Dr. R. DeSantis

R\&D Manager

Ansaldo DBGV

Viale Sarca 336

Milano, ITALY 20126

Mr. Malcolm Russell

NDE Applications

CEGB

Bridgewater Road

Bedminster Down

Bristol, ENGLAND

Mr. John Tomlinson

Central Electricity Generating Board

NDT Applications Centre

Timpson Road

Manchester, U.K. M23 9LL

ONSITE

50 Pacific Northwest Laboratory

R. J. Kurtz (43)

Publishing Coordination (2)

Technical Report Files (5) 



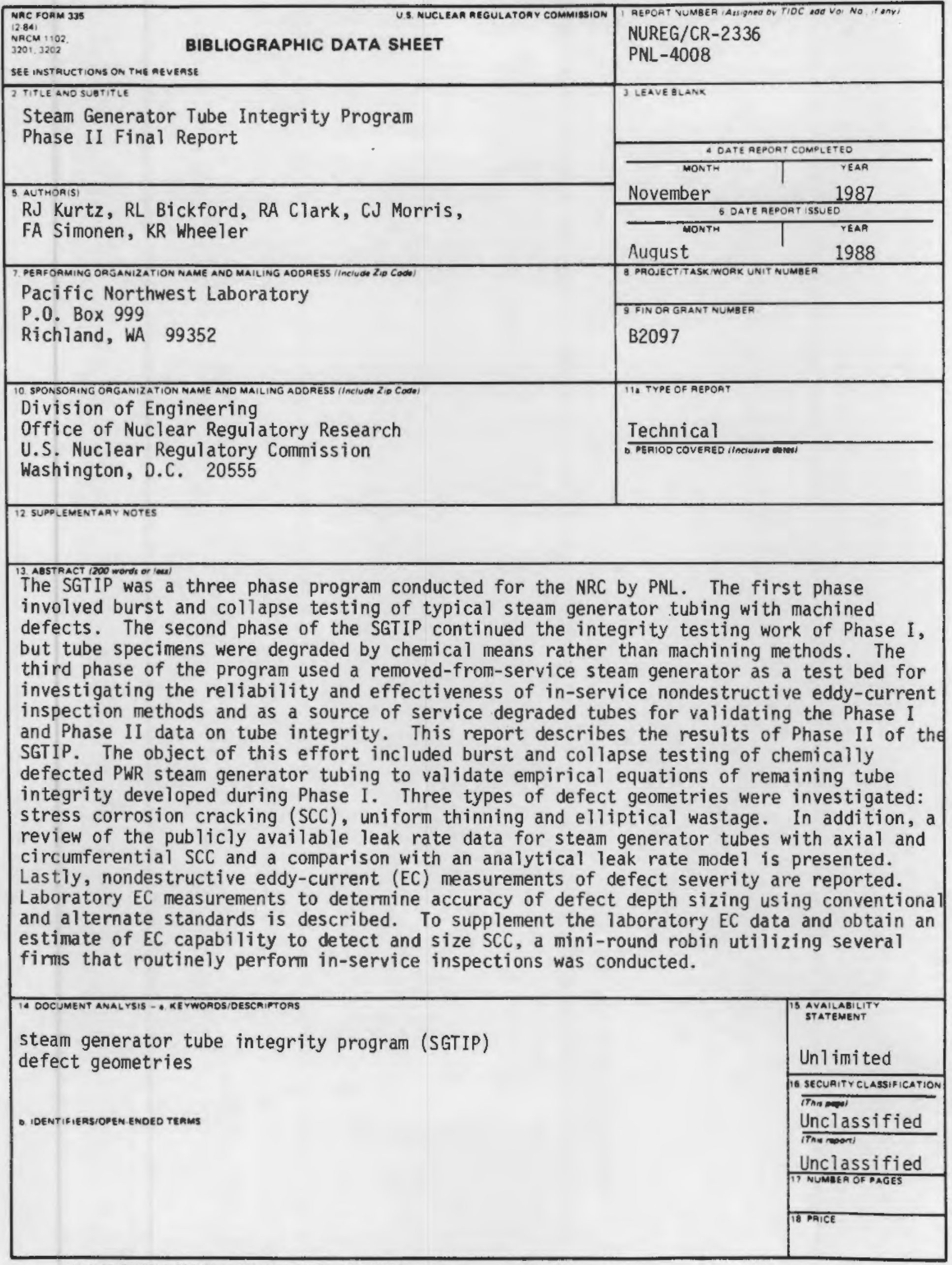


